\title{
Innovative use of simulated patients for educational purposes
}

Citation for published version (APA):

Bokken, L. (2009). Innovative use of simulated patients for educational purposes. [Doctoral Thesis, Maastricht University]. Datawyse / Universitaire Pers Maastricht. https://doi.org/10.26481/dis.20090304lb

Document status and date:

Published: 01/01/2009

DOI:

10.26481/dis.20090304lb

Document Version:

Publisher's PDF, also known as Version of record

\section{Please check the document version of this publication:}

- A submitted manuscript is the version of the article upon submission and before peer-review. There can be important differences between the submitted version and the official published version of record.

People interested in the research are advised to contact the author for the final version of the publication, or visit the DOI to the publisher's website.

- The final author version and the galley proof are versions of the publication after peer review.

- The final published version features the final layout of the paper including the volume, issue and page numbers.

Link to publication

\footnotetext{
General rights rights.

- You may freely distribute the URL identifying the publication in the public portal. please follow below link for the End User Agreement:

www.umlib.nl/taverne-license

Take down policy

If you believe that this document breaches copyright please contact us at:

repository@maastrichtuniversity.nl

providing details and we will investigate your claim.
}

Copyright and moral rights for the publications made accessible in the public portal are retained by the authors and/or other copyright owners and it is a condition of accessing publications that users recognise and abide by the legal requirements associated with these

- Users may download and print one copy of any publication from the public portal for the purpose of private study or research.

- You may not further distribute the material or use it for any profit-making activity or commercial gain

If the publication is distributed under the terms of Article $25 \mathrm{fa}$ of the Dutch Copyright Act, indicated by the "Taverne" license above, 


\title{
Innovative use of simulated patients for educational purposes
}

\author{
L. Bokken
}


(C) L. Bokken, Nijmegen 2009

ISBN 9789052788081

Printed by Datawyse | Universitaire Pers Maastricht Cover Lay-out: Karin van der Zanden

Publication of this thesis was financially supported by $\underset{\text { KINDERVOEING }}{\text { Ris }}$ 


\title{
Innovative use of simulated patients for educational purposes
}

\author{
PROEFSCHRIFT
}

Ter verkrijging van de graad van doctor aan de Universiteit Maastricht, op gezag van de Rector Magnificus, Prof. mr. G.P.M.F. Mols volgens het besluit van het College van Decanen, in het openbaar te verdedigen op woensdag 4 maart 2009 om 16.00 uur

door

L. Bokken

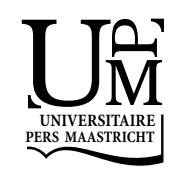




\section{Promotores}

Prof.dr. C.P.M. van der Vleuten

Prof.dr. A.J.J.A. Scherpbier

\section{Copromotor}

Dr. J.J.E. Rethans

\section{Beoordelingscommissie}

Prof.dr. R.P. Koopmans (voorzitter)

Dr. J. van Dalen

Prof.dr. R.L. Kneebone (Imperial College, London)

Prof.dr. S.G. Oei (Máxima Medisch Centrum, Eindhoven-Veldhoven)

Prof.dr. L.W.T. Schuwirth 


\section{Contents}

Chapter 1

General Introduction

Chapter 2

Feedback by simulated patients in undergraduate medical education:

A systematic review of literature

Accepted by Medical Education

Chapter 3

The case of "Miss Jacobs": Adolescent simulated patients and the quality of their role playing, feedback and personal impact

Submitted

\section{Chapter 4}

Lessons learned from an adolescent simulated patient educational program: Five years of experience

Medical Teacher 2008 October 20:1-8 (Epub ahead of print)

\section{Chapter 5}

The longitudinal simulated patient program: Evaluations by teachers and students and feasibility Medical Teacher 2008 October 20:1-8 (Epub ahead of print)

Chapter 6

Performance-related stress symptoms in simulated patients

Medical Education 2004;38(10):1089-94

Chapter 7

The impact of simulation on people who act as simulated patients:

A focus group study

Medical Education 2006;40(8):781-6 
Strengths and weaknesses of simulated and real patients in the teaching of skills to medical students: A review

Simulation in Health Care 2008;3(3):161-9

\section{Chapter 9}

Students' views on the use of real patients and simulated patients in undergraduate medical education

Accepted by Academic Medicine

Chapter 10

Instructiveness of real patients and simulated patients in undergraduate medical education: A randomized experiment Submitted

Chapter 11

163

General discussion

Summary 


\section{Chapter 1}

General Introduction 


\section{Background of the study}

In 1964 the neurologist Barrows introduced the "programmed patient", a person without neurological symptoms who was trained to simulate a neurological disorder and to assess third-year medical students. ${ }^{1}$ During the years, the term programmed patient was replaced by the terms simulated patient and standardized patient, both abbreviated to SP. Although the terms simulated patient and standardized patient are often used interchangeably, there is a distinct difference between them. ${ }^{2,3}$ The simulated patient is defined as "a normal person who has been carefully coached to present the symptoms and signs of an actual patient". 4 The emphasis is on the simulation of reality. ${ }^{3}$ Standardized patients are "people with or without actual disease who have been trained to portray a medical case in a consistent fashion". They may portray their own problem(s) or ones based on those of other patients. ${ }^{5}$ The emphasis is on consistency of presentation. Standardized patients are used for evaluation purposes, particularly for highstakes examinations, which require standardized and consistent role play in order to create equal conditions for the examinees. ${ }^{6}$ For teaching purposes, authenticity is more important than consistency and thus simulated patients are more suitable in this context. ${ }^{7}$ Standardized patients may be simulated patients or real patients with stable findings, for example heart murmurs. The level of training of the simulated patients and real patients can be varied on the basis of the aims of the teaching and examination. For example, high stakes examinations require extensively trained simulated patients to ensure standardization whereas teaching situations or formative assessments require real patients or simulated patients that have just been given an outline of what is expected from them because of their authenticity. In fact, there is a continuum of real patients in clinical practice (without any training) and simulated patients who have been trained extensively to portray a patient role (Figure 1). ${ }^{3}$

Figure 1. Continuum of simulated patients and real patients ${ }^{3}$

High training level

Low training level

\begin{tabular}{|l|l|}
\hline $\begin{array}{l}\text { Modified/rehearsed real } \\
\text { patient }\end{array}$ & Complex patient scenario \\
\hline Unaltered real patient & Simple patient scenario \\
\hline
\end{tabular}

Real patient

Simulated patient 
Standardized patients are recognized as a feasible, reliable, valid and costeffective tool in the evaluation of clinical competence. ${ }^{2,8-10}$ SPs can be trained to give constructive feedback to learners, in teaching situations and/or formative assessments. Furthermore, SPs can be trained to reliably and accurately assess the performance of students and practicing doctors, which makes having an observer present in the room redundant. Consequently, students and doctors can act more natural, enabling the assessment of their actual performance. ${ }^{8}$ For this reason, (unannounced) SPs are used to evaluate the performance of doctors in real practice, in addition to their use for teaching and evaluation purposes in medical education. ${ }^{6,11}$

SPs can also be trained to teach clinical skills, such as communication, history taking and physical examination skills, to students. SPs who actively teach are referred to as patient instructors. The patient instructor (PI) is defined as a "nonphysician who has been taught to simulate an actual patient encounter and who functions in the multiple roles of patient, teacher and evaluator". ${ }^{12,13}$ For example, the PI provides feedback to a student and teaches the student about gynecological examination skills while the student performs a gynecological examination on the PI. Similar to standardized patients, PIs may be simulated patients or real patients with stable findings.

In this thesis, we will focus on the use of simulated patients for teaching purposes in undergraduate medical students.

Barrows described many advantages of simulated patients as opposed to real patients. ${ }^{6}$ First of all, their ability to provide feedback to students is considered a major advantage of the use of SPs. Secondly, SPs are available at any time and in any setting, unlike encounters with real patients whose presence in hospital or general practice is difficult to control. Thirdly, SPs offer safety since students need not feel embarrassed if their interviewing and physical examination skills are imperfect. Mistakes are acceptable, even in difficult and sensitive situations, such as the pelvic examination or breaking bad news. SP encounters are therefore considered a transitional stage to real patient encounters. Another advantage of SPs is that their performance can be adapted to specific educational purposes. For example, an SP encounter can be interrupted to discuss the case or give tips to the student ("time-out") and SPs can be examined repeatedly to perfect students' examination techniques. The passage of time can also be ignored with SPs thus allowing students to have longitudinal SP encounters and practice continuity of care in a limited period. Furthermore, the difficulty of the patient encounter can be adapted to match a student's competence level. 
The use of SPs can minimize variability in learning by allowing each student to question and examine an SP who is simulating the same medical problem in the same way. SPs can simulate a wide range of physical findings, for example wheezing, abdominal tenderness, muscle weakness and tremor. ${ }^{6}$ Another advantage is that people of different age groups can be trained as SPs. For example, adolescents can be trained as SPs allowing students to practice communicating about items like risk-taking activities and confidentiality with adolescents. ${ }^{14,15}$

Assumed disadvantages of SPs are the time consuming recruitment and training and costs. ${ }^{6,16}$ Another disadvantage is that SPs have been found to report negative effects such as exhaustion, irritability and physical complaints due to role playing. ${ }^{17,18}$ SPs are also not able to simulate many physical signs such as heart murmurs or oedema. ${ }^{3}$ Moreover, it has been suggested that, despite their strengths, SPs can never replace real patient encounters. ${ }^{19}$

In conclusion, SPs are believed to have numerous advantages and disadvantages as opposed to real patients in their use for teaching purposes in medical education. Although there is substantial research on the use of SPs, with over 450 peer-reviewed papers published between 1996 and 2006, most studies have focused on technical aspects of SP performance such as reliability and consistency or have used SPs to assess student performance in order to evaluate the efficacy of new teaching interventions. ${ }^{20}$ Furthermore, most research has been conducted in settings in which SPs are mainly used for evaluation purposes (as opposed to teaching purposes), for example in the USA and Canada. There is paucity of studies on the practical implications of the assumed advantages and disadvantages in the use of SPs for teaching purposes. Furthermore, little is known about the added value of the use of SPs as opposed to real patients. ${ }^{21}$ Knowledge on the practical implications of SPs' advantages and disadvantages is essential to optimize the use of SPs for teaching purposes. Information on the added value of SPs as opposed to real patients, particularly with regard to their (perceived) instructiveness, is also important in order to understand if and under what circumstances real patients are preferable to SPs for teaching purposes.

\section{Research questions of thesis}

The following research questions are addressed in this thesis:

1. What are the practical implications of the perceived advantages and disadvantages of the use of SPs in the undergraduate medical curriculum? How 
can the SPs' strengths be applied in medical education? What are the limitations of the use of SPs in medical education? How can the limitations be diminished?

2. What are the advantages and disadvantages of SPs as opposed to real patients? What do students regard more instructive: an encounter with a real patient or an SP encounter? What variables influence the perceived instructiveness?

The answers to these questions were explored in the setting of the medical curriculum at the Maastricht University. For that reason, the use of SPs and real patients in the Maastricht Medical School will be further explained.

\section{Setting}

SPs have been employed for more than 30 years at the Skillslab of Maastricht Medical School, which now has a pool of about 100 SPs. The SPs are primarily used in the teaching of undergraduate medical students. During the three preclinical years of the six-year problem-based learning (PBL) curriculum, all students $(\mathrm{N}=340$ per year) can practice communication and physical examination skills in teacher-independent encounters with SPs in the Skillslab. ${ }^{22}$ The encounters are planned once every three weeks and consist of simulated consultations in which student-pairs, with one student in the role of the doctor and the other as observer, see an SP and take a history and/or perform a physical examination. The student-pairs change roles for each SP encounter. During the encounters SPs play a role that is relevant for and linked to curriculum the student is enrolled in. The authenticity of the role playing is considered essential in the use of SPs for teaching purposes. ${ }^{7}$ It is thought that the role will gain credibility if it stays close to the SP's true situation and character. Consequently, SPs at the Skillslab are trained to perform a patient role by means of "method acting". With this acting style, the actor draws on his or her personal experience in portraying a role. SPs therefore portray a patient role that is tailored to their own personality. After the encounter, the SPs give feedback to the "student-doctor" on their experiences as a patient during the consultation. The SPs are trained to give feedback on the basis of four feedback rules (Figure 2). 
Figure 2. Feedback rules for SPs

- Priority rule - SPs should start their feedback by answering the student's questions about the achievement of his or her individual learning goals. After this, the SP can give feedback on matters that stuck to the SPs memory and other matters.

- Domain rule - The SP is only allowed to give feedback with regard to his or her own experiences as a patient during the encounter with the student (i.e. no feedback on medical content).

- "I statements" rule - SPs should give feedback from their own point of view, using "I statements", for example, "I didn't feel comfortable during the conversation since I didn't understand your questions" instead of "You should be more clear because people don't understand your questions and then feel uncomfortable".

- Neutrality rule - SP should not give judgments about the student's performance, positive nor negative. Furthermore, SPs should tune their feedback to the individual student and refrain from comparing with fellow students, for example "You listened to me very well" instead of "You listened better than the other student I have spoken with".

The SP encounters are recorded on DVD. In the week after the encounter, students and teachers individually watch the recorded encounters. Furthermore, the encounters are discussed in tutorial groups composed of 10 students and one teacher. ${ }^{22}$

Annually, the clinical skills of all medical students, preclinical and clinical, are assessed by means of an Objective Structured Clinical Examination (OSCE). In the OSCEs SPs are used to assess communication skills. The individual student has an encounter with an SP which is observed and evaluated by an attending physician or behavioral scientist. For their performance during the OSCEs, the SPs are trained to perform a predetermined, standardized and more or less fixed role. The SPs do not give feedback to the students during the OSCEs. Since the use of SPs in the assessment of skills is a very small part of their overall use at the Skillslab of the Maastricht Medical School, all studies in this thesis refer to the use of SPs in a teaching setting and not in assessments.

Real patients are used in a variety of educational formats in the preclinical medical curriculum of the Maastricht University. For example, real patients are used in case presentations during lectures for all students in a year and real patients with specific disorders (e.g. Diabetes Mellitus or Multiple Sclerosis) are used for the small group teaching of history taking skills and physical examination skills at the Skillslab. Furthermore, students have encounters with real patients at general practitioner's offices. Since the introduction of a new medical curriculum in 2001, the use of real patients has become fully integrated in the third year of medical school. ${ }^{23,24}$ Here, weekly encounters with real patients 
in the outpatient clinic in the Maastricht University Hospital are used as triggers for learning in tutorials related to the encounters.

\section{Outline of thesis}

We will provide an overview of the thesis which consists of eleven chapters, divided over two sections. In the first section, consisting of chapters 2 to 7 , we focus on our first research question regarding the advantages and disadvantages of SPs in undergraduate medical education.

In chapter 2 we discuss one of the major advantages of SPs: their ability to provide feedback on an encounter with a student. The importance of feedback by SPs is generally well recognized. Feedback is considered an integral part in the teaching with SPs and SPs provide feedback on a broad scale in medical education. However, little is known about the most effective ways in which SPs can provide feedback to undergraduate medical students and about the training of SPs in providing feedback. We systematically reviewed the literature to identify ways in which SPs provide feedback to undergraduate medical students and to identify ways in which SPs are trained to provide feedback.

In chapter 3 and 4 we focus on adolescent SPs. People of various age groups can be trained as SPs. This is an important advantage of SPs since it enables students to practice specific communication skills required for interaction with various age groups in a safe learning environment. In chapter 3 we assess the quality of the role playing by adolescent SPs and the quality of the feedback they provide to students. For this, we make use of a validated questionnaire (the MaSP) designed to assess the performance of individual SPs with regard to role playing and feedback. ${ }^{7}$ Furthermore, we evaluate the impact of the role playing on adolescent SPs. Although no negative effects were reported in studies in adolescents trained as standardized patients, the impact of performing a patient role in adolescents trained as simulated patients has not previously been evaluated. Since SPs trained as simulated patients incorporate more of their own personal backgrounds in their roles, the impact of the performance might differ from the impact of the performance in SPs trained in a standardized role. In chapter 4, we evaluate the adolescent SP program from the points of view of teachers, students and adolescent SPs over five years. We report on the important lessons learned during the five years.

In chapter 5 we describe a longitudinal SP program. An important advantage of SPs is that their roles can be adjusted to the learning needs of the student. SPs 
are mostly used in single-case encounters in which students have repeated unconnected encounters with SPs and receive feedback from SPs and/or teachers or peers afterwards. For training students in chronic care, however, longitudinal patient encounters are more suitable. We developed a longitudinal SP program and explored the evaluations of students and teachers regarding the new program. Furthermore, we compared the evaluations of the longitudinal SP program to the single-case SP program and we explored the feasibility of the program.

In chapter 6 and 7, we report on SPs experiencing stress symptoms due to their performance of a patient role. This is a limitation of the use of SPs. In chapter 6, we quantitatively explore the occurrence and severity of stress symptoms in SPs with use of a questionnaire that was developed for this study. In chapter 7, we qualitatively explore the impact of simulation and the factors that might affect this by means of focus group discussions. The discussions led to various suggestions for measures to reduce the impact of simulation.

In the second section, consisting of the chapters 8 to 10 , we focus on our second research question regarding the advantages and disadvantages of SPs as opposed to real patients.

In chapter 8 the literature was reviewed to identify the strengths and weaknesses of the roles of SPs and real patients in undergraduate medical education. Four types of patient roles are identified: real patients as an educational resource (passive role); real patients as teachers (active role); SPs as an educational resource; and SPs as teachers. Each of the four patient roles has specific advantages and disadvantages from the perspectives of teachers, students and patients. In chapter 9 we explore the views of students with regard to the advantages and disadvantages of real patients and SPs in the undergraduate medical curriculum in a focus group study.

In chapter 10 we perform an experiment in which first year medical students are randomized to having an encounter with a real patient or an encounter with a SP. We assess the perceived instructiveness of the encounter with both quantitative (questionnaires) and qualitative (focus groups) methods.

In the final chapter, chapter 11 , the general discussion and conclusions are presented. Recommendations for the use of SPs in undergraduate medical education are made and suggestions for further research are generated.

Since all chapters have been submitted or published as individual papers, there might be some overlap within the chapters. 


\section{References}

1. Barrows HS, Abrahamson S. The programmed patients: a technique for appraising student performance in clinical neurology. Journal of Medical Education. 1964;39:802-805.

2. Adamo G. Simulated and standardized patients in OSCEs: achievements and challenges 19922003. Med Teach. May 2003;25(3):262-270.

3. Collins JP, Harden RM. AMEE Medical Examination Guide No 13: real patients, simulated patients and simulators in clinical examinations. Med Teach. 1998;20(6):508-521.

4. Barrows HS. How to design a problem-based curriculum for the pre-clinical years. New York: Springer; 1985.

5. RCSA. Consensus statement of the Researchers in Clinical Skills Assessment (RCSA) on the use of standardized patients to evaluate clinical skills. Acad Med. 1993;68(6):475-477.

6. Barrows HS. An overview of the uses of standardized patients for teaching and evaluating clinical skills. Academic Medicine. 1993;68(6):443-451.

7. Wind LA, Van Dalen J, Muijtjens AM, Rethans JJ. Assessing simulated patients in an educational setting: the MaSP (Maastricht Assessment of Simulated Patients). Medical Education. Jan 2004;38(1):39-44.

8. Rethans JJ. Needs assessment in continuing medical education through standardized patients. Journal of Continuing Education in the Health Professions 1998;18:172-178.

9. Van der Vleuten CPM, Swanson DB. Assessment of clinical skills with standardized patients: State of the art. Teaching and Learning in Medicine. 1990;2:58-76.

10. Vu NV, Barrows HS. Use of standardized patients in clinical assessments: Recent developments and measurement findings. Educational Researcher. 1994;23(3):23-30.

11. Rethans JJ, Gorter S, Bokken L, Morrison L. Unannounced standardized patients in real practice: a systematic literature review. Med Educ. Jun 2007;41(6):537-549.

12. Stillman PL, Burpeau-Di Gregorio MY, Nicholson GI, Sabers DL, Stillman AE. Six years of experience using patient instructors to teach interviewing skills. $J$ Med Educ. Dec 1983;58(12):941-946.

13. Stillman PL, Ruggill JS, Rutala PJ, Sabers DL. Patient instructors as teachers and evaluators. Journal of Medical Education. 1980;55(3):186-193.

14. Blake K, Gusella J, Greaven S, Wakefield S. The risks and benefits of being a young female adolescent standardized patient. Medical Education. Jan 2006;40(1):26-35.

15. Blake K, Mann KV, Kaufman DM, Kappelman M. Learning adolescent psychosocial interviewing using simulated patients. Academic Medicine. Oct 2000;75(10 Suppl):S56-58.

16. Lane C, Rollnick S. The use of simulated patients and role-play in communication skills training: a review of the literature to August 2005. Patient Educ Couns. Jul 2007;67(1-2):1320.

17. McNaughton N, Tiberius R, Hodges B. Effects of portraying psychologically and emotionally complex standardized patient roles. Teach Learn Med. 1999;11(3):135-141.

18. Woodward CA, Gliva-McConvey G. The effect of simulating on standardized patients. Academic Medicine. 1995;70(5):418-420.

19. Stillman PL, Regan MD, Philbin M, Haley HL. Results of a survey on the use of standardized patients to teach and evaluate clinical skills. Academic Medicine. 1990;65(5):288-292.

20. Howley L, Szauter K, Perkowski L, Clifton M, McNaughton N. Quality of standardized patient research reports in the medical education literature: review and recommendations. Med Educ. Apr 2008;42(4):350-358. 
21. Spencer J, Blackmore D, Heard S, et al. Patient-oriented learning: a review of the role of the patients in the education of medical students. Medical Education. 2000;34(10):851-857.

22. Van Dalen J, Bartholomeus P, Kerkhofs E, et al. Teaching and assessing communication skills in Maastricht: the first twenty years. Medical Teacher. May 2001;23(3):245-251.

23. Diemers AD, Dolmans DH, Van Santen M, Van Luijk SJ, Janssen-Noordman AM, Scherpbier AJ. Students' perceptions of early patient encounters in a PBL curriculum: a first evaluation of the Maastricht experience. Med Teach. Mar 2007;29(2-3):135-142.

24. Diemers AD, Dolmans DH, Verwijnen MG, Heineman E, Scherpbier AJ. Students' opinions about the effects of preclinical patient contacts on their learning. Adv Health Sci Educ Theory Pract. Jul 2007 (Epub ahead of print). 


\section{Chapter 2}

\section{Feedback by simulated patients in undergraduate medical education: A systematic review of literature}

L. Bokken, T. Linssen, A. Scherpbier, C. van der Vleuten, JJ. Rethans Accepted by Medical Education 


\begin{abstract}
Background: Although the importance of feedback by simulated patients (SPs) is generally recognized, little is known about the most effective ways for SPs to provide feedback. Also, little is known about the training of SPs to provide feedback.

Objective: To provide a systematic overview of the ways in which SPs provide feedback to undergraduate medical students, the domain on which SPs provide feedback and the ways in which SPs are trained to provide feedback.

Methods: Systematic search of literature in Pubmed, Psycinfo and Eric and search for additional papers in reference lists. Papers were selected on the basis of pre-established in- and exclusion criteria and classified, using a preestablished form, on the basis of three aspects: feedback training, process of feedback and domain of feedback.

Results: Forty-nine studies were included and described in detail on the basis of the three previously mentioned aspects. The ways in which SPs were trained to give feedback were largely heterogeneous, similar to the process of feedback provided by SPs. Only few studies described feedback processes that are in accordance to the general recommendations for effective feedback. Although feedback from the patient's perspective is generally recommended, most SPs provided feedback on clinical skills and communication skills.

Discussion: There appear to be no clear standards with regard to effective feedback training for SPs. Furthermore, the process of feedback provided by SPs and the domain on which SPs give feedback often seem to lack a solid scientific basis. Suggestions for further research are provided.
\end{abstract}




\section{Introduction}

Feedback to students is an integral part of the teaching with standardized or simulated patients (SPs). SPs are unique since they can be trained to give feedback from a patient's perspective. ${ }^{1,2}$ The ability of SPs to give immediate and specific feedback on an encounter with a student is one of the advantages of SPs compared to real patients. ${ }^{2-4}$ Feedback can be defined as "specific information about the comparison between a trainee's observed performance and a standard, given with the intent to improve the trainee's performance". ${ }^{5}$ Immediate, oral or written feedback provided by SPs after a student encounter is widely used in many medical schools. ${ }^{4}$

Students highly value the feedback provided by SPs. ${ }^{6-9}$ Their feedback is valued equally or more positively than the feedback provided by doctors. ${ }^{10-12}$ Students trained by SPs showed equal or even better skills, for example communication skills or pelvic examination skills, compared to students trained by faculty teachers. ${ }^{13-17}$ Even at six months after the training, students trained by SPs showed better skills compared to students trained by more traditional teaching methods, consisting of a lecture and small group discussions. ${ }^{18}$ Feedback by SPs might be an important factor contributing to this.

SPs provide feedback to undergraduate medical students on a variety of domains, for example on interviewing skills or physical examination skills, and in a variety of formats, for example verbally or with the use of written checklists. ${ }^{4}$ Although the importance of feedback by SPs is generally recognized and feedback by SPs is widely used in many medical schools, little is known about the most effective ways in which SPs can provide feedback to undergraduate medical students. ${ }^{19}$ We also know little about the training of SPs in providing feedback.

The aims of this review were 1) to identify the ways in which SPs provide feedback to undergraduate medical students 2) to identify the domain on which SPs provide feedback and 3) to identify the ways in which SPs are trained to provide feedback.

\section{Methods}

We searched the databases Pubmed, Psycinfo and Eric using the search terms "feedback", "standardized patients or simulated patients" and "undergraduate medical education". The databases were searched from their onset throughout 
July 2007. SPs that actively teach medical students and provide them with feedback are often called patient instructors. Patient instructors who teach in the field of gynecology or urology are also referred to as gynecologic teaching associates, genitourinary teaching associates, urogenital teaching associates or urological teaching associates. Therefore we also used the search terms "patient instructors", "gynecologic teaching associates", "genitourinary teaching associates", "urogenital teaching associates" or "urological teaching associates" and "(undergraduate) medical education". We included empirical research papers and descriptive papers in which SPs gave immediate, direct, specific, constructive and formative feedback to undergraduate medical students.

Theoretically, there is a difference between standardized patients (persons with or without symptoms trained to portray a patient problem in a standardized, consistent manner) and simulated patients (persons trained to realistically portray a patient role). ${ }^{1}$ Both standardized and simulated patients give feedback to students and the terms are often used interchangeably. Therefore, the theoretical difference between standardized and simulated patients was not considered important for our study. In our study, SPs were defined as lay persons with or without symptoms, trained to portray a patient role realistically and consistently.

Papers in which SPs did not give feedback directly to the students but to teachers who subsequently gave feedback to the students or papers that were not clear on who provided feedback (faculty or SP), were excluded. Papers in which SPs gave feedback directly to students in the presence of teachers were included. Feedback should be formative as it is "given with the intent to improve the student's performance". Therefore, studies in which the SPs only rated the performance of students on a checklist, for example in (summative) assessments, were excluded. The uniqueness of the feedback by SPs is that it is given from a patient's perspective. To maintain the feedback to be purely from the patient's perspective and to prevent bias from knowledge about physical examination techniques and history taking for example, we only included papers in which lay persons were trained as SPs. Studies in which faculty teachers, residents, medical students or other health care professionals were trained as SPs were therefore excluded.

Papers were selected by one of the authors (LB) on the basis of their abstracts. When the selection could not be made on the basis of the abstract alone or when there was no abstract available, the full text paper was used. In case of uncertainty regarding the in- or exclusion of a paper, selection of the paper was discussed with a second author (TL) until consensus was reached. 
Using the search terms described earlier we found 394 papers. Of these 394 papers, 38 papers were selected on the basis of the in- and exclusion criteria. References of selected papers were also checked for additional, relevant papers that were missed in the initial search. This yielded another 50 papers of which 14 papers met the in- and exclusion criteria. The full text paper of one study could not be obtained. Since the abstract provided too limited information, this study was excluded from the review. Two papers described follow-up results of previously published studies. Each of these papers was analyzed together with the previously published study, since the SPs were trained and used in exactly the same way. Ultimately, a total number of 49 studies were included in the review.

Two independent reviewers (TL and LB) classified the papers using a preestablished form (Box 1). The form was developed by one researcher (LB) on the basis of literature and revised based on comments of all authors. The completed forms of both reviewers were then compared and any disagreements were discussed until consensus was reached. The studies were classified on the basis of three aspects: 1) the training of SPs in providing feedback 2) the process of feedback provided by SPs and 3) the domain of feedback provided by SPs.

The process of feedback refers to the ways in which SPs provide feedback to students. In overview papers on feedback in general, so not specifically tailored to SPs, several recommendations for providing effective feedback in medical education have been made (Box 2). ${ }^{5,2-25}$ In this review, we compared the process of feedback provided by SPs with the pre-established recommendations for providing effective feedback in medical education. As part of the process of feedback, feedback can be provided verbally or in writing. Elnicki et al. found that learners perceived verbal, face-to-face feedback as equally valuable compared to written feedback. ${ }^{26}$ However, Kluger and DeNisi found that verbal feedback was less effective. ${ }^{23}$ Also, feedback can be provided to students individually or in the presence of peers or faculty teachers. Kluger and DeNisi found that feedback in a group was more effective, although the effect was minimized after excluding some of the studies from the meta-analysis. ${ }^{23}$ Information on these items (written versus verbal feedback and individual versus group feedback) is considered important for the purpose of this study, even though there is no gold standard provided by literature. 
Box 1. Form used to classify the selected studies

Reviewer: $\quad \square$ TL $\square$ LB
Title of paper:
Authors:
Year of publication:
Does the study fulfill the inclusion criteria?
Do SPs give feedback themselves and directly to students? $\square$ Yes $\square$ No
Do SPs give formative feedback? $\quad \square$ Yes $\square$ No
Are the SPs lay persons? $\quad \square$ Yes $\square$ No
Is the study about undergraduate medical education?
Does the study provide information on training,
process of feedback or domain of feedback?
Type of research: $\square$ Yescriptive
Is feedback training being described? $\square$ Y Yes $\square$ No No
If yes, how does feedback training take place? ...
How do SPs provide feedback?
$\square$ Verbal $\square$ Written $\square$ Both (written and verbal)
How do students receive feedback from SPs?
$\square$ Individual (one to one) $\square$ In the presence of peers
If peers are present, what is the ratio of SPs to students? ...
Is there a teacher present? $\quad \square$ Yes $\square$ No
On what domain do SPs provide feedback?
$\square$ Clinical skills $\square$ Communication skills $\square$ Patient's perspective
$\square$ Other: ...
Do SPs actively teach or instruct students (in their role as patient instructors or gynecologic
teaching associates)? ...

The domain of feedback refers to the content of feedback provided by SPs. SPs can give feedback on clinical skills, for example on history and physical examination, or on communication and interpersonal skills. ${ }^{4}$ Feedback on medical issues is often linked with active instruction by SPs, for example in patient instructors or gynecologic teaching associates. SPs can also provide feedback from the patient's perspective. In providing this type of feedback, the SP focuses on how he or she felt during the consultation with the student. ${ }^{27}$ The feedback is "mirroring"; the patient recalls the reactions he or she experienced during the consultation with the student and gives them back to the student. ${ }^{28}$ This is the uniqueness and strength of feedback given by SPs. For that reason, SPs have been recommended to provide feedback from the patient's perspective. ${ }^{2,29}$ 
Box 2. Recommendations for providing effective feedback in medical education

- Safe learning environment; the expectations of the students are clear and confidentiality is emphasized.

- Feedback starts with the student's self-evaluation.

- Feedback is related to learning goals defined by the student and therefore compatible to the student's prior knowledge and relevant for the student.

- Standard with which the performance of the students is compared is clear.

- Feedback is interactive; students are encouraged to reflect on their performance and to make learning goals for future encounters.

- Feedback is specific and descriptive with examples of what happened.

- Feedback focuses on observable behaviour, not on the student him or herself.

- Feedback is labelled as subjective information, using "I" statements.

- Give positive feedback before negative feedback.

- Limit feedback, preferably to two to three key points.

- Feedback is provided immediately after a performance and on a regular basis.

In our study, information on the domain of feedback provided by SPs is classified on the basis of previously mentioned themes: patient's perspective, clinical skills (history taking and physical examination skills), communication skills (communication and interpersonal skills) and instruction by SPs.

\section{Results}

Of the 49 studies included in our review, 22 used experimental designs and 27 were descriptive in nature. In the large majority of studies, feedback by SPs was used as a tool to teach clinical skills to medical students. For example, feedback by SPs was used in the teaching of smoking-cessation techniques to undergraduate medical students ${ }^{30,31}$ or to teach students about reproductive medicine. ${ }^{32}$ We found only one comparative study in which two different ways of providing feedback to undergraduate medical students were evaluated. In this study, Pfeiffer et al. assessed whether SPs are more lenient in giving direct, face-to-face feedback to students as opposed to giving no direct feedback. ${ }^{33}$ No difference was found with respect to the feedback on history taking skills and physical examination skills and only a small difference was found with regard to the feedback on interviewing and interpersonal skills. This suggests that direct feedback by SPs is accurate and reliable.

We will now address the three aspects, feedback training, process of feedback and domain of feedback provided by SPs. Detailed information from the selected studies with regard to these aspects is included in Table 1. 

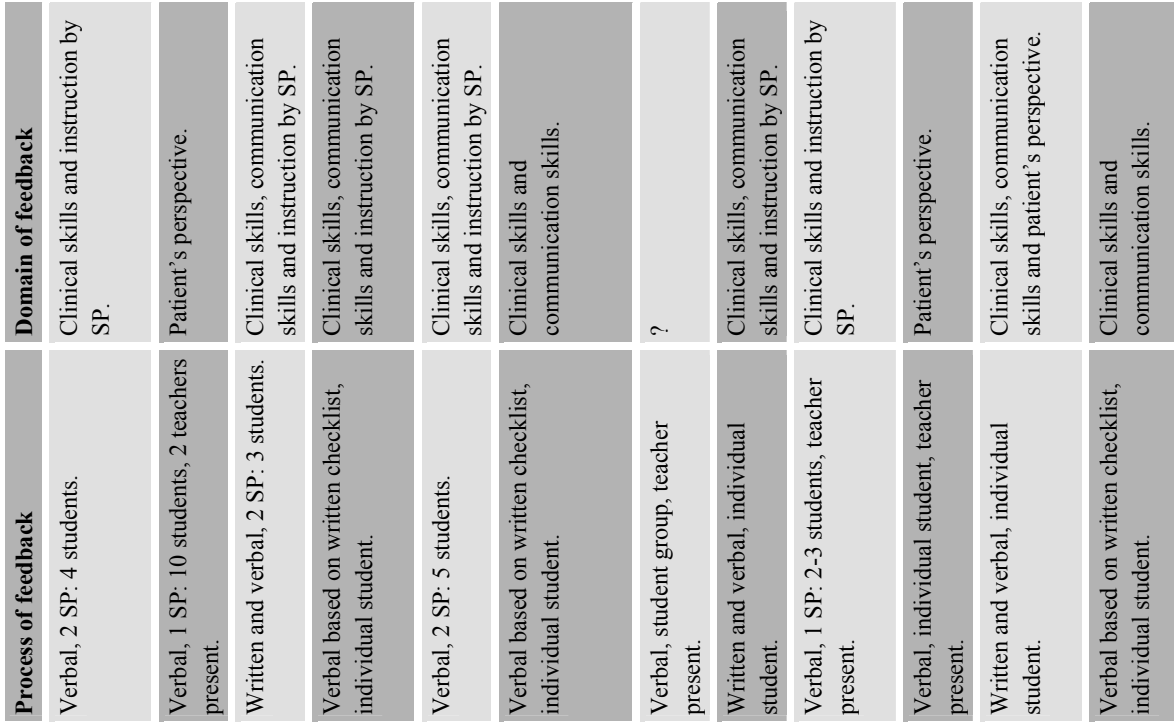

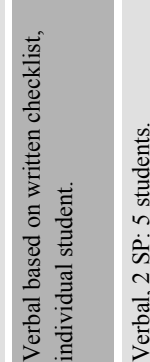

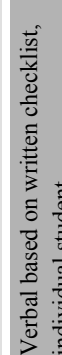
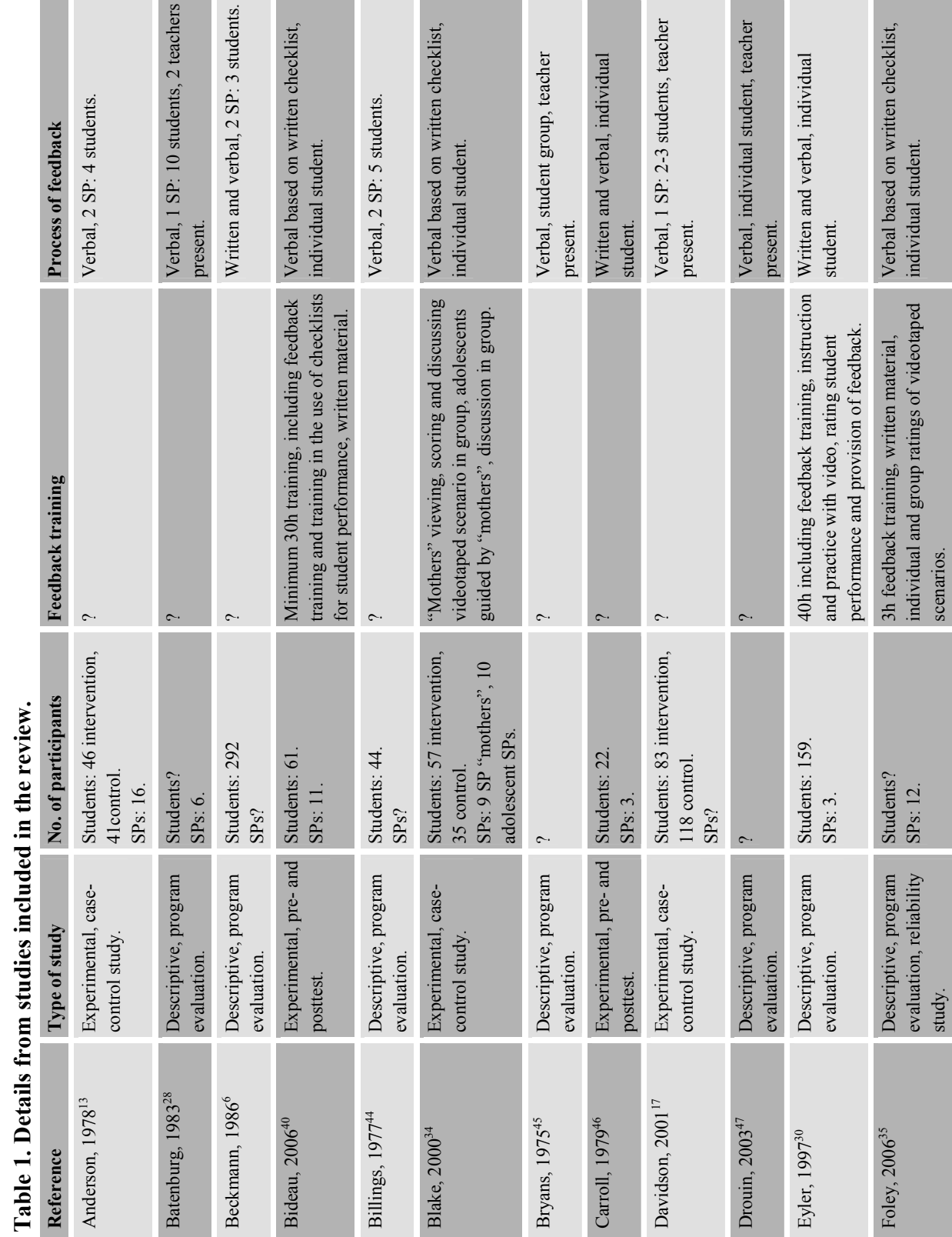


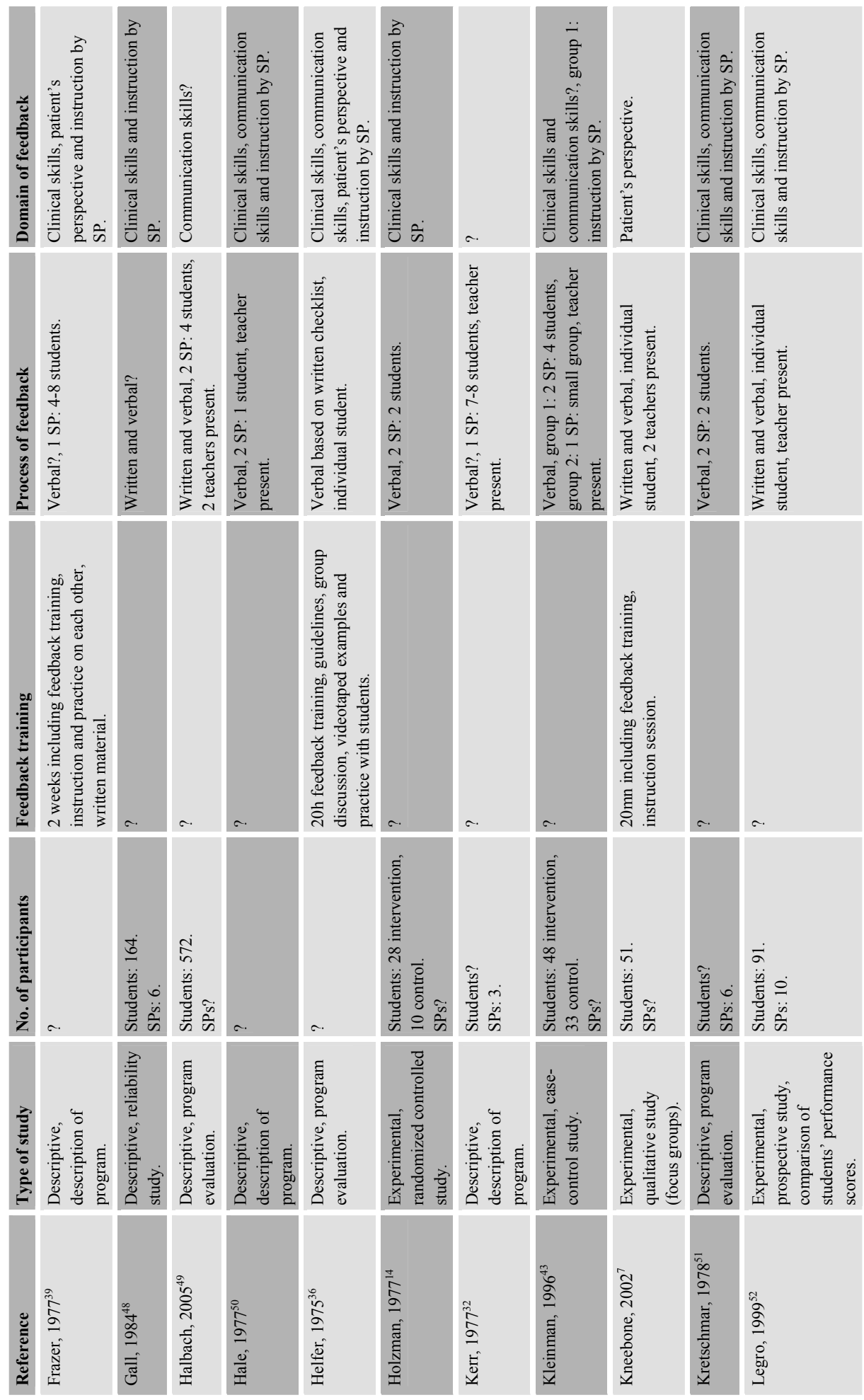



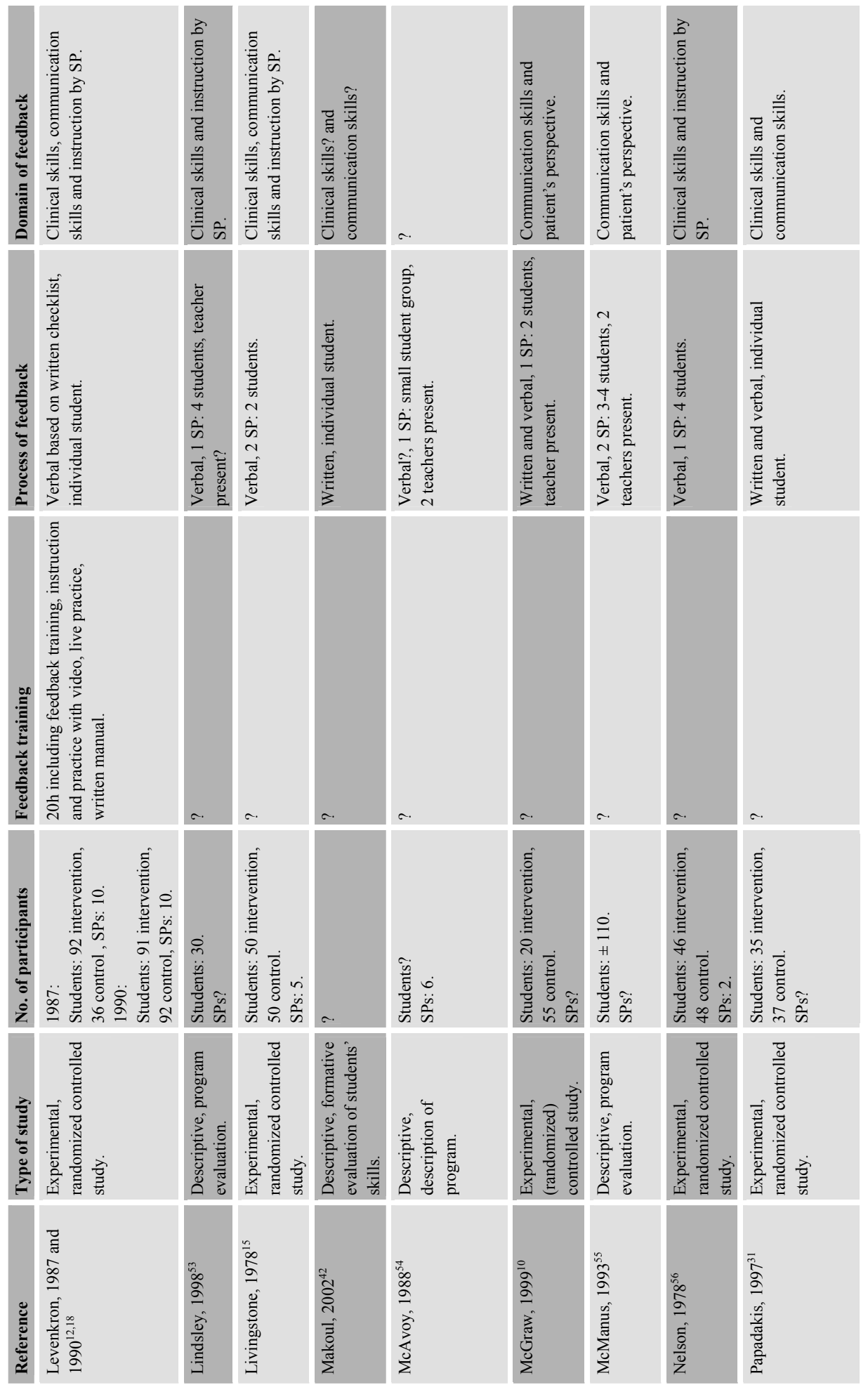
FEEDBACK BY SPS

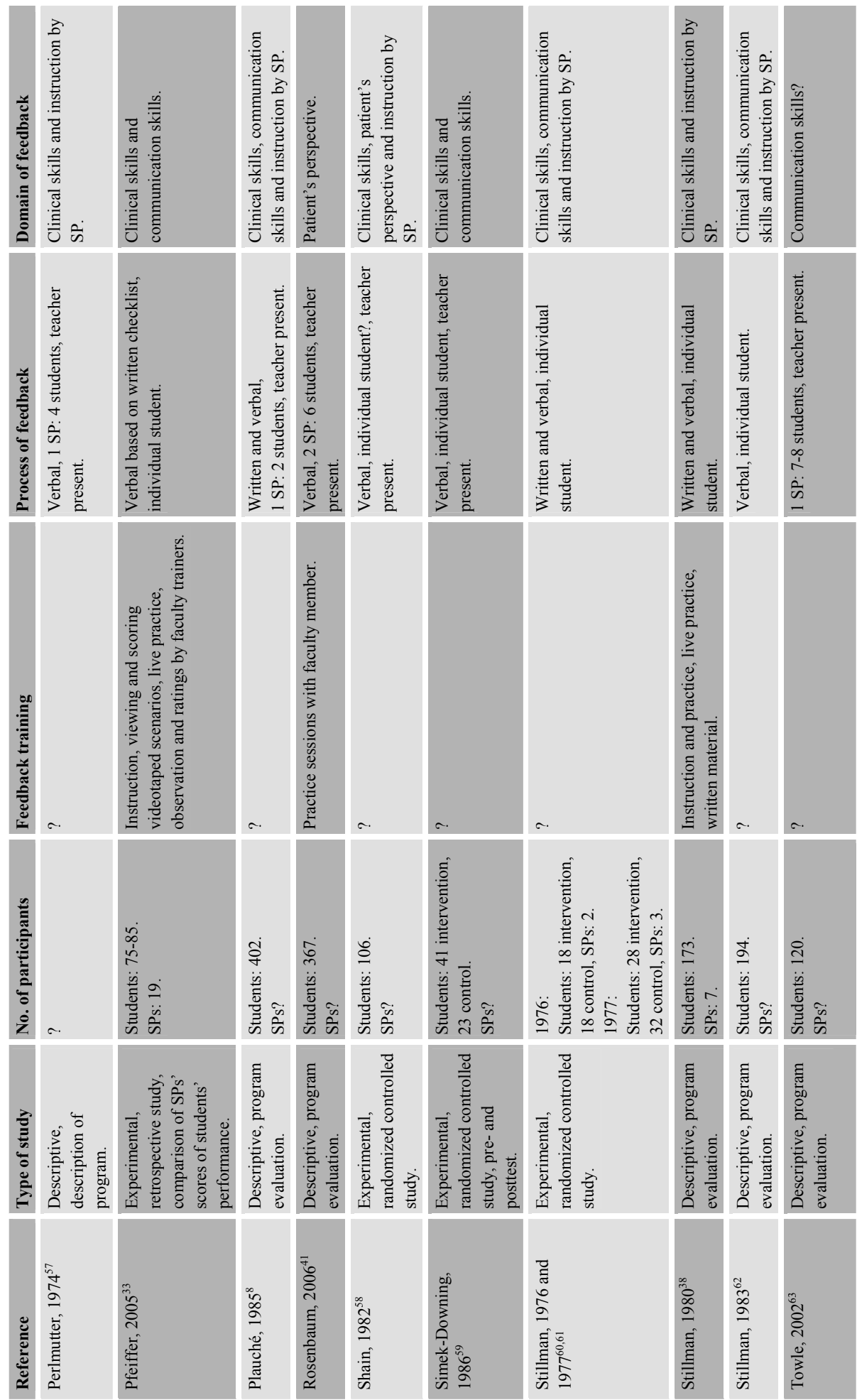



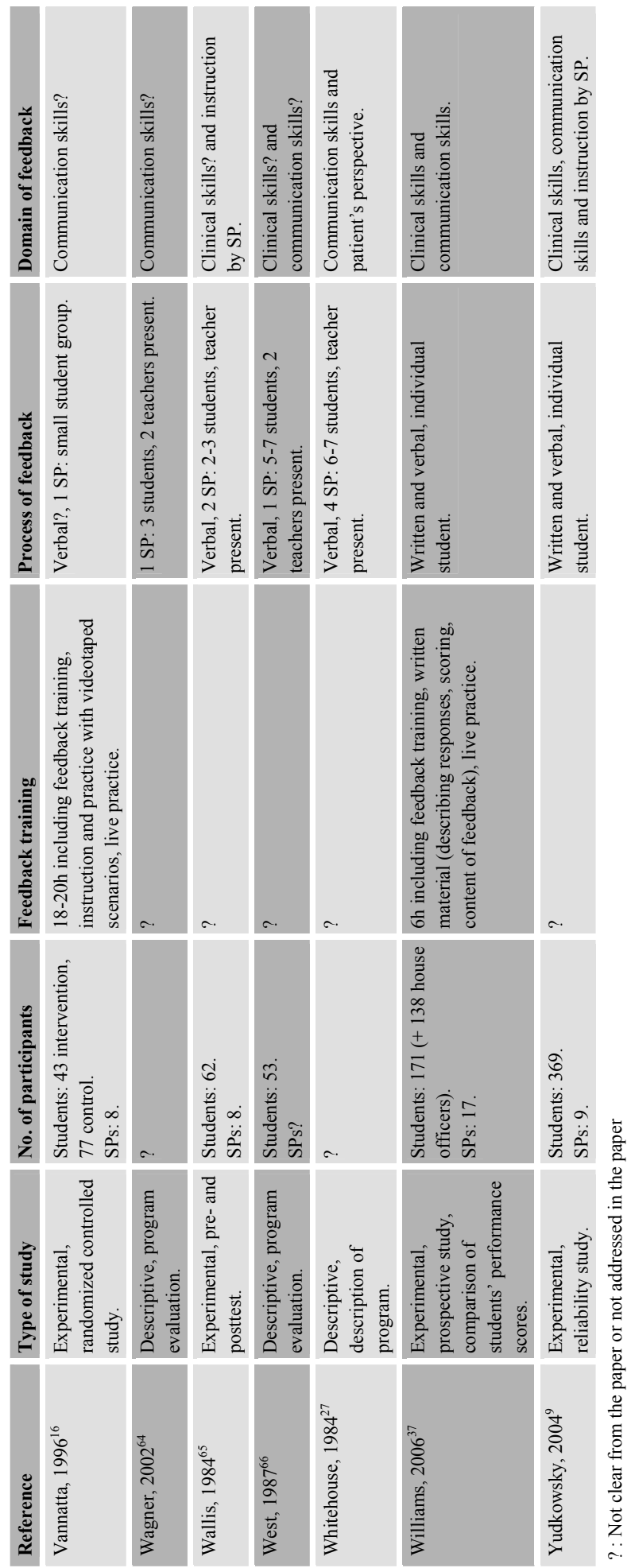


\section{Training of SPs in giving feedback}

Only 13 studies provided information on the training of SPs in giving feedback to students. Most of these papers provided limited information. Generally, feedback training was a smaller part of the total training of SPs which also included training for role playing and for teaching skills to students. The total training time varied from 20 minutes in experienced SPs to 40 hours in newly recruited SPs. ${ }^{7,30}$ Training of SPs in recording checklist items and giving feedback consisted of studying videotaped interviews and practicing feedback with SP trainers ${ }^{12,16,18,30,33-36}$ and/or live interview and feedback practice. ${ }^{12,16,18,33,36-38}$ In one study SPs could practice giving feedback on each other. ${ }^{39}$ In 7 studies, SPs received written instructional material or an instruction manual, for example articles or guidelines on giving feedback. ${ }^{12,18,35-40}$

Rosenbaum et al. found that SPs are able to provide more genuine feedback if they are trained by using patient-generated SP cases instead of pre-written cases. ${ }^{41}$ Similar results have been found in a study in our setting. ${ }^{3}$

In conclusion, there is large heterogeneity with regard to the ways in which SPs are trained to provide feedback and there are no clear standards for training. There is evidence that feedback can be more genuine by using patient-generated SP cases.

\section{Process of feedback}

Most of the papers briefly described the process of feedback provided by SPs. However, we found 3 papers describing the process of feedback in greater detail. $^{7,12,33}$ Kneebone et al. reported on feedback sessions starting with a student's self-evaluation, followed by feedback from the SP and teachers. ${ }^{7}$ In a study by Pfeiffer et al. feedback was provided in four steps. First, the SP asked the student to self-evaluate his/her performance. Then the SP gave detailed feedback on interpersonal and interviewing skills and the SP reviewed a checklist on the content of the consultation he/she had completed. Finally, the student could practice parts of the consultation that were weak. ${ }^{33}$ In a study by Levenkron et al. in which SPs taught students on risk-factor counseling skills, another process of feedback provided by SPs was described. First, the criterion for ideal response was identified, on the basis of a checklist that was used in scoring the consultation. After this, the student's response was described and rephrased to 
approximate the ideal response. Finally, the student was invited to rehearse the ideal response in his/her own words. ${ }^{12}$

In 14 studies SPs provided students with written and verbal feedback. In these studies SPs mostly provided feedback on the domain of clinical skills and/or communication skills. We found only 3 studies in which the SPs gave written and verbal feedback from a patient's perspective. ${ }^{7,10,30}$ Written feedback mostly consisted of structured checklists or forms. Occasionally, written comments could also be made on the forms. ${ }^{10,30}$ In most studies (N=32) SPs gave verbal feedback, sometimes based on completed checklists and forms. In one study, SPs only provided the students with written feedback, existing of completed checklists and evaluative comments. ${ }^{42}$

In 19 studies SPs provided feedback to students individually. In the majority of studies, however, SPs gave feedback to a student in the presence of others, for example peers and other SPs. The group of peer students present was small, with a maximum of 10 students. One or two teachers were present during feedback in $24(49 \%)$ of all studies.

In summary, although most studies provide limited and heterogeneous information on the process of feedback given by SPs, the process of feedback that is described in more detail is in accordance with some of the recommendations for effective feedback, for example "start with the student's self-evaluation" and "clear standard with which the student's performance is compared". SPs mostly provide verbal feedback to students, whether or not based on written checklists, and mostly in the presence of other students or SPs.

\section{Domain of feedback}

In a large majority of the studies $(\mathrm{N}=35)$ SPs gave feedback on clinical skills. Feedback on clinical skills included scoring aspects of history or physical examination. For example, in studies on teaching smoking cessation techniques to students: "obtaining a patient's smoking history" and "asking after the age of onset of smoking"30,31 or in a study on teaching gynecological examination skills to students: "inserts speculum fully before opening" and "palpates abdomen to find uterine fundi". ${ }^{43}$ In 31 studies SPs gave feedback on communication skills. Feedback on communication skills included scoring aspects of communication, for example, "treats the patient with respect" and "addresses the patient with her last name". ${ }^{37}$ 
In $26(74 \%)$ of the studies in which SPs gave feedback on clinical skills and in $15(48 \%)$ of the studies in which SPs gave feedback on communication skills, SPs also gave instruction to the students (in their roles as patient instructors or gynecologic teaching associates). In 20 of all 49 studies, SPs did not give instruction to students. SPs gave feedback on clinical skills in 9 (45\%) of these studies and feedback on communication skills in $16(80 \%)$ of these studies.

In 12 of all 49 studies, SPs gave feedback from the patient's perspective. In 4 of these studies, feedback was solely given from the patient's perspective; no feedback was given on clinical skills or communication skills and no instruction was given to students. When providing feedback from a patient's perspective, SPs recalled how they felt during the consultation. In some studies structured checklists were used to support this, consisting of items like "the student made eye-contact with you" or "the questions were understandable". ${ }^{10}$

In summary, although feedback from the patient's perspective is generally recommended, SPs mostly provide feedback on the domain of clinical skills and communication skills. Even if studies in which SPs give instruction to students are excluded, SPs provide feedback on clinical and communication skills in the majority of studies.

\section{Discussion}

Although we found many studies in which feedback by SPs is used as a tool to teach skills to medical students, we found only one comparative study in which two methods for SPs to provide feedback were evaluated. This is a remarkable finding. There might be several explanations for the scarcity of comparative studies found. First of all, although we tried to be as systematic and comprehensive as possible in our search for literature, there is always a risk of missing important papers in any review paper. Furthermore, in overview papers on feedback in general (not specifically tailored to SPs) many effective methods for providing feedback have been identified (Box 2). The evidence provided by these studies might be so evident that studies on effective ways for SPs to give feedback are not considered to provide additional information. In this case, we would expect the majority of the studies to report on SPs giving feedback to students on the basis of the general recommendations for effective feedback. However, we found only three studies reporting on SPs giving feedback on the basis of some of these recommendations. There was no information on followup of other feedback recommendations, for example "focus on behavior" or 
"give positive feedback before negative feedback". We also found a large heterogeneity in the feedback provided by SPs. This suggests the most effective ways for SPs to give feedback are not so evident. In addition, with regard to some ways to provide feedback, for example written versus verbal or group versus individual, studies on feedback in general have not provided a clear answer on which is best. For these reasons, we feel that more (comparative) research is needed to identify the most effective ways for SPs to provide feedback. For example, research comparing the effectiveness of feedback by SPs based on the general recommendations for effective feedback to spontaneous feedback provided by SPs.

Although it has been recommended that SPs provide feedback to students from the patient's perspective, SPs gave feedback on this domain in only a quarter of all studies. The majority of feedback by SPs was given on clinical skills and communication skills. Feedback on these domains is essential in the teaching of skills to students. Therefore it is not surprising that most SPs who gave feedback on clinical skills and communication skills also gave instruction to students. However, in the majority of studies in which SPs gave no instruction to students, SPs did give feedback on clinical skills and communication skills as well. Further research is needed to identify the domains on which SPs can most effectively provide feedback to students. Until then, we suggest that SPs provide feedback from the patient's perspective (in addition to feedback on clinical skills and/or communication skills in case SPs give instruction to students) since feedback on this domain is the uniqueness and strength of the feedback provided by SPs.

We were surprised by the small number of studies reporting on the training of SPs to give feedback. Similar to the ways in which SPs gave feedback, there is large heterogeneity in the ways in which SPs were trained to give feedback. Further research is needed to identify the most effective ways for training SPs in providing feedback. For example, comparative research on the impact of different ways of training on the effectiveness feedback provided by SPs.

There are some limitations to this study. First of all, papers were selected and included in the review by one researcher. Although the selection of papers was discussed with a second researcher in case of uncertainty, this might have biased our results. Furthermore, we did not consider the quality of the papers included in the review. This might also have biased our results. Finally, since we found scarcity of evidence regarding feedback provided by SPs, no response to interesting issues such as the effect of the level of student experience on SP 
feedback and the impact of training on authenticity of feedback by SPs, could be provided.

In conclusion, the ways in which SPs provide feedback to undergraduate medical students and the ways in which SPs are trained to provide feedback are largely heterogeneous. There appear to be no clear standards for effective training of SPs in providing feedback. Furthermore, the process of feedback provided by SPs and the domain on which SPs give feedback often seem to lack a solid scientific basis. Further research with regard to the most effective ways for SPs to provide feedback and the most effective ways for training SPs in providing feedback is needed.

\section{References}

1. Barrows HS. An overview of the uses of standardized patients for teaching and evaluating clinical skills. Academic Medicine. 1993;68(6):443-451.

2. Wallace P. Coaching standardized patients. For use in assessment of clinical competence. New York: Springer Publishing Company; 2007.

3. Bartholomeus P, Graat JMJM. De rol van de simulatiepatient in het medisch onderwijs herzien: hoe echter, hoe beter [Revision of the role of simulated patients in Maastricht: the closer to real life the better]. In: Houtkoop E, Pols J, Pollemans MC, Scherpbier AJJA, Verwijnen GM, eds. Gezond Onderwijs-3. 's Gravenhage: Haagse Hogeschool; 1994:37-41.

4. Stillman PL, Regan MD, Philbin M, Haley HL. Results of a survey on the use of standardized patients to teach and evaluate clinical skills. Academic Medicine. 1990;65(5):288-292.

5. van de Ridder JM, Stokking KM, McGaghie WC, ten Cate OT. What is feedback in clinical education? Med Educ. Feb 2008;42(2):189-197.

6. Beckmann CR, Sharf BF, Barzansky BM, Spellacy WN. Student response to gynecologic teaching associates. Am J Obstet Gynecol. Aug 1986;155(2):301-306.

7. Kneebone R, Kidd J, Nestel D, Asvall S, Paraskeva P, Darzi A. An innovative model for teaching and learning clinical procedures. Med Educ. Jul 2002;36(7):628-634.

8. Plauche WC, Baugniet-Nebrija W. Students' and physicians' evaluations of gynecologic teaching associate program. J Med Educ. Nov 1985;60(11):870-875.

9. Yudkowsky R, Downing S, Klamen D, Valaski M, Eulenberg B, Popa M. Assessing the headto-toe physical examination skills of medical students. Med Teach. Aug 2004;26(5):415-419.

10. McGraw RC, O'Conner HM. Standardized patients in the early acquisition of clinical skills. Medical Education. 1999;33(8):572-578.

11. McLaughlin K, Gregor L, Jones A, Coderre S. Can standardized patients replace physicians as OSCE examiners? BMC Med Educ. 2006;6:12.

12. Levenkron JC, Greenland P, Bowley N. Using patient instructors to teach behavioral counseling skills. J Med Educ. Aug 1987;62(8):665-672.

13. Anderson KK, Meyer TC. The use of instructor-patients to teach physical examination techniques. J Med Educ. Oct 1978;53(10):831-836. 
14. Holzman GB, Singleton D, Holmes TF, Maatsch JL. Initial pelvic examination instruction: the effectiveness of three contemporary approaches. Am J Obstet Gynecol. Sep 15 1977;129(2):124-129.

15. Livingstone RA, Ostrow DN. Professional patient-instructors in the teaching of the pelvic examination. Am J Obstet Gynecol. Sep 1 1978;132(1):64-67.

16. Vannatta JB, Smith KR, Crandall S, Fischer PC, Williams K. Comparison of standardized patients and faculty in teaching medical interviewing. Academic Medicine. 1996;71(12):13601362.

17. Davidson R, Duerson M, Rathe R, Pauly R, Watson RT. Using standardized patients as teachers: a concurrent controlled trial. Academic Medicine. 2001;76(8):840-843.

18. Levenkron JC, Greenland P, Bowley N. Teaching risk-factor counseling skills: a comparison of two instructional methods. Am J Prev Med. 1990;6(2 Suppl):29-34.19. Hatchett P, Haun C, Goldenhar L. Training standardized patients to give feedback to medical trainees: the state of the art. ASPE project awards University of Cincinnati College of Medicine, Department of Education 2004.

20. Ende J. Feedback in clinical medical education. Jama. Aug 12 1983;250(6):777-781.

21. Holmwood CB. The gentle art of feedback. Aust Fam Physician. Oct 1993;22(10):1811-1813.

22. Brinko KT. The practice of giving feedback to improve teaching. What is effective? J High Educ. 1993;64(5):574-593.

23. Kluger AN, DeNisi A. The effects of feedback interventions on performance: A historical review, a meta-analysis and a preliminary feedback intervention theory. Psychological Bulletin. 1996;119(2):254-284.

24. Hewson MG, Little ML. Giving feedback in medical education: verification of recommended techniques. J Gen Intern Med. Feb 1998;13(2):111-116.

25. Hattie J, Timperley H. The power of feedback. Review of Educational Research. 2007;77(1):81-112.

26. Elnicki DM, Layne RD, Ogden PE, Morris DK. Oral versus written feedback in medical clinic. J Gen Intern Med. Mar 1998;13(3):155-158.

27. Whitehouse C, Morris P, Marks B. The role of actors in teaching communication. Med Educ. Jul 1984;18(4):262-268.

28. Batenburg V, Gerritsma JG. Medical interviewing: initial student problems. Med Educ. Jul 1983;17(4):235-239.

29. Olive KE, Elnicki DM, Kelley MJ. A practical approach to developing cases for standardized patients. Adv Health Sci Educ Theory Pract. 1997;2(1):49-60.

30. Eyler AE, Dicken LL, Fitzgerald JT, Oh MS, Wolf FM, Zweifler AJ. Teaching smokingcessation counseling to medical students using simulated patients. Am J Prev Med. May-Jun 1997;13(3):153-158.

31. Papadakis MA, Croughan-Minihane M, Fromm LJ, Wilkie HA, Ernster VL. A comparison of two methods to teach smoking-cessation techniques to medical students. Acad Med. Aug 1997;72(8):725-727.

32. Kerr MG, Templeton AA, Parboosingh J. Simulated patients as a learning resource in the study of reproductive medicine. Med Educ. Nov 1977;11(6):374-376.

33. Pfeiffer CA, Kosowicz LY, Holmboe E, Wang Y. Face-to-face clinical skills feedback: lessons from the analysis of standardized patient's work. Teach Learn Med. Summer 2005;17(3):254-256.

34. Blake K, Mann KV, Kaufman DM, Kappelman M. Learning adolescent psychosocial interviewing using simulated patients. Acad Med. Oct 2000;75(10 Suppl):S56-58. 
35. Foley KL, George G, Crandall SJ, Walker KH, Marion GS, Spangler JG. Training and evaluating tobacco-specific standardized patient instructors. Fam Med. Jan 2006;38(1):28-37.

36. Helfer RE, Black MA, Helfer ME. Pediatric interviewing skills taught by nonphysicians. Am J Dis Child. Sep 1975;129(9):1053-1057.

37. Williams BC, Hall KE, Supiano MA, Fitzgerald JT, Halter JB. Development of a standardized patient instructor to teach functional assessment and communication skills to medical students and house officers. J Am Geriatr Soc. Sep 2006;54(9):1447-1452.

38. Stillman PL, Ruggill JS, Rutala PJ, Sabers DL. Patient instructors as teachers and evaluators. J Med Educ. Mar 1980;55(3):186-193.

39. Frazer NB, Miller RH. Training practical instructors (programmed patients) to teach basic physical examination. J Med Educ. Feb 1977;52(2):149-151.

40. Bideau M, Guerne PA, Bianchi MP, Huber P. Benefits of a program taking advantage of patient-instructors to teach and assess musculoskeletal skills in medical students. Ann Rheum Dis. Dec 2006;65(12):1626-1630.

41. Rosenbaum ME, Ferguson KJ. Using patient-generated cases to teach students skills in responding to patients' emotions. Med Teach. Mar 2006;28(2):180-182.

42. Makoul G, Altman M. Early assessment of medical students' clinical skills. Acad Med. Nov 2002;77(11):1156.

43. Kleinman DE, Hage ML, Hoole AJ, Kowlowitz V. Pelvic examination instruction and experience: a comparison of laywoman-trained and physician-trained students. Acad Med. Nov 1996;71(11):1239-1243.

44. Billings JA, Stoeckle JD. Pelvic examination instruction and the doctor-patient relationship. $J$ Med Educ. Oct 1977;52(10):834-839.

45. Bryans AM, Southall GA, Valberg LS, Waldron JJ, Valberg B, Kraus AS. A new type of facility in medical education: the Clinical Learning Center. J Med Educ. Mar 1975;50(3):277284.

46. Carroll JG, Monroe J. Teaching medical interviewing: a critique of educational research and practice. J Med Educ. Jun 1979;54(6):498-500.

47. Drouin J, Rivet C. Training medical students to communicate with a linguistic minority group. Acad Med. Jun 2003;78(6):599-604.

48. Gall EP, Meredith KE, Stillman PL, et al. The use of trained patient instructors for teaching and assessing rheumatologic care. Arthritis and Rheumatism. 1984;27(5):557-563.

49. Halbach JL, Sullivan LL. Teaching medical students about medical errors and patient safety: evaluation of a required curriculum. Acad Med. Jun 2005;80(6):600-606.

50. Hale RW, Schiner W. Professional patients: an improved method of teaching breast and pelvic examination. J Reprod Med. Sep 1977;19(3):163-166.

51. Kretzschmar RM. Evolution of the Gynecology Teaching Associate: An education specialist. American Journal of obstetrics and gynecology. 1978;131(4):367-372.

52. Legro RS, Gnatuk CL, Kunselman AR, Cain J. Oocyte donors as gynecologic teaching associates. Obstet Gynecol. Jan 1999;93(1):147-150.

53. Lindsley HB, Welch KE, Bonaminio G. Using patients to teach functional assessment of patients with arthritis. Academic Medicine. 1998;73(5):583.

54. McAvoy BR. Teaching clinical skills to medical students: the use of simulated patients and videotaping in general practice. Med Educ. May 1988;22(3):193-199.

55. McManus IC, Vincent CA, Thom S, Kidd J. Teaching communication skills to clinical students. Bmj. May 15 1993;306(6888):1322-1327. 
56. Nelson LH. Use of professional patients in teaching pelvic examinations. Obstet Gynecol. Nov 1978;52(5):630-633.

57. Perlmutter JF, Friedman EA. Use of a live mannequin for teaching physical diagnosis in gynecology. J Reprod Med. Apr 1974;12(4):163-164.

58. Shain RN, Crouch SH, Weinberg PC. Evaluation of the gynecology teaching associate versus pelvic model approach to teaching pelvic examination. J Med Educ. Aug 1982;57(8):646-648.

59. Simek-Downing L, Quirk ME, Letendre AJ. Simulated versus actual patients in teaching medical interviewing. Fam Med. Nov-Dec 1986;18(6):358-360.

60. Stillman PL, Sabers DL, Redfield DL. The use of paraprofessionals to teach interviewing skills. Pediatrics. May 1976;57(5):769-774.

61. Stillman PL, Sabers DL, Redfield DL. Use of trained mothers to teach interviewing skills to first-year medical students: a follow-up study. Pediatrics. Aug 1977;60(2):165-169.

62. Stillman PL, Burpeau-Di Gregorio MY, Nicholson GI, Sabers DL, Stillman AE. Six years of experience using patient instructors to teach interviewing skills. $J$ Med Educ. Dec 1983;58(12):941-946.

63. Towle A, Hoffman J. An advanced communication skills course for fourth-year, postclerkship students. Acad Med. Nov 2002;77(11):1165-1166.

64. Wagner PJ, Lentz L, Heslop SD. Teaching communication skills: a skills-based approach. Acad Med. Nov 2002;77(11):1164.

65. Wallis LA, Tardiff K, Deane K. Changes in students' attitudes following a pelvic teaching associate program. J Am Med Womens Assoc. Mar-Apr 1984;39(2):46-48.

66. West DA, West MM. Problem-based learning of psychopathology in a traditional curriculum using multiple conceptual models. Med Educ. Mar 1987;21(2):151-156. 


\section{Chapter 3}

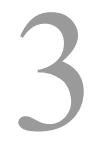

\section{The case of "Miss Jacobs":}

Adolescent simulated patients and the quality of their role playing, feedback and personal impact

L. Bokken, J. van Dalen, JJ. Rethans Submitted 


\begin{abstract}
Objective: Adolescents as standardized patients are relatively new in medical education. Studies have mostly explored the impact of role playing on adolescents trained to perform standardized patient roles. No studies were found with regard to the quality of adolescents' role playing. We evaluated the effects of performing a patient role on adolescents trained as simulated patients (SPs), in contrast to standardized patients, and evaluated the quality of adolescent SPs' role playing and feedback.

Methods: Nine young women, aged 16-18 years, were trained to portray roles of adolescents asking their general practitioner for an oral contraceptive. Three adolescent men were trained to portray roles of some of the girls' boyfriends. Each role was developed in consultation with the individual adolescent and was largely based on reality. Students rated the quality of the adolescent SP's role playing and feedback after each SP encounter on a validated questionnaire (the MaSP). The adolescent SPs and faculty teachers both completed questionnaires on their experiences.

Results: 341 students gave the SPs' general performance a mean mark of 7.5 out of 10 . The faculty teachers were also generally positive about the role playing and feedback. Nevertheless, there were some concerns about the quality of the feedback. Adolescent SPs reported no negative effects due to their performance. Conclusion: Generally, students and teachers were satisfied with the quality of the role playing and feedback provided by the adolescent SPs. The adolescent SPs experienced no negative effects related to their performance, which confirms earlier findings among adolescent standardized patients.
\end{abstract}




\section{Introduction}

Since the introduction of standardized patients by Barrows in $1964,{ }^{1-3}$ this role has mostly been played by adults. Relatively recently, adolescents have made their debut in this role. ${ }^{4,5}$ They have contributed to the training and assessment not only of medical students ${ }^{5,6}$ but also of junior and senior doctors. ${ }^{7,8}$ Adolescents have performed patient roles in front of audiences of 20-30 doctors ${ }^{7}$ or in encounters with individual students, either alone or in the presence of a simulated parent. ${ }^{5,8,9}$ Feedback from adolescent standardized patients has been shown to be very effective in teaching interviewing skills to medical students. ${ }^{6}$

Most research on adolescent standardized patients has focused on the impact of performing a patient role on the adolescent. ${ }^{4,5,10,11}$ None of these studies have reported adverse effects. Possibly, this is attributable to careful selection of adolescent standardized patients. ${ }^{5,10,11}$

In the studies we have referred to so far, the adolescents were trained to play predefined roles based on relatively fixed patient scenarios, with emphasis on standardized and consistent role performance. ${ }^{5,7-9}$ Within the context of this paper, we need to clarify the difference between the role of a standardized patient and that of a simulated patient (Box 1). Because standardized patients are mostly used for assessment it is essential that their performance is uniform and consistent. Simulated patients, however, perform mostly in teaching contexts and provide formative feedback, for which authenticity and credibility of performance are more important. Thus, to enhance authenticity and credibility of performance, roles are created that are close to the personality of the person playing the role. ${ }^{12}$ Since simulated patients are trained to incorporate more of their own personal backgrounds into their roles, the impact of role performance on adolescent simulated patients might differ from that on adolescent standardized patients. Recent studies reported moderate stress symptoms in adults due to performing simulated patient roles $^{13,14}$ but we have found no studies reporting similar effects in adolescents. In one study, adolescents indicated that it took them less time to get into and out of their patient role if the role was close to their own personality. ${ }^{11}$

Because of the scarcity of published literature on the quality of adolescent standardized and simulated patients as well as on the impact of role playing on adolescent simulated patients, we performed a study to evaluate: 1) the quality of role playing and the quality of feedback provided by adolescent simulated patients and 2) the effects of role performance on adolescents trained to perform an individualized simulated patient role. 


\section{Box 1. Definitions of key terms}

Adolescent: A person between the ages 10-19 years (definition by the World Health Organization).

Standardized patient: An individual trained to perform the role of a patient, with emphasis on standardized and consistent role playing. The patient scenarios are standardized and predetermined.

Simulated patient (SP): An individual trained to perform the role of a patient, with emphasis on authentic role playing. The patient scenarios are individualized and largely based on the individual's personal background.

Because simulated patients are the key topic of this study, we will use the abbreviation SP to refer to this role while no abbreviation will be used to refer to standardized patients.

\section{Methods}

\section{Setting}

Every three weeks students in Years 1-3 of the 6-year medical undergraduate curriculum of Maastricht University practice communication and physical examination skills in contacts with SPs. ${ }^{15}$ These contacts consist of simulated consultations involving two students and one SP, with one student playing the role of doctor and the other student observing. Except for the symptoms, SPs play a role that is tailored to their personal characteristics and background. In addition to role-related training, SPs also receive feedback training enabling them to give feedback to the student-doctor at the end of the consultation in accordance with four feedback rules (Box 2). The SP encounters are recorded on DVD and discussed in groups of approximately 10 students and a teacher. All group members have individually watched the recorded encounters, including the feedback given by the SP, before discussing the encounters in a subsequent group meeting. Students watched the recordings of the encounter they were involved in (in the role of doctor of observer) and the recorded encounters of other student-doctors in their group. Teachers watched the recorded encounters of all five student-doctors in their group. The groups meet throughout the year with the same teacher. This SP program is developed and organized by the Skillslab and is fully integrated with the Maastricht undergraduate medical curriculum. $^{15}$ 


\section{Box 2. Feedback rules for SPs}

- Priority rule - SPs should start their feedback by answering the student's questions about the achievement of his or her individual learning goals. After this, the SP can give feedback on matters that stuck to the SPs memory and other matters.

- Domain rule - The SP is only allowed to give feedback with regard to his or her own experiences during the encounter with the student.

- "I statements" rule - SPs should give feedback from their own point of view, using "I statements", for example, "I didn't feel comfortable during the conversation since I didn't understand your questions" instead of "You should be more clear because people don't understand your questions and then feel uncomfortable".

- Neutrality rule - SP should not give judgments about the student's performance, positive nor negative. Furthermore, SPs should tune their feedback to the individual student and refrain from comparing with fellow students, for example "You listened to me very well" instead of "You listened better than the other student I have spoken with".

In Year 2, students are offered a 6-week "Puberty and Adolescence" module. An important objective of this module is learning to communicate with adolescents about contraception and sexuality. In 2002, adolescent SP encounters were introduced to support students' learning about this topic. Student-SP encounters last 30 minutes at most and are scheduled on 3 consecutive days between 4 and 8.30 p.m. to be outside of school hours. The study reported in this paper was conducted in the academic year 2006-2007.

\section{Recruitment and selection of adolescent SPS}

The first adolescent SPs to be recruited were all daughters of Skillslab staff members. The SPs were encouraged to bring along their girlfriends as well. In the year of the study, the group of adolescent SPs recruited for the program consisted partly of adolescent SPs who had participated in 2005-2006 (N=5) and partly of new SPs recruited by word-of-mouth. Some of the SPs' boyfriends came along and asked if they could participate too. We agreed, since we thought having real couples as SP couples would enhance authenticity. A total of 12 adolescents, 9 female and 3 male (6 individual female roles and 3 couples), were selected. Although young couples seeing their general practitioner (GP) for matters related to sexuality may seem somewhat unusual to many, this is not an uncommon occurrence in the Netherlands.

The objectives of the SP consultations and the feedback were explained to the SPs in a 90 minute meeting with one of the researchers. The scenarios of the SP roles were introduced as well. We told the SPs that we would greatly appreciate 
it if they informed their parents of their participation in our program and also of the content of their roles. In order to promote this, we gave them a letter addressed to their parents explaining the program and what it entailed. However, we also told the SPs that it was their personal choice whether they gave the letter to their parents or not. The SPs were paid 9 Euro per hour for participation. We planned a maximum of 8 consultations per day for 1 SP.

\section{Role content}

The content of the role was aligned with the content of the "Puberty and Adolescence" module. All the girls played the role of "Miss Jacobs", coming to see her GP to ask about oral contraception. However, the reasons for seeing her GP differed for each SP and the student-doctor could only discover this by careful history taking and after establishing a good rapport with the patient and gaining her trust. The individual roles were created together with the SPs and were largely based on reality. Because these consultations were demanding in terms of the required quality of communication skills, physical examination was not included in the consultation. To illustrate the SP role we will describe 2 individualized scenarios.

1. The past two years Miss Jacobs (aged 17 years) has had severe abdominal pains, back pain and headaches during her periods. It started about a year after her menarche. She has been taking ibuprofen for 3 months but this has not helped at all. She has heard from a friend and also at school in biology class that taking an oral contraceptive might help. At the same time she has a lot of questions about "the pill", such as: "What are the side effects? What if I forget to take one? What about sexually transmitted diseases?"

2. Miss Jacobs (aged 16 years) says she comes to see her general practitioner because she wants to start taking "the pill", but she is not quite sure of this. Her boyfriend (aged 17 years, who accompanies her) is putting pressure on her and has even threatened to end the relationship if she refuses to use an oral contraceptive. When she told him she was going to see her GP, he wanted to come with her. The doctor's positive remarks, for example "there are not many side effects", are welcomed by the boyfriend with: "I told you so!!". However, Miss Jacobs is not quite ready to make an immediate decision whether she wants to start using an oral contraceptive. She just wants some information to help her think things over. To her boyfriend it is simple: "just take it". When the doctor shows that $\mathrm{s} / \mathrm{he}$ is under the impression that this may not be what Miss Jacobs 
really wants for herself, Miss Jacobs is clearly relieved. Subconsciously, she is seeking support from her doctor.

\section{Students}

As with all regular SP sessions, all second-year students $(\mathrm{N}=363)$ can enroll voluntarily for a session in pairs, with one student as a doctor and the other as an observer. Students are unaware of the exact content and purpose of the adolescent SP encounters. All SP consultations are held in special SP consultation rooms in the Skillslab, equipped with recording equipment. For each planned consultation a spare SP or SP couple is available.

\section{Instruments}

We used the Maastricht Assessment of Simulated Patients (MaSP) questionnaire to evaluate the quality of SP performance and feedback as perceived by the students. ${ }^{12}$ The MaSP contains 10 items about the authenticity of SP role performance and 10 items about feedback provided by SPs, all to be rated on a 4-point Likert scale ( $1=$ totally disagree, $4=$ totally agree). Students are also asked to rate, on a 10-point scale ( $1=$ very poor; $10=$ excellent), how they valued the overall quality of SP performance including feedback. In addition, students are invited to give additional comments. The MaSP has been proven to be valid, reliable and feasible for assessing SP performance in an educational setting. ${ }^{12}$ In our study, the students were asked to complete the MaSP immediately after their consultation with an adolescent SP.

After their last student-SP encounter, the SPs were asked to complete a 17-item questionnaire about their experiences and to give comments. The questionnaire evaluated how performing as an SP had affected the adolescents.

The teachers who discussed the SP encounters with the students were also asked to fill out a questionnaire containing open-ended questions about the adolescent SP consultations. For example, questions concerning the reactions of the students in the group and the teacher's opinion on the quality of the adolescent SPs' performance and feedback. 


\section{Analysis}

We analyzed the data using SPSS (13.0) for Windows. Frequencies were calculated for all items. Since the distribution was not normal, Mann-Whitney Tests were used to analyze differences between the MaSP scores of the studentdoctors and observers.

\section{Results}

The adolescents were aged between 16-18 years (mean age 17.1 years). All were in secondary school. Of the 363 students eligible to participate in the SP encounters, 341 (94\%) participated. This is comparable to participation rates for other SP encounters. Of the 341 participating students, 138 acted as "doctors", 137 observed and 66 failed to state their role in the questionnaire.

Table 1 shows students' evaluations of SP performance as measured by the MaSP. The general performance rating was 7.5 (on a 10-point scale). There were significant differences between some of the scores of the student-doctors and those of observers. Compared to the observers, student-doctors could better judge from the reactions of the SP whether or not he/she was listening (item 13) and whether the SPs spoke about his or her role in the first person (item 17). Additionally, the student-doctors gave higher ratings compared to the observers when asked whether they thought the SP acted in a friendly manner (item 20). There were no significant differences between the general performance ratings from student-doctors and observers.

The teachers were positive about the quality of SP role performance and feedback. For example: "Authentic", "good roles and good feedback" and "more straightforward feedback (compared to that of other, adult, SPS)". The teachers commented that the adolescent SP encounters addressed interesting aspects of communication, such as "learning to deal with 2 people in a consultation (dividing attention)", "dealing with peers professionally (less formally, yet remaining serious)", "setting personal boundaries in a consultation (with a quarrelling couple)" and "asking questions/talking about sexuality". Additionally, teachers reported that in some groups students had admitted to feeling attracted to the "patient" during the consultation, a feeling they found difficult to deal with. This led to a discussion about professionalism in the group.

Table 2 shows the SPs' evaluations of the encounters. All of them had informed their parents of their participation in the program (item 7). The adolescents 
experienced nothing that made them regret the experience (item 10) and indicated that they would be willing to act as an SP again (item 8). The evaluation showed no differences between male and female SPs.

\section{Table 1. The MaSP 2006-2007}

(4-point Likert scale; $1=$ complete disagreement, $4=$ complete agreement)

Authenticity during the consultation
1. SP appears authentic.
2. SP could be a real patient.
3. SP is clearly role playing.
4. SP appears to withhold information unnecessarily.
5. SP stays in his/her role all the time.
6. SP is testing the student.
7. SP simulates physical complaints unrealistically.
8. SP's appearance fits the role.
9. SP answers questions in a natural manner.
10. Number of times the SP starts a conversation with
the student(s) during time-out.
Feedback after the consultation
11. Number of times the SP leaves the room between
the consultation and feedback.
12. SP stimulates student to ask questions.
13. I can judge from the reactions of the SP whether or
14. SP communicates how (s)he felt during the
consultation.

\begin{tabular}{c|c}
$\begin{array}{c}\text { All students } \\
\mathbf{N}=\mathbf{3 4 1}\end{array}$ & $\begin{array}{c}\text { Student- } \\
\text { Doctors } \\
\mathbf{N}=\mathbf{1 3 8}\end{array}$ \\
\end{tabular}
Observers
$\mathbf{N}=\mathbf{1 3 7}$

\begin{tabular}{l|l|l|l|l|l|}
\hline Mean & SD & Mean & SD & Mean & SD
\end{tabular}

\begin{tabular}{|l|l|l|l|l|l|}
\hline 3.5 & .6 & 3.5 & .6 & 3.4 & .6 \\
\hline 3.6 & .5 & 3.6 & .5 & 3.6 & .5 \\
\hline 1.6 & .7 & 1.6 & .8 & 1.6 & .7 \\
\hline 1.5 & .7 & 1.5 & .8 & 1.4 & .6 \\
\hline 3.4 & .7 & 3.5 & .7 & 3.4 & .7 \\
\hline
\end{tabular}

\begin{tabular}{|l|l|l|l|l|l|}
\hline 3.4 & .7 & 3.5 & .7 & 3.4 & .7 \\
\hline 1.5 & .7 & 1.5 & .7 & 1.5 & .7 \\
\hline \multicolumn{2}{|r|}{ n.a } & \multicolumn{2}{|c|}{ n.a } & \multicolumn{2}{|c|}{ n.a } \\
\hline 3.8 & .5 & 3.7 & .5 & 3.8 & .4 \\
\hline 3.5 & .6 & 3.6 & .6 & 3.5 & .7 \\
\hline
\end{tabular}

15. SP gives feedback about medical issues.

16. SP gives examples from the consultation.

17. SP speaks about his/her role in the first person ("I")

\begin{tabular}{|c|c|c|c|c|c|}
\hline \multicolumn{2}{|c|}{$3.7 \%$} & \multicolumn{2}{|c|}{$2.4 \%$} & \multicolumn{2}{|c|}{$3.3 \%$} \\
\hline \multicolumn{2}{|c|}{$100 \%$} & \multicolumn{2}{|c|}{$100 \%$} & \multicolumn{2}{|c|}{$100 \%$} \\
\hline 2.4 & .9 & 2.4 & .9 & 2.4 & .8 \\
\hline 3.4 & .6 & $3.5^{*}$ & .6 & $3.3 *$ & .6 \\
\hline 3.3 & .8 & 3.3 & 8 & 3.2 & .8 \\
\hline 1.5 & .8 & 1.5 & .8 & 1.5 & .8 \\
\hline 2.7 & 1.0 & 2.8 & 1.1 & 2.7 & 1.0 \\
\hline 3.5 & .7 & $3.6^{*}$ & .7 & $3.5^{*}$ & .7 \\
\hline 2.9 & .8 & 3.0 & .9 & 2.8 & .9 \\
\hline 1.3 & .7 & 1.4 & .8 & 1.3 & .6 \\
\hline 3.7 & .5 & $3.8^{*}$ & .4 & $3.7 *$ & .5 \\
\hline 7.5 & .9 & 7.5 & .9 & 7.3 & .9 \\
\hline
\end{tabular}

18. SP gives constructive criticism.

19. SP compares student to other students.

20. SP acts in a friendly manner.

Overall rating of the SP encounter on a 10-point scale.

n.a. $=$ not applicable

$*$ = Significant difference between student-doctors and observers 
Table 2. Evaluation of adolescent SP encounter by adolescent SPs ( $=12)$

(4-point Likert scale; 1=complete disagreement, 4=complete agreement)

\begin{tabular}{|c|c|c|}
\hline & Median & $25-75 \%$ \\
\hline 1. I felt like a real patient. & 3 & $3-3$ \\
\hline $\begin{array}{l}\text { 2. The content of the role was explained to me with sufficient clarity } \\
\text { during the group session. }\end{array}$ & 4 & $4-4$ \\
\hline $\begin{array}{l}\text { 3. The content of the role was explained to me too briefly during the } \\
\text { group session. }\end{array}$ & 1 & $1-1$ \\
\hline 4. I found this role difficult to play. & 2 & $1-2$ \\
\hline 5. The number of consecutive performances on 1 day was no problem. & 4 & $3.25-4$ \\
\hline 6. My parents know of my participation in this project. & \multicolumn{2}{|c|}{ 100\%: Yes } \\
\hline $\begin{array}{l}\text { 7. It was difficult to persuade my parents to allow me to participate in } \\
\text { this project. }\end{array}$ & 1 & $1-1$ \\
\hline 8. I would very much like to participate again next year. & 4 & $4-4$ \\
\hline $\begin{array}{l}\text { 9. Playing this role has made me aware of personal issues I had not } \\
\text { noticed before. }\end{array}$ & 1 & $1-1$ \\
\hline $\begin{array}{l}\text { 10. If I had known in advance what participation would entail, I would not } \\
\text { have participated. }\end{array}$ & 1 & $1-1$ \\
\hline $\begin{array}{l}\text { 11. I had no problem with the presence of other SPs when the personalized } \\
\text { role was created during training. }\end{array}$ & 3 & $3-4$ \\
\hline 12. At the end of a 1-day session I did not feel well. & 1 & $1-1.75$ \\
\hline 13. It was difficult for me to give feedback. & 3 & $2-3$ \\
\hline $\begin{array}{l}\text { 14. I was given sufficient personal attention before, during and after role } \\
\text { playing. }\end{array}$ & 4 & $3.25-4$ \\
\hline 15. If I had not been paid I would not have acted as a simulated patient. & 1.5 & $1-3$ \\
\hline 16. I would have preferred a personal debriefing at the end of the sessions. & 1 & $1-1.75$ \\
\hline $\begin{array}{l}\text { 17. This question is to be answered by the boys only }(\mathrm{N}=3) \text { : I felt I could } \\
\text { participate fully. }\end{array}$ & 3 & $3-4$ \\
\hline
\end{tabular}

\section{Discussion}

Judgments of students and teachers about the quality of role performance and feedback by adolescent SPs are positive, with high ratings from students for overall quality of role performance and feedback. Nevertheless, the results show that improvements are needed on some points. When giving feedback, the SPs could give more encouragement to students to ask questions and more examples from the encounter to illustrate their feedback. Adolescent SPs indicated that 
giving feedback was quite difficult. These findings suggest feedback should be addressed more extensively during training of adolescent SPs.

There are some significant differences between the evaluations of studentdoctors and those of observers. We think this may be due to the inherently different perspectives of these student roles, with student-doctors being more focused on the patient than observers.

A reassuring finding is that the adolescent SPs reported no negative effects due to their performance in an individualized role, unlike the moderate stress reported by some adult SPs whose training involved identification with the patient they portrayed. ${ }^{13,14}$ In fact, the adolescents said they would like to continue their SP work. The impact on adolescents of performing as a simulated patient appeared not to be different from the impact of performing as a standardized patient. ${ }^{4,5,10,11}$ Role playing even appears to be easier if the role is close to the adolescent's personality. ${ }^{11}$ This is encouraging because we believe that, for teaching purposes, authenticity of SP roles is more important than uniformity.

There are some limitations to this study. First of all, we might have obtained more robust data with the questionnaire we have used in a previous study to assess the impact on adult of portraying simulated roles. ${ }^{13}$ It is possible that the questionnaire we used in this study has missed some subtle negative effects of role performance. This is an important area for future research. Another limitation is that the study was performed in the setting of one particular undergraduate curriculum. Although we believe that most of the results are transferable to other educational settings using simulated patients, some might not be. Other limitations are the small number of SPs and the risk of bias due to the fee they were paid. So, although the results are encouraging and suggest that adolescent SPs have a valuable role to play in undergraduate medical education, they will need backing up by studies among more SPs and in different settings.

\section{Conclusion}

The results appear to support our view that, provided more attention is given to feedback, encounters with adolescent SPs offer authentic and high-quality learning experiences for undergraduate medical students. Playing an authentic SP role, based on their own personal characteristics and experiences, does not appear to have a negative impact on adolescents, a finding that is supported by similar findings about standardized patient roles. We think that for teaching 
situations the absence of negative effects combined with greater authenticity and easier role playing makes the use of adolescent simulated patients preferable to adolescent standardized patients.

\section{References}

1. Barrows HS. An overview of the uses of standardized patients for teaching and evaluating clinical skills. AAMC. Academic Medicine. Jun 1993;68(6):443-451; discussion 451-443.

2. Barrows HS, Abrahamson S. The programmed patients: a technique for appraising student performance in clinical neurology. Journal of Medical Education. 1964;39:802-805.

3. Stillman PL, Regan MD, Philbin M, Haley HL. Results of a survey on the use of standardized patients to teach and evaluate clinical skills. Academic Medicine. 1990;65(5):288-292.

4. Blake K, Greaven S. Adolescent girls as simulators of medical illness. Medical Education. Sep 1999;33(9):702-703.

5. Blake K, Gusella J, Greaven S, Wakefield S. The risks and benefits of being a young female adolescent standardized patient. Medical Education. Jan 2006;40(1):26-35.

6. Blake K, Mann KV, Kaufman DM, Kappelman M. Learning adolescent psychosocial interviewing using simulated patients. Academic Medicine. Oct 2000;75(10 Suppl):S56-58.

7. Hardoff D, Schonmann S. Training physicians in communication skills with adolescents using teenage actors as simulated patients. Medical Education. Mar 2001;35(3):206-210.

8. Lane JL, Ziv A, Boulet JR. A pediatric clinical skills assessment using children as standardized patients. Archives of Pediatrics \& Adolescent Medicine. Jun 1999;153(6):637-644.

9. Brown R, Doonan S, Shellenberger S. Using children as simulated patients in communication training for residents and medical students: a pilot program. Academic Medicine. Dec 2005;80(12):1114-1120.

10. Hanson M, Tiberius R, Hodges B, et al. Adolescent standardized patients: method of selection and assessment of benefits and risks. Teaching and Learning in Medicine. Spring 2002;14(2):104-113.

11. Woodward CA, Gliva-McConvey G. Children as standardized patients: initial assessment of effects. Teaching and Learning in Medicine. 1995;7(3):188-191.

12. Wind LA, Van Dalen J, Muijtjens AM, Rethans JJ. Assessing simulated patients in an educational setting: the MaSP (Maastricht Assessment of Simulated Patients). Medical Education. Jan 2004;38(1):39-44.

13. Bokken L, van Dalen J, Rethans JJ. Performance-related stress symptoms in simulated patients. Medical Education. Oct 2004;38(10):1089-1094.

14. Bokken L, van Dalen J, Rethans JJ. The impact of simulation on people who act as simulated patients: a focus group study. Medical Education. Aug 2006;40(8):781-786.

15. Van Dalen J, Bartholomeus P, Kerkhofs E, et al. Teaching and assessing communication skills in Maastricht: the first twenty years. Medical Teacher. May 2001;23(3):245-251. 


\section{Chapter 4}

\section{Lessons learned from an adolescent simulated patient educational program: Five years of experience}

L. Bokken, J. van Dalen, A. Scherpbier, C. van der Vleuten, JJ. Rethans Medical Teacher 2008 October 20:1-8 (Epub ahead of print) 


\begin{abstract}
Objective: Adolescents as standardized patients (SPs) are relatively new in medical education. We evaluated the views of teachers, students and adolescent SPs with regard to the adolescent SP program in our undergraduate curriculum and the changes that were made to the program in the past five years (from 2002-2003 until 2006-2007).

Method: Adolescent girls were recruited to portray roles of adolescents asking their general practitioner for an oral contraceptive. Students rated the quality of the adolescent SPs' role performance and feedback on a validated questionnaire (the MaSP). Both adolescent SPs and faculty teachers completed questionnaires on their experiences.

Results: Over the past five years, 201 to 341 students gave the adolescent SPs' general performance a mean mark that varied from 7.5 to 8 out of 10 . Generally, evaluations by teachers and adolescent SPs about the adolescent SP program were also very positive. The quality of the feedback by adolescent SPs has shown improvement over the past five years, although adolescents find it quite difficult to give feedback.

Conclusion: Teachers, students and adolescent SPs have highly valued the adolescent SP program over the past five years. The program has been changed on the basis of the lessons learned and has become mature.
\end{abstract}




\section{Introduction}

Since the introduction of standardized patients (SPs) by Barrows in 1964, adults have extensively been used as SPs in medical education. ${ }^{1-3}$ However, the use of adolescent SPs in the teaching and evaluation of skills in undergraduate medical students ${ }^{4-6}$ as well as in residents and professionals ${ }^{7,8}$ has scarcely been reported. In the research on the use of adolescent SPs two major themes can be identified. The first focuses on the effects of role playing on the adolescent. Most studies found no negative effects of role playing on adolescent SPs. ${ }^{4,6,9,10}$ However, in a recent study adolescent SPs performing a suicidality role showed behavioral effects suggesting a transient depressive reaction. ${ }^{11}$ Careful selection of adolescent SPs may limit some possible adverse effects. ${ }^{6,9,10}$ The second research theme focuses on structured feedback provided to students by adolescent SPs. Adolescent SPs can effectively teach interviewing skills to medical students by giving structured feedback. ${ }^{5,12}$ Instruments such as the structured communication adolescent guide (SCAG) developed by Blake and colleagues can be helpful for adolescent SPs in providing feedback. ${ }^{12}$ When giving feedback, adolescents performing a risk-taking role preferred coming out of role since they did not want to be seen as risk-takers. ${ }^{13}$

Communication skills required for consultation with adolescents differ from those required for adults. ${ }^{5,14}$ For example, obtaining history for risk-taking behavior (smoking, drinking, drug abuse and sexual risk-taking) is important in adolescents. ${ }^{14}$ Furthermore, in communicating with adolescents on sexual issues doctors should pay more explicit attention to sexuality and confidentiality. ${ }^{15}$ Because of these specific challenges, learning how to communicate with adolescents should be an important part of the communication skills training in the medical curriculum. ${ }^{5,6,16}$

At the medical school of the University of Maastricht the second year of the undergraduate curriculum contains a six-week module entitled "Puberty and Adolescence". Here, an important objective is to communicate about contraceptives and sexuality in consultations with adolescents. An adolescent SP program, integrated in the regular SP program, was first introduced in the year 2002-2003 and has since been operational.

Studies have reported on single experiments with adolescent $\mathrm{SPs}^{7,8,10,16}$ or on short term follow-up of adolescent SPs. ${ }^{4,6,13}$ However, we have found no studies in which an adolescent SP program was evaluated over multiple years. The aims of this study were to evaluate: 1) the views of teachers, students and adolescent SPs, with regard to the adolescent SP program 2) the extent to which 
the views of teachers, students and adolescent SPs have changed over the past five years and 3 ) the lessons that were learned from our five year experience.

\section{Methods}

\section{Setting}

Once every three weeks undergraduate students (Year 1-3) of the medical school of the University of Maastricht have the opportunity to practice communication and physical examination skills in encounters with simulated patients (SPs) at the Skillslab. ${ }^{17}$ These encounters, involving one SP and two students, are simulated doctor-patient encounters with one student-"doctor" and a second student observing. The encounters take place in the regular SP offices at the Skillslab. After an encounter, the SP gives feedback to the student-"doctor". Before giving feedback to the student, the SP leaves the room to have a moment to reflect on the encounter and formulate the feedback. The SPs are trained to give feedback on the basis of four feedback rules. These rules are summarized in Box 1. The SP encounters are recorded on DVD and discussed one week later in a group of ten students and a teacher. All group members individually watch the recorded encounters, including the feedback given by the SP, before discussing the encounters in the following group meeting. This simulated program at the Skillslab is fully integrated with the undergraduate curriculum of the medical school of the University of Maastricht. ${ }^{17}$

In the year 2002-2003 adolescent SP encounters were introduced during the regular planned SP sessions of the module "Puberty and Adolescence". The encounters, 30 minutes maximum duration, were scheduled on three consecutive days from 4 to $8.30 \mathrm{pm}$, in order to avoid the participating adolescents missing school. Since we did not know the maximum number of consultations the adolescents could cope with, we initially planned a maximum of four consecutive consultations per day. 


\section{Box 1. Feedback rules for SPs}

- Priority rule - SPs should start their feedback by answering the student's questions about the achievement of his or her individual learning goals. After this, the SP can give feedback on matters that stuck to the SPs memory and other matters.

- Domain rule -The SP is only allowed to give feedback with regard to his or her own experiences (as a patient) during the encounter with the student. Comments on the professional medical content are not allowed.

- "I statements" rule - SPs should give feedback from their own point of view, using "I statements", for example, "I didn't feel comfortable during the conversation since I didn't understand your questions" instead of "You should be more clear because people don't understand your questions and then feel uncomfortable".

- Neutrality rule - SP should not give judgments about the student's performance, positive nor negative. Furthermore, SPs should tune their feedback to the individual student and refrain from comparing with fellow students, for example "You listened to me very well" instead of "You listened better than the other student I have spoken with".

\section{Recruitment and selection of adolescents}

All SPs were initially recruited among the adolescent children (girls) of Skillslab staff members $(\mathrm{N}=30)$. We also encouraged the staff to ask their children to invite girlfriends. On the basis of four consecutive consultations per session per day, sixteen adolescent SPs would be sufficient. These were recruited for the role, with an age range between 13 and 19 years.

In a 90-minute meeting with all 16 girls we explained the objectives of the simulated sessions and introduced the simulated role scenario. Two girls had brought their boyfriends to the meeting asking if they could participate as well. Since we wanted the roles to be as authentic as possible, we agreed to their participation, forming a couple with the girls. At the start of the program, the adolescents were invited to provide the students with feedback on the encounter but only if they felt comfortable doing so. We emphasized that we would appreciate it if the adolescent SPs would inform their parents about their participation in the program and the content of the role. Therefore, we gave each SP a letter signed by the SP coordinator and addressed to their parents, explaining the set-up. However, we emphasized that it was the adolescents' own choice whether they handed over the letter to their parents or not. The adolescents were paid $€ 9$ per hour for their participation, including training. 


\section{Content of role}

The content of the role was based on the curricular module the students followed at the time of the SP sessions. All girls played that they visited their general practitioner, expressing their wish to get an oral contraceptive. All girls would start the consultation with "I would like to get the pill". However, behind this first question there were four different reasons for the encounter. The student-doctors would only discover the reason after careful exploration of this seemingly obvious question and after winning the patient's trust. The reasons were: 1) " . . . since I have a boyfriend and I don't want to get pregnant"; 2) " . . . since I suffer so much from abdominal pain during my menstruation"; 3) " . . . since I suffer so much from abdominal pain during my menstruation" but actually this was not true, she wanted the pill for not getting pregnant and did not dare to ask for it; 4) ". . . since my boyfriend wants me to take the pill". The sixteen girls were asked to choose the role that came closest to what they would do in reality, but we wanted four girls for each variant. For the remainder of the role the girls were asked to play as if this was real (own age, life style, smoking and drinking habits, etc). To prevent the case to be too diagnostically complex for second year students, we only told the girls that if they already had had their menarche, they should act that their menstruations were regular and without vaginal discharge.

\section{Students}

As usual with all other regular three-week simulations session all second-year medical students, ranging from 228 students in the year 2002-2003 to 363 students in 2006-2007, were offered to register for this session in pairs, consisting of a "doctor" and an observer.

\section{Instruments}

To assess how the students evaluated the adolescent SPs, the Maastricht Assessment of Simulated Patients (MaSP) was used. ${ }^{18}$ This questionnaire consists of ten items focusing on authenticity of SP role playing and ten on the quality of feedback. Answers can be given on a 4 point Likert scale ( $1=$ complete disagreement, $4=$ complete agreement). In addition, respondents can assign a 
general mark (on a 10 point scale) for SP performance and can make free comments. The MaSP has proven to be valid, reliable and feasible to assess the performance of (adult) SPs in an educational setting. ${ }^{18}$ During the first year of the adolescent SP program, the adolescent SPs did not have to give feedback to the students, only if they felt comfortable doing so. At that time a reduced version of the MaSP was used, without the ten items on giving feedback. Later, when the giving of feedback by adolescent SP was integrated in the consultation (see "changes in the adolescent SP program" below), the entire MaSP was used. All students were asked to complete the MaSP immediately after the consultation.

After their final encounter all adolescent SPs were asked to complete a 17-item questionnaire about their experiences on a 4 point Likert scale $(1=$ complete disagreement, $4=$ complete agreement). In addition they could make spontaneous comments. During the past five years some items of the questionnaire have been revised on the basis of the changes in the adolescent SP program.

Teachers of the student groups in which the recorded encounters are discussed, were asked to fill out a written questionnaire containing open-ended questions on the adolescent SP consultation, for example about the quality of the role playing and feedback of the adolescent SPs and the reactions of the students in their group.

\section{Analysis}

We analyzed the data with SPSS (13.0) for Windows, calculating frequencies for all items. Differences between MaSP scores of the years 2002-2003 or 20032004 and 2006-2007 were calculated using the T-test for two independent samples. The T-test was used because the MaSP scores were normally distributed by approximation because of the large numbers of students. Since scores on the items 10 and 11 of the MaSP were nominal (Yes or No), differences between the years 2002-2003 or 2003-2004 and 2006-2007 with regard to these items were calculated using the Chi-Square test. Effect sizes were calculated following the guidelines described by Hojat and $\mathrm{Xu} .{ }^{19}$ Differences between the evaluations of adolescent SPs of the years 2002-2003 and 2006-2007 were calculated with the Mann-Whitney test, because the evaluations were not normally distributed. A p-value smaller than 0.05 was considered to be statistically significant. 


\section{Results}

Over the past five years, 201 to 341 students have evaluated the adolescent SPs' performance on the MaSP. Table 1 shows the evaluations on the short version of the MaSP in the first year of the program and on the entire MaSP in the four following years. Marks for the overall performance of the adolescent SPs were high, varying from 7.5 to 8.0 on a 10 point scale. Many students commented on the authenticity of the encounter, for example: "I could see she was very nervous, but I would expect that from a young girl visiting her doctor" or "Only after the consultation I found out that this was a role and not a real wish of the girl".

Table 2a shows the MaSP scores on authenticity of the role playing and marks for the general performance of the adolescent SP of the first year of the program (2002-2003) and those of the latest year (2006-2007). There are several significant differences between the MaSP scores. For example, in the first year of the program, students felt the adolescent SPs to be more authentic (item 1) and more like a real patient (item 2) compared to the students of the year 20062007. However, effect sizes of most differences were small, indicating a small difference of negligible practical importance. ${ }^{19}$ Exception is the effect size for the mark of the general performance of the adolescent SP which was 0.80 . This indicates that the decrease in the overall mark from 8.0 to 7.5 represents a considerable reduction in the general evaluation of these SP encounters.

Table $2 b$ shows the MaSP scores on feedback of the first year in which the complete MaSP, including the items on feedback, was used (2003-2004) and of those three years later (2006-2007). There are several significant differences between these scores. Again, the effect sizes of most differences were small, except for effect size on the item "SP compares student with other students" which was 0.54 , indicating a medium difference of moderate practical importance.

Reactions of the teachers about the quality of the role playing and the feedback throughout the years were also positive, for example: "very good roles and very authentic role playing", "very natural and spontaneous feedback" and "more straightforward feedback (compared to other SP contacts)". The teachers remarked that the adolescent SP encounters addressed interesting aspects of communication, for example: "dealing with peers professionally (less formally, yet remaining serious)", "learning to deal with two people in a consultation (dividing attention), "defining personal barriers in a consultation (with a quarrelling couple)" and "asking questions about/discussing sexuality". 
Table 1. Student evaluations regarding the adolescent SP program: MaSP scores 2002-2007 (4 point Likert scale; $1=$ complete disagreement, $4=$ complete agreement)

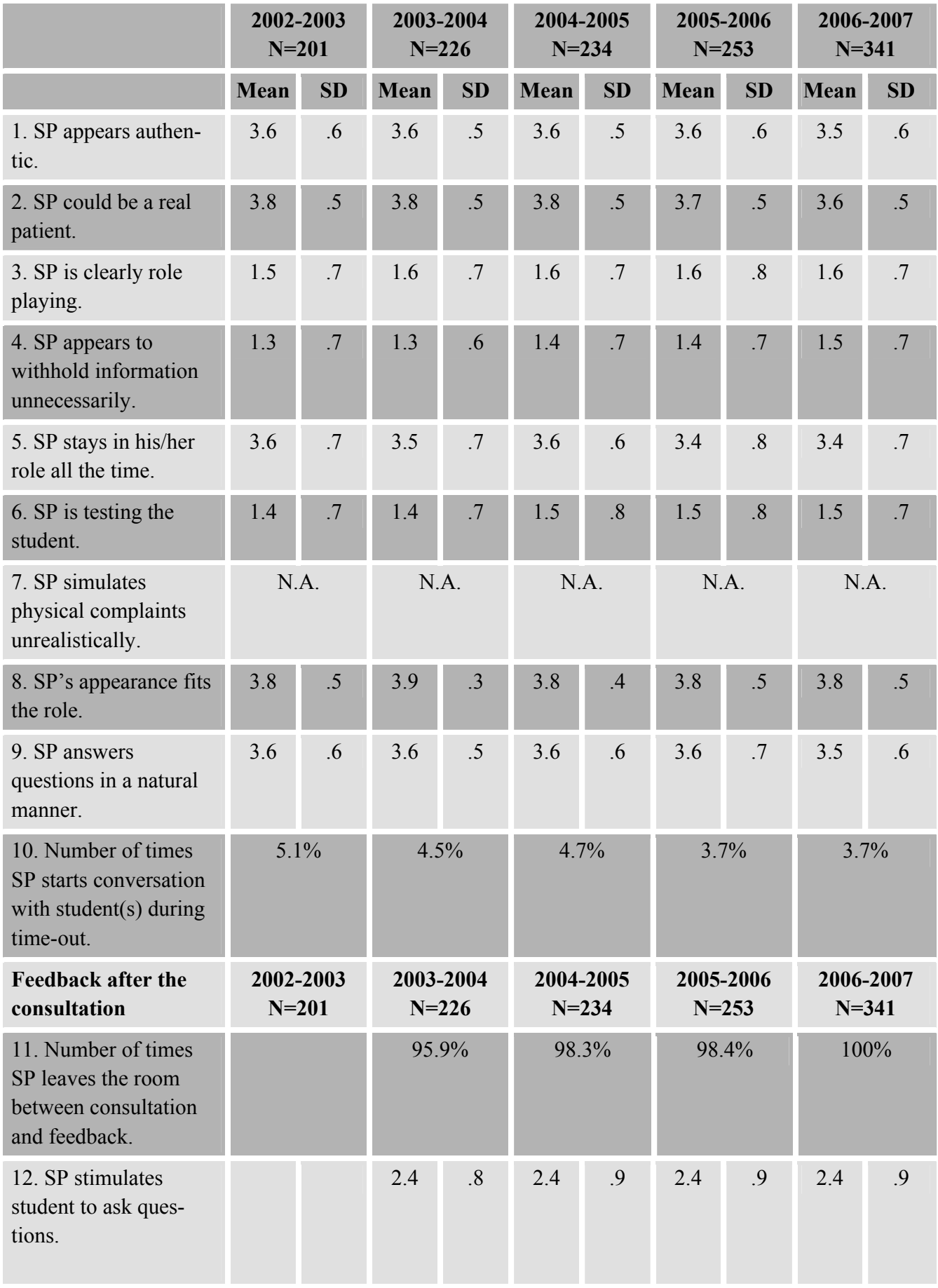




\begin{tabular}{|c|c|c|c|c|c|c|c|c|c|c|}
\hline & \multicolumn{2}{|c|}{$\begin{array}{c}2002-2003 \\
N=201\end{array}$} & \multicolumn{2}{|c|}{$\begin{array}{c}\text { 2003-2004 } \\
\mathrm{N}=\mathbf{2 2 6}\end{array}$} & \multicolumn{2}{|c|}{$\begin{array}{c}2004-2005 \\
N=234\end{array}$} & \multicolumn{2}{|c|}{$\begin{array}{c}2005-2006 \\
N=253\end{array}$} & \multicolumn{2}{|c|}{$\begin{array}{c}2006-2007 \\
N=341\end{array}$} \\
\hline & Mean & SD & Mean & SD & Mean & SD & Mean & SD & Mean & SD \\
\hline $\begin{array}{l}\text { 13. I can judge from } \\
\text { the reactions of the SP } \\
\text { whether or not (s)he is } \\
\text { listening to the student. }\end{array}$ & & & 3.4 & .6 & 3.4 & .6 & 3.4 & .6 & 3.4 & .6 \\
\hline $\begin{array}{l}\text { 14. SP communicates } \\
\text { how ( } s \text { )he felt during } \\
\text { the consultation. }\end{array}$ & & & 3.2 & 8 & 3.3 & .8 & 3.2 & .7 & 3.3 & .8 \\
\hline $\begin{array}{l}\text { 15. SP gives feedback } \\
\text { about medical issues. }\end{array}$ & & & 1.8 & .9 & 1.5 & .8 & 1.5 & .8 & 1.5 & .8 \\
\hline $\begin{array}{l}\text { 16. SP gives examples } \\
\text { from the consultation. }\end{array}$ & & & 2.6 & 1.0 & 2.7 & 1.1 & 2.7 & 1.0 & 2.7 & 1.0 \\
\hline $\begin{array}{l}\text { 17. SP speaks about } \\
\text { his/her role in the first } \\
\text { person ("I"). }\end{array}$ & & & 3.3 & .8 & 3.5 & .7 & 3.5 & .6 & 3.5 & .7 \\
\hline $\begin{array}{l}\text { 18. SP gives construc- } \\
\text { tive criticism. }\end{array}$ & & & 2.9 & .8 & 2.9 & .9 & 3.0 & .8 & 2.9 & .8 \\
\hline $\begin{array}{l}\text { 19. SP compares } \\
\text { student to other } \\
\text { students. }\end{array}$ & & & 1.9 & 1.1 & 1.5 & .9 & 1.6 & 1.0 & 1.3 & .7 \\
\hline $\begin{array}{l}\text { 20. SP acts in a friendly } \\
\text { manner. }\end{array}$ & & & 3.8 & .5 & 3.7 & .5 & 3.8 & .4 & 3.7 & .5 \\
\hline $\begin{array}{l}\text { Overall rating of the SP } \\
\text { encounter on a } 10 \text {-point } \\
\text { scale. }\end{array}$ & 8.0 & .7 & 7.7 & .9 & 7.7 & .9 & 7.7 & .8 & 7.5 & .9 \\
\hline
\end{tabular}

N.A.: Not Applicable 
Table 2a. Differences between MaSP scores years 2002-2003 and 2006-2007

\begin{tabular}{|c|c|c|c|c|c|c|}
\hline \multirow[t]{2}{*}{ Authenticity during the consultation } & \multicolumn{2}{|c|}{$\begin{array}{c}2002-2003 \\
N=201\end{array}$} & \multicolumn{2}{|c|}{$\begin{array}{c}2006-2007 \\
N=341\end{array}$} & \multirow[b]{2}{*}{$(95 \% \mathrm{CI})$} & \multirow[b]{2}{*}{ ES } \\
\hline & Mean & SD & Mean & SD & & \\
\hline 1. SP appears authentic. & 3.6 & .6 & 3.5 & .6 & $(0.01 / 0.22)^{*}$ & .19 \\
\hline 2. SP could be a real patient. & 3.8 & .5 & 3.6 & .5 & $(0.12 / 0.29)^{*}$ & .42 \\
\hline 3. SP is clearly role playing. & 1.5 & .7 & 1.6 & .7 & $(-0.24 / 0.01)$ & .14 \\
\hline $\begin{array}{l}\text { 4. SP appears to withhold information unneces- } \\
\text { sarily. }\end{array}$ & 1.3 & .7 & 1.5 & .7 & $(-0.26 /-0.01)^{*}$ & .19 \\
\hline 5. SP stays in his/her role all the time. & 3.6 & .7 & 3.4 & .7 & $(0.05 / 0.30)^{*}$ & .26 \\
\hline 6. SP is testing the student. & 1.4 & .7 & 1.5 & .7 & $(-0.16 / 0.08)$ & .14 \\
\hline $\begin{array}{l}\text { 7. SP simulates physical complaints unrealisti- } \\
\text { cally. }\end{array}$ & \multicolumn{2}{|c|}{ N.A. } & \multicolumn{2}{|c|}{ N.A. } & N.A. & \\
\hline 8. SP's appearance fits the role. & 3.8 & .5 & 3.8 & .5 & $(-0.01 / 0.15)$ & .00 \\
\hline 9. SP answers questions in a natural manner. & 3.6 & .6 & 3.5 & .6 & $(0.01 / 0.21)^{*}$ & .19 \\
\hline $\begin{array}{l}\text { 10. Number of times SP starts conversation } \\
\text { with student(s) during time-out. }\end{array}$ & \multicolumn{2}{|c|}{$5.1 \%$} & \multicolumn{2}{|c|}{$3.7 \%$} & $(0.51 / 3.01)$ & .00 \\
\hline $\begin{array}{l}\text { Overall rating of the SP encounter on a } 10 \text { - } \\
\text { point scale. }\end{array}$ & 8.0 & .7 & 7.5 & .9 & $(0.40 / 0.71)^{*}$ & .80 \\
\hline
\end{tabular}

Table 2b. Differences between MaSP scores years 2003-2004 and 2006-2007

\begin{tabular}{|c|}
\hline Feedback after the consultation \\
\hline $\begin{array}{l}\text { 11. Number of times SP leaves the room } \\
\text { between consultation and feedback. }\end{array}$ \\
\hline 12. SP stimulates student to ask questions. \\
\hline $\begin{array}{l}\text { 13. I can judge from the reactions of the SP } \\
\text { whether or not (s)he is listening to the stu- } \\
\text { dent. }\end{array}$ \\
\hline
\end{tabular}

14. SP communicates how (s)he felt during the consultation.

15. SP gives feedback about medical issues.

16. SP gives examples from the consultation.

\begin{tabular}{|c|c|}
\hline $\begin{array}{c}\text { 2003-2004 } \\
\mathbf{N}=\mathbf{2 2 6}\end{array}$ \\
\hline Mean $\quad$ SD \\
\hline $95.9 \%$ \\
\hline
\end{tabular}

\begin{tabular}{|c|c|c|c|}
\hline \multicolumn{2}{|c|}{$\begin{array}{c}2006-2007 \\
N=341\end{array}$} & \multirow[b]{2}{*}{ (95\% CI) } & \multirow[b]{2}{*}{ ES } \\
\hline Mean & SD & & \\
\hline \multicolumn{2}{|c|}{$100 \%$} & $(0.93 / 0.99)^{*}$ & .01 \\
\hline
\end{tabular}

\begin{tabular}{|l|l|}
\hline 2.4 & .8 \\
\hline 3.4 & .6 \\
\hline
\end{tabular}

\begin{tabular}{|l|l|l|l|}
\hline 2.4 & .9 & $(-0.23 / 0.07)$ & .00 \\
\hline 3.4 & .6 & $(-0.11 / 0.10)$ & .00 \\
\hline
\end{tabular}

3.2

.8

3.3

$(-0.22 / 0.05)$

17. SP speaks about his/her role in the first person ("I").

18. SP gives constructive criticism.

19. SP compares student with other students.

20. SP acts in a friendly manner.

\begin{tabular}{|c|c|}
\hline 1.8 & .9 \\
\hline 2.6 & 1.0 \\
\hline 3.3 & .8 \\
\hline
\end{tabular}

\begin{tabular}{|l|l|l|l|}
\hline 1.5 & .8 & $(0.12 / 0.41)^{*}$ & .29 \\
\hline
\end{tabular}

\begin{tabular}{l|l|l|l|}
2.7 & 1.0 & $(-0.35 /-0.01)^{*}$ & .17
\end{tabular}

\begin{tabular}{|c|c|c|c|c|c|}
\hline 2.9 & .8 & 2.9 & .8 & $(-0.12 / 0.16)$ & .00 \\
\hline 1.9 & 1.1 & 1.3 & .7 & $(0.42 / 0.74) *$ & .54 \\
\hline 3.8 & .5 & 3.7 & .5 & $(-0.26 / 0.13)$ & .20 \\
\hline
\end{tabular}

N.A.: Not Applicable

* Significant difference MaSP scores between years 
The adolescent SPs' evaluations of the first year of the program (2002-2003) revealed that all adolescents $(\mathrm{N}=18)$ had voluntarily informed their parents about their participation. They experienced no personal disadvantages (median $1 ; 25-75$ percentiles $1-2$ ) and would love to play again (median 4; 25-75 percentiles 4-4). All SPs had tried to provide the student with feedback on the encounter. The adolescent SPs' evaluations of the program four years later (2006-2007) revealed that the adolescent SPs did not consider the number of consecutive performances a day (maximum eight) a problem (median 4; 25-75 percentiles 3.25-4). The provision of feedback, on the other hand, was found to be quite difficult (median 3; 25-75 percentiles 2-3). No significant differences were found between the scores on the identical items of both questionnaires (20022003 and 2006-2007).

\section{Changes in the adolescent SP program}

On the basis of the evaluations of students, SPs and teachers, the adolescent SP program has been changed during the past five years. During the first year of the adolescent SP program, the adolescent SPs were invited to provide the students with feedback on the encounter but only if they felt comfortable doing so. All adolescent SPs had actually tried to provide the students with feedback after the consultation. The quality of the feedback (without feedback training) was considered good by the teachers. Therefore, in following years of the adolescent SP program, providing feedback was fully integrated in the program, just like in the regular SP program. The adolescents were also trained in providing feedback.

Initially, we had planned a maximum number of four consecutive consultations per day, since we did not know how many consultations the adolescents could cope with. During subsequent years, an increasing number of performances per day were scheduled, to a maximum of eight performances per day. This resulted in a smaller number of adolescents required for the SP program (from 18 SPs in 2002-2003 to 12 SPs in 2006-2007), although the number of second year students increased in these years (from 228 students in 2002-2003 to 363 students in 2006-2007). In addition, the recruitment of adolescent SPs became easier during the five years of the program. Initially the SPs were recruited among the adolescent daughters of Skillslab staff members. Later the SPs were recruited among adolescents who had participated in the program during previous years and by word-of-mouth. Ages of all recruited adolescents ranged 
between 13 and 20 years. Reasons for adolescent SPs not participating in following years were, for example, other (school-related) commitments or becoming too old (19-20 years) to participate in the adolescent SP program. In subsequent years the adolescent SP roles also became more individualized in order to improve the authenticity of the performance. These individualized roles developed in a discussion with each adolescent SP. They were largely inspired by reality. Instead of the four, more or less "fixed" roles used in the first year of the program, we used up to nine variations in subsequent years. Box 2 provides an overview of the individualized role scenarios.

\section{Box 2. Overview of individualized role scenarios for adolescent SPs}

- Request for the use of an oral contraceptive during the holidays.

- Request for start of an oral contraceptive but the girl is not sure whether she really wants it, her boyfriend has pressurized her.

- Request for start of an oral contraceptive but the girl is not sure whether she really wants it, the parents of her boyfriend have pressurized her.

- "I have painful menstruation. Would an oral contraceptive help me?".

- "I would like to start the pill because I think I'm ready for it".

- Girl comes with a boy (not her boyfriend), "last night the condom ruptured".

- "I have painful menstruation. Would an oral contraceptive help me?", but really the girl wants an oral contraceptive to prevent pregnancy but doesn't dare to tell the GP.

- Girl comes with boyfriend, she asks for information on oral contraceptives but he pressurizes her to start an oral contraceptive.

- Girl comes with boyfriend, they are arguing when entering the GP's office: he thinks he has an STD and blames her for that. She denies it comes from her.

\section{Discussion}

This is the first study to report on the evaluations of an adolescent SP program over multiple years. In general, the evaluations by students were very positive. Although there are several significant differences between the first two years of the program (2002-2003 and 2003-2004) and the last year of the program (2006-2007) only two are of moderate or crucial practical importance. First of all, the mark for the overall performance of the adolescent SPs has decreased by half a point (from 8.0 to 7.5 on a 10 point scale) over five years. There might be several explanations for this finding. Compared to other studies on adolescent SPs, the recruitment and selection of adolescents for our program was less strict. During later years of the program, recruitment became even less strict as some adolescent SPs were recruited by word-of-mouth. This might have influenced 
the performance of the adolescent SPs. Furthermore, during the years the program demanded more of the adolescents with regard to the number of performances per day and with regard to providing feedback to students. This might also have influenced the performance of the adolescent SPs, including the quality of the feedback. However, the mark for the performance of the adolescent SPs remains high. This might be explained by the fact that, for the first time in their studies, students have an encounter with "patients" younger than themselves. Also, the students might appreciate the practice of discussing intimate matters, such as sexuality.

Secondly, SPs have compared students less with other students in providing feedback, which is a desirable effect. Overall, there seems to be a trend towards more positive evaluations on the feedback by adolescent SPs over the past four years. The training of adolescent SPs in providing feedback might be an important factor contributing to this. In addition, students might have become more aware of the importance of feedback by SPs, therefore valuing it more. They might also have become more competent in asking for feedback. Providing feedback remains an important point for attention, particularly since the adolescent SPs themselves said that providing feedback was quite difficult. Unlike previous research in which adolescent SPs performed a role away from their individual characteristics, the adolescent SPs in our program performed a role that was close to their personality. Coming out of role might have been difficult for our adolescent SPs, consequently reporting that giving feedback is quite difficult. Perhaps, instruments like the structured communication adolescent guide (SCAG) ${ }^{12}$ are helpful for the adolescent SPs in giving feedback to students, although validation of the SCAG in our setting would be necessary.

The adolescent SPs generally remain positive about the adolescent SP program. Adolescent SPs considered the maximum number of eight consecutive performances a day no problem. Adolescents might find the performance easy as the role is close to their personality. Over the past five years adolescent SPs have not reported negative effects due to their performance. The rapid turn-over of the adolescent SP population, however, is one of the practical disadvantages of the adolescent SP program. Since only adolescents within a small age range can be used, a large part of the adolescent SP population has to be newly recruited and trained each year.

There are some limitations to this study. First of all, although the MaSP has been validated to assess the performance of adult SPs, it has not been validated to assess adolescent SPs' performance. This might have influenced our results. Furthermore, the adolescent SP program has undergone several adjustments on 
the basis of the evaluations of teachers, SPs and students during the past five years. Therefore, the evaluations of the program of subsequent years might have been positively biased. Also, our results were obtained in the setting of the Maastricht undergraduate medical curriculum. Although we think that many results of our study are transferable to adolescent SP programs in different settings, some might not be. Further research on evaluations of adolescent SP programs over multiple years might provide us with more information on these issues.

In summary, this study supports our view that the adolescent SP program remains valuable over multiple years, from the point of view of teachers, students as well as adolescent SPs. Important lessons were learned during the past five years and as a result of that several adjustments were made to the program. The major lessons learned are summarized in Box 3. Although further research on evaluations of adolescent SP program over multiple years is important, we think that the adolescent SP program has proven to be a valuable contribution in the undergraduate medical curriculum.

\section{Box 3. Overview of lessons learned from the adolescent SP program}

- The adolescent SP program offers a highly valued learning experience, for students, teachers and SPs.

- The program remains to be highly valued over a period of five years.

- Adolescents can be trained to perform authentic, individualized SP roles.

- Adolescent SPs do not suffer from negative effects due to their performance.

- There is a rapid turnover of the adolescent SP population.

- Adolescent SPs can provide students with feedback after the encounter.

- The quality of the feedback can be improved by training the adolescent SPs in the giving of feedback.

- Adolescent SPs find it quite hard to give feedback and therefore more attention should be paid training adolescents in providing feedback, for example by learning them to come out of role more easily or by making use of the structured communication adolescent guide (SCAG).

- Role performance by adolescent SPs should be further improved, for example by careful recruitment and selection of adolescent SPs or by decreasing the number of performances per day.

- Adolescent SPs performing a role close to their personality feel comfortable with a maximum number of eight performances a day. 


\section{References}

1. Barrows HS. An overview of the uses of standardized patients for teaching and evaluating clinical skills. AAMC. Academic Medicine. Jun 1993;68(6):443-451; discussion 451-443.

2. Barrows HS, Abrahamson S. The programmed patients: a technique for appraising student performance in clinical neurology. Journal of Medical Education. 1964;39:802-805.

3. Stillman PL, Regan MD, Philbin M, Haley HL. Results of a survey on the use of standardized patients to teach and evaluate clinical skills. Academic Medicine. 1990;65(5):288-292.

4. Blake K, Greaven S. Adolescent girls as simulators of medical illness. Medical Education. Sep 1999;33(9):702-703.

5. Blake K, Mann KV, Kaufman DM, Kappelman M. Learning adolescent psychosocial interviewing using simulated patients. Academic Medicine. Oct 2000;75(10 Suppl):S56-58.

6. Blake K, Gusella J, Greaven S, Wakefield S. The risks and benefits of being a young female adolescent standardized patient. Medical Education. Jan 2006;40(1):26-35.

7. Hardoff D, Schonmann S. Training physicians in communication skills with adolescents using teenage actors as simulated patients. Medical Education. Mar 2001;35(3):206-210.

8. Lane JL, Ziv A, Boulet JR. A pediatric clinical skills assessment using children as standardized patients. Archives of Pediatrics \& Adolescent Medicine. Jun 1999;153(6):637-644.

9. Hanson M, Tiberius R, Hodges B, et al. Adolescent standardized patients: method of selection and assessment of benefits and risks. Teaching and Learning in Medicine. Spring 2002;14(2):104-113.

10. Woodward CA, Gliva-McConvey G. Children as standardized patients: initial assessment of effects. Teaching and Learning in Medicine. 1995;7(3):188-191.

11. Hanson MD, Niec A, Pietrantonio AM, et al. Effects associated with adolescent standardized patient simulation of depression and suicidal ideation. Acad Med. Oct 2007;82(10 Suppl):S61-64.

12. Blake K, Vincent N, Wakefield S, Murphy J, Mann K, Kutcher M. A structured communication adolescent guide (SCAG): assessment of reliability and validity. Med Educ. May 2005;39(5):482-491.

13. Blake K, Greaven S. Recruiting and following adolescent standardized patients. Academic Medicine. May 1999;74(5):584.

14. Behrman, Kliegman, Jenson. Nelson Textbook of Pediatrics, 17th edition. Philadelphia: Saunders; 2004:641-646.

15. Boekeloo BO, Schamus LA, Cheng TL, Simmens SJ. Young adolescents' comfort with discussion about sexual problems with their physician. Archives of Pediatrics \& Adolescent Medicine. Nov 1996;150(11):1146-1152.

16. Brown R, Doonan S, Shellenberger S. Using children as simulated patients in communication training for residents and medical students: a pilot program. Academic Medicine. Dec 2005;80(12):1114-1120.

17. Van Dalen J, Bartholomeus P, Kerkhofs E, et al. Teaching and assessing communication skills in Maastricht: the first twenty years. Medical Teacher. May 2001;23(3):245-251.

18. Wind LA, Van Dalen J, Muijtjens AM, Rethans JJ. Assessing simulated patients in an educational setting: the MaSP (Maastricht Assessment of Simulated Patients). Medical Education. Jan 2004;38(1):39-44.

19. Hojat M, Xu G. A visitor's guide to effect sizes: statistical significance versus practical (clinical) importance of research findings. Advances in Health Sciences Education 2004;9(3):241-249. 


\section{Chapter 5}

\section{The longitudinal simulated patient program: Evaluations by teachers and students and feasibility}

L. Bokken, T. Linssen, A. Scherpbier, C. van der Vleuten, JJ. Rethans Medical Teacher 2008 October 20:1-8 (Epub ahead of print) 


\begin{abstract}
Objective: Simulated patients (SPs) are mostly used in single-case encounters. However, for chronic care training longitudinal patient encounters are more suitable. Evaluations of students and teachers regarding a new, longitudinal SP program were explored and compared to the single-case SP program. Furthermore, the feasibility of the program was explored.

Methods: Year 3 students participating in the longitudinal SP program $(\mathrm{N}=272)$ had four encounters with the same SP portraying a chronic health problem in eight months. Student evaluations regarding the longitudinal SP program were assessed with a validated questionnaire (the MaSP) and both teachers and students completed another questionnaire on their views.

Results: In general, students and teachers were positive about the longitudinal SP program. We found no differences between student evaluations regarding the longitudinal SP program and those regarding the single-case SP program. The longitudinal SP program appeared not to be feasible because of uncooperative faculty staff and the workload.

Conclusions: Students consider the longitudinal SP program as good as the single-case SP program. In its current form the longitudinal SP program appeared not to be feasible. Further research is needed in our search for an instructive, enjoyable and feasible SP program to teach students about continuity of care.
\end{abstract}




\section{Introduction}

Simulated patients (SPs) are widely used in medical education and assessment. ${ }^{1,2}$ SPs are mostly used in single-case encounters in which the student has one encounter with the SP and receives feedback from the SP and/or teachers or peers afterwards. An important shortcoming of these single-case encounters is the lack of opportunity for students to learn about continuity of care. Practicing physicians, however, offer continuity of care to most of their patients as they manage patient problems over multiple consecutive consultations. ${ }^{3}$ This is particularly true in the management of chronic diseases. With the rapidly growing prevalence of chronic illnesses, there have been several calls for medical schools to improve the training of students in chronic care. ${ }^{4-7}$ This training requires extensive, longitudinal patient encounters rather than snapshotlike, single-case encounters. ${ }^{5}$

Few studies have focused on longitudinal SP encounters to prepare students for continuity of care. ${ }^{8-11}$ Evaluations of students with regard to the longitudinal SP encounters were generally positive. ${ }^{8,9}$ None of the studies have compared student evaluations regarding longitudinal SP encounters with those regarding single-case SP encounters. Furthermore, none of the studies have reported on the feasibility of a longitudinal SP program.

In a recently published study, we explored the experiences of SPs with a new, longitudinal SP program in which individual students saw the same SP during four consecutive consultations over eight months and received feedback from the SP after each consultation. ${ }^{12}$ Compared to single-case encounters, SPs found the longitudinal SP encounters more realistic and developed a more familiar relationship with the students. Furthermore, the SPs were able to provide the students with more detailed feedback after the encounter. ${ }^{12}$

The aims of the current study were 1) to explore the evaluations of students and teachers regarding the longitudinal SP program 2) to compare the evaluations of students regarding the longitudinal SP program with those regarding the singlecase SP program and 3) to explore the feasibility of the longitudinal SP program in terms of the difficulties that were encountered.

Since the longitudinal encounters were considered to be more realistic and the feedback provided by the SPs was more detailed, we hypothesized that students valued these encounters more than the single-case encounters. 


\section{Methods}

\section{Setting}

Once every three weeks, students in the preclinical years of the six-year medical curriculum of Maastricht University (Years 1-3) have the opportunity to practice communication and physical examination skills in elective encounters with simulated patients (SPs) at the Skillslab. ${ }^{13}$ During these encounters student-pairs see an SP and take a history and/or perform a physical examination, with one student in the role of the doctor and the other as observer. The student-pairs change roles for each SP encounter. The SPs provide the "student-doctor" with feedback at the end of the encounter. The encounters are single-case sessions in which the SPs portray patients with different medical problems. The sessions are digitally video recorded and discussed in tutorial groups comprised of 10 students and one teacher. The SP program is fully integrated with the preclinical problem-based medical curriculum.

In Year 3 of the medical curriculum, chronic diseases are addressed. Year 3 students rotate through four ten week clusters focusing on different domains of chronic disease: abdomen, locomotor, circulation-lungs and psychomedical. In each cluster, students have regular encounters with real patients (as opposed to paper patients in the first two years) with chronic health problems, used as triggers for learning. ${ }^{14,15}$ The students are divided into four groups which rotate through the clusters in a different order (Figure 1).

Figure 1. Rotation of student groups through clusters in year 3

\begin{tabular}{|c|c|c|c|c|}
\hline \multicolumn{5}{|l|}{ Clusters } \\
\hline Student groups & Weeks 1-10 & Weeks 11-20 & Weeks 21-30 & Weeks 31-40 \\
\hline Group $1(\mathrm{~N}=74)$ & Abdomen & Locomotor & $\begin{array}{l}\text { Circulation \& } \\
\text { lungs }\end{array}$ & Psychomedical \\
\hline Group $2(N=74)$ & Locomotor & $\begin{array}{l}\text { Circulation \& } \\
\text { lungs }\end{array}$ & Psychomedical & Abdomen \\
\hline Group $3(N=74)$ & $\begin{array}{l}\text { Circulation \& } \\
\text { lungs }\end{array}$ & Psychomedical & Abdomen & Locomotor \\
\hline Group $4(\mathrm{~N}=70)$ & Psychomedical & Abdomen & Locomotor & $\begin{array}{l}\text { Circulation \& } \\
\text { lungs }\end{array}$ \\
\hline
\end{tabular}


In 2004-2005 the new, longitudinal SP program was introduced in Year 3. The program was offered to all Year 3 students. A total number of 32 SPs were selected from our SP pool and trained for 8 different patient roles. Per patient role, 4 SPs were trained. The patient roles were related to the four clusters on chronic diseases in Year 3. There were two patient roles related to chronic diseases discussed in the cluster abdomen (Diabetes Mellitus and Inflammatory Bowel Disease), two roles related to the locomotor cluster (arthrosis / Bechterew disease and radiculopathy), two roles related to the circulation-lungs cluster (congestive heart failure and coronary syndrome) and two roles related to the psychomedical cluster (depression and anxiety disorder). The patient roles were tailored to the SPs' personality and based on details of the SPs' personal lives (e.g. age, marital status, occupation). Each SP was coupled with 10-11 individual students, their "general practitioner" (GP), for 4 consecutive encounters in an eight month period (1 encounter per cluster).

During the first SP encounter, the SP came to get acquainted with his or her new "GP". This encounter focused on the chronic disease portrayed by the SP. The domain of the chronic disease portrayed by the SPs was related to the cluster the student was enrolled in at the start of Year 3. For example, students starting with the cluster abdomen were coupled with SPs portraying patients with Diabetes Mellitus or Inflammatory Bowel Disease and students starting with the cluster locomotor were coupled with SPs portraying patients with arthrosis / Bechterew disease or radiculopathy. During subsequent encounters, the SPs visited their "GPs" with a new problem, on top of their chronic health problem. Each encounter the students had to both manage the new problem and continue their care for the SPs' chronic disease. Students had to be aware of symptoms of the new medical problem interacting with the SPs' chronic disease, for example fever in patients with Diabetes Mellitus which can lead to hyperglycemia or a sprained ankle which can lead to deterioration of symptoms in patients with radiculopathy. Figure 2 provides outlines of the problems SPs portray in each of the four encounters in the clusters abdomen and locomotor.

Extensive documentation was necessary to guarantee continuity and realism in the consultations. Students kept notes on their individual patient's medical record (Figure 3 ) in order to prepare for the subsequent encounter. 
Figure 2. Outlines of problems portrayed by the SP over 4 encounters, for 2 clusters

\begin{tabular}{|c|c|c|c|c|}
\hline \multicolumn{5}{|c|}{ Cluster Abdomen } \\
\hline Student pair & Encounter 1 & Encounter 2 & Encounter 3 & Encounter 4 \\
\hline Student 1 & $\begin{array}{l}\text { SP with Diabetes } \\
\text { Mellitus makes } \\
\text { acquaintance to } \\
\text { new "GP". }\end{array}$ & $\begin{array}{l}\text { SP visits "GP" } \\
\text { with symptoms of } \\
\text { pneumonia. }\end{array}$ & $\begin{array}{l}\text { SP visits "GP" } \\
\text { with sprained } \\
\text { ankle. }\end{array}$ & $\begin{array}{l}\text { SP visits "GP" } \\
\text { with symptoms of } \\
\text { peptic ulcer. }\end{array}$ \\
\hline Student 2 & $\begin{array}{l}\text { SP with Crohn } \\
\text { disease makes } \\
\text { acquaintance to } \\
\text { new "GP". }\end{array}$ & $\begin{array}{l}\text { SP visits "GP" } \\
\text { with painful } \\
\text { shoulder. }\end{array}$ & $\begin{array}{l}\text { SP visits "GP" } \\
\text { (after a phone call } \\
\text { by the GP's } \\
\text { receptionist) } \\
\text { because of } \\
\text { possible } \\
\text { osteosarcoma in } \\
\text { painful shoulder. }\end{array}$ & $\begin{array}{l}\text { SPs visits "GP" } \\
\text { to discuss } \\
\text { problems related } \\
\text { to the previous } \\
\text { encounter } \\
\text { (e.g. wish for } \\
\text { second opinion). }\end{array}$ \\
\hline
\end{tabular}

\section{Cluster Locomotor}

\begin{tabular}{|l|l|l|l|l|}
\hline Student pair & Encounter 1 & Encounter 2 & Encounter 3 & Encounter 4 \\
\hline Student 1 & $\begin{array}{l}\text { SP with radiculo- } \\
\text { pathy makes } \\
\text { acquaintance to } \\
\text { new "GP". }\end{array}$ & $\begin{array}{l}\text { SP visits "GP" } \\
\text { with symptoms of } \\
\text { pneumonia. }\end{array}$ & $\begin{array}{l}\text { SP visits "GP" } \\
\text { with sprained } \\
\text { ankle. }\end{array}$ & $\begin{array}{l}\text { SP visits "GP" } \\
\text { with symptoms of } \\
\text { peptic ulcer. }\end{array}$ \\
\hline Student 2 & $\begin{array}{l}\text { SP with arthrosis } \\
\text { makes acquaint- } \\
\text { ance to new } \\
\text { "GP". }\end{array}$ & $\begin{array}{l}\text { SP visits "GP" } \\
\text { with painful } \\
\text { shoulder. }\end{array}$ & $\begin{array}{l}\text { SP visits "GP" } \\
\text { (after a phone call } \\
\text { by the GP's } \\
\text { receptionist) } \\
\text { because of } \\
\text { possible osteosar- } \\
\text { coma in painful } \\
\text { shoulder. }\end{array}$ & $\begin{array}{l}\text { SPs visits "GP" to } \\
\text { related to the } \\
\text { previous } \\
\text { encounter }\end{array}$ \\
\hline
\end{tabular}


Figure 3. Report of the SP encounter for students

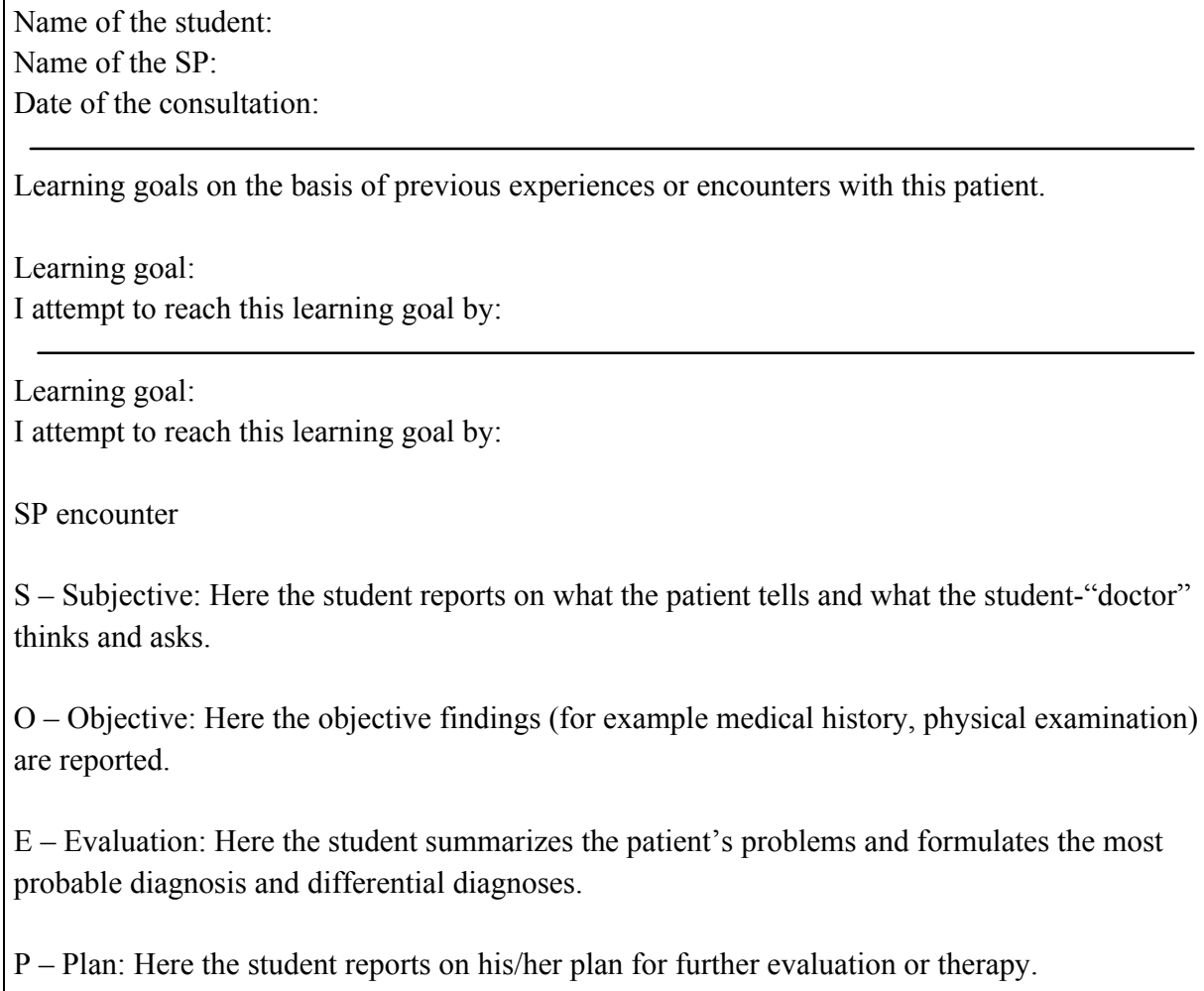

After the encounter the students' notes were reviewed by faculty for managerial decisions made by the student. Information on diagnostic evaluations planned by the student or decisions on treatment, were taken over on an "individual management plan". This provided an overview per SP of individual student plans following each encounter. In response to these individual student plans, faculty members were able to make new instructions for SPs for consecutive encounters with the same students. The SP was able to build responses to the student's individual management plan into his or her performance in the consecutive encounter. For example, if the student had referred the SP to a neurologist, the SP would play he or she had visited the neurologist and hand over the neurologist's return letter to the student, or if the student had not diagnosed a pneumonia (and had not prescribed antibiotics), the SP would hand over a note from the emergency room the SP had visited after deterioration of the symptoms. 
The SPs also kept notes on their student registration forms (Figure 4), in order to help them prepare for a consecutive consultation. The SPs were also provided with photographs of their "GPs".

\section{Figure 4. Registration form of the SP encounter for SPs}

Name of the SP:

Name of the student:

Number of encounter with this student: $1 / 2 / 3 / 4$

Notes about the encounter

What did the student ask about your symptoms or about your chronic disease? (For example, for how long have you suffered from your complaints or what you have done about them)

What kind of physical examination did the student do? (For example measuring your blood pressure)

What didn't the student ask you (what he/she should have done)? Do you still have questions?

Describe the course of action. (For example, when do you have to return to the doctor, were you prescribed medication, what medication)

Describe your overall impression of this encounter.

Describe typical characteristics of the students from which you can remember this encounter for the next time. (For example, the student that forgot to close the door or the student that rushed through the consultation)

Other matters you find important? (For example how do you feel with this doctor)

\section{Students}

As usual with the regular, single-case SP encounters, all Year 3 medical students in 2004-2005 ( $\mathrm{N}=292)$ could register for the longitudinal SP encounters voluntarily. The students were aware of the content and specific set-up of the longitudinal SP program. Evaluations of the students participating in the longitudinal SP program in 2004-2005 were compared to evaluations of a control group of Year 3 students $(\mathrm{N}=341)$ participating in the regular, singlecase SP program in 2005-2006. 


\section{Instruments}

To assess how the students evaluated the longitudinal SP program, the Maastricht Assessment of Simulated Patients (MaSP) was used. ${ }^{16}$ This questionnaire consists of 10 items focusing on authenticity of SP role playing and 10 on the quality of feedback. Answers can be given on a 4 point Likert scale (1=complete disagreement, $4=$ complete agreement). In addition, respondents can assign a general mark (on a 10 point scale) for SP performance and can make free comments. The MaSP has proven to be valid, reliable and feasible to assess the performance of SPs in an educational setting. ${ }^{16}$ All students, both "student-doctors" and observers, were asked to complete the MaSP immediately after the consultation.

At the end of Year 3, students as well as teachers from the tutorial groups in which the SP encounters are discussed completed a questionnaire to evaluate the longitudinal SP program. The questionnaires for both students and teachers consisted of 38 items using a 5-point Likert scale (1=completely disagree, $5=$ completely agree). Of these 38 items, 19 items on the student questionnaire and 15 items on the teacher questionnaire referred to the longitudinal SP program itself. The remaining items concerned the functioning of the teacher and student group and the organization of the SP encounters in general. The respondents could also make spontaneous comments.

\section{Analysis}

We analyzed the data with SPSS (version 15) for Windows, calculating frequencies for all items. Since we wanted to compare the evaluations of students regarding the longitudinal SP program with those regarding the single-case SP program, differences between MaSP scores of the years 2004-2005 (longitudinal SP program) and 2005-2006 (single-case SP program) were calculated using the T-test for two independent samples. The T-test was used because the MaSP scores were normally distributed by approximation because of the large numbers of students. Since scores on the items 10 and 11 of the MaSP were nominal (Yes or No), differences between the years 2004-2005 and 2005-2006 with regard to these items were calculated using the Chi-Square test. Effect sizes were calculated following the guidelines described by Hojat and $\mathrm{Xu}^{17} \mathrm{~A} \mathrm{p}$ value smaller than 0.05 was considered to be statistically significant. 


\section{Results}

Of the 292 Year 3 students eligible to participate in the longitudinal SP program, 272 (93\%) participated. This is comparable to participation in the regular, single-case SP program. The mean number of individual students coupled with one SP was 8.5 (range 5-11). The response rates on the student and teacher evaluations were $72 \%$ and $100 \%$ respectively. The response rate on the MaSP was $56 \%$ in $2004-2005$ and $69 \%$ in $2005-2006$. Table 1 shows the evaluations of the students regarding the longitudinal SP program.

Students liked the idea of having multiple encounters with chronically ill SP (item 1) and kept the agreements made with the SPs in previous encounters in mind during successive encounters (item 6). However, in comparison with single-case SP encounters, students felt they did not learn more about communication skills from the longitudinal SP encounters (item 5) and they only moderately preferred the longitudinal SP encounters (item 7), with large dispersion. Furthermore, students did not like the fact that the content of the SP encounter was often not related to the cluster they were enrolled in (item 9), although there was again large dispersion.

Table 2 shows the evaluations of the teachers of the groups in which the SP encounters were discussed. Teachers were well aware of the aims of the longitudinal SP program (item 2) and thought the longitudinal SP program offered a unique learning opportunity (item 11). In addition, teachers thought the students grew in their roles of doctors of "their" SPs (item 3). Both students and teachers were satisfied about the organization of the longitudinal SP program (item 8 (3.69 on a 5-point scale) and 1 (4.23 on a 5-point scale) respectively) although teachers were more enthusiastic than students.

Table 3 shows the MaSP scores for the longitudinal SP program (2004-2005) and those for the single-case SP program (2005-2006).

There are several significant differences between the MaSP scores. For example, students felt the SPs in the longitudinal program to be more authentic (item 1) and more like real patients (item 2) compared to SPs in the single-case program. 
Table 1. Evaluations of students regarding the longitudinal SP program $(\mathrm{N}=196)$

\begin{tabular}{|c|c|c|}
\hline & Mean & SD \\
\hline 1. The idea of having multiple encounters with a chronically ill SP is good. & 3.98 & .84 \\
\hline $\begin{array}{l}\text { 2. Having multiple encounters with the same SP is really different than having } \\
\text { encounters with varying SPs. }\end{array}$ & 3.90 & .87 \\
\hline 3. I felt like the real GP of "my" SP. & 3.12 & .97 \\
\hline $\begin{array}{l}\text { 4. During the year I increasingly attuned my behavior during the SP encounter } \\
\text { to "my" SP. }\end{array}$ & 3.50 & .88 \\
\hline $\begin{array}{l}\text { 5. I learned more about communication skills by having multiple encounters } \\
\text { with the same SP compared to having encounters with different SP. }\end{array}$ & 3.05 & .98 \\
\hline $\begin{array}{l}\text { 6. In successive encounters with the SP, I kept the agreements made with the } \\
\mathrm{SP} \text { in previous encounters in mind. }\end{array}$ & 4.05 & .80 \\
\hline $\begin{array}{l}\text { 7. If I have to choose between having a different SP for each encounter and } \\
\text { having the same SP, I'd choose the last option. }\end{array}$ & 3.43 & 1.01 \\
\hline 8. The longitudinal SP program was well organized. & 3.69 & .83 \\
\hline $\begin{array}{l}\text { 9. I found it a problem that the content of the SP encounter was often not } \\
\text { related to the cluster I was enrolled in. }\end{array}$ & 3.42 & 1.19 \\
\hline $\begin{array}{l}\text { 10. The fact that I received the results of laboratory tests I ordered made the } \\
\text { encounter more realistic. }\end{array}$ & 3.47 & .94 \\
\hline 11. In general, the SPs portrayed their roles well. & 4.02 & .64 \\
\hline 12. I received relevant feedback from the SPs. & 3.46 & .94 \\
\hline $\begin{array}{l}\text { 13. The longitudinal SP program offered sufficient opportunities to practice } \\
\text { my communication skills. }\end{array}$ & 3.91 & .75 \\
\hline $\begin{array}{l}\text { 14. The longitudinal SP program offered sufficient opportunities for having SP } \\
\text { encounters. }\end{array}$ & 3.99 & .64 \\
\hline $\begin{array}{l}\text { 15. The longitudinal SP program offered sufficient opportunities to discuss the } \\
\text { SP encounters in the group. }\end{array}$ & 3.84 & .77 \\
\hline 16. During the year I learned a lot from the SP encounters. & 3.43 & .87 \\
\hline $\begin{array}{l}\text { 17. During the year I learned a lot from discussing the SP encounters in the } \\
\text { group. }\end{array}$ & 3.49 & .94 \\
\hline 18. I've had enough training in the integration of knowledge and skills. & 3.60 & .78 \\
\hline 19. I've had enough training in continuity of care in the SP encounters. & 3.57 & .88 \\
\hline
\end{tabular}


Table 2. Evaluations of teachers regarding the longitudinal SP program $(\mathrm{N}=\mathbf{2 2})$

\begin{tabular}{|c|c|c|}
\hline & Mean & SD \\
\hline 1. The longitudinal SP program was well organized. & 4.23 & .75 \\
\hline 2 I was aware of the aims of the SP program. & 4.45 & .83 \\
\hline 3. The students grew in their roles of doctors of "their" SPs. & 4.23 & .81 \\
\hline 4. In general, the SPs portrayed their roles well. & 4.33 & .48 \\
\hline 5. The SPs provided the students with relevant feedback. & 3.53 & .70 \\
\hline $\begin{array}{l}\text { 6. The longitudinal SP program offered sufficient opportunities to learn } \\
\text { about continuity of care. }\end{array}$ & 3.62 & .74 \\
\hline $\begin{array}{l}\text { 7. The program offered sufficient opportunities to practice communication } \\
\text { skills. }\end{array}$ & 4.24 & .63 \\
\hline $\begin{array}{l}\text { 8. The program offered sufficient opportunities to practice documentation of } \\
\text { the encounters. }\end{array}$ & 3.81 & .75 \\
\hline $\begin{array}{l}\text { 9. The program offered sufficient opportunities to discuss the SP encounters } \\
\text { in the group. }\end{array}$ & 4.14 & .66 \\
\hline 10. The health problems the SPs portrayed were sufficiently challenging. & 3.81 & .75 \\
\hline $\begin{array}{l}\text { 11. Having multiple encounters with the same SP offered a unique learning } \\
\text { opportunity. }\end{array}$ & 3.90 & .70 \\
\hline $\begin{array}{l}\text { 12. The students have had enough training in the integration of knowledge } \\
\text { and skills. }\end{array}$ & 3.48 & .93 \\
\hline $\begin{array}{l}\text { 13. The students have had enough training in making the transition from } \\
\text { identifying the reason for consultation to taking a focused history. }\end{array}$ & 3.95 & .50 \\
\hline $\begin{array}{l}\text { 14. The students have had enough training in making the transition from } \\
\text { history to physical examination. }\end{array}$ & 4.05 & .38 \\
\hline $\begin{array}{l}\text { 15. The students have had enough training in making the transition from } \\
\text { physical examination to explanation and planning. }\end{array}$ & 3.86 & .79 \\
\hline
\end{tabular}


Table 3. Student evaluations of longitudinal SP encounters (2004-2005) compared to evaluations of regular SP encounters (2005-2006): MASP scores

\begin{tabular}{|c|c|c|c|c|c|c|}
\hline \multirow[t]{2}{*}{ Authenticity during the consultation } & \multicolumn{2}{|c|}{$\begin{array}{c}2004-2005 \\
N=1209\end{array}$} & \multicolumn{2}{|c|}{$\begin{array}{c}2005-2006 \\
N=943\end{array}$} & \multirow[b]{2}{*}{$(95 \% \mathrm{CI})$} & \multirow[b]{2}{*}{ ES } \\
\hline & Mean & SD & Mean & SD & & \\
\hline 1. SP appears authentic. & 3.67 & .51 & 3.52 & .59 & $(0.11 / 0.20)^{*}$ & .25 \\
\hline 2. SP could be a real patient. & 3.68 & .53 & 3.59 & .59 & $(0.05 / 0.14)^{*}$ & .15 \\
\hline 3. SP is clearly role playing. & 1.49 & .71 & 1.56 & .75 & $(-0.13 /-0.01)^{*}$ & .09 \\
\hline $\begin{array}{l}\text { 4. SP appears to withhold information } \\
\text { unnecessarily. }\end{array}$ & 1.38 & .64 & 1.55 & .81 & $(-0.23 /-0.11)^{*}$ & .21 \\
\hline 5. SP stays in his/her role all the time. & 3.62 & .61 & 3.62 & .60 & $(-0.05 / 0.05)$ & \\
\hline 6. SP is testing the student. & 1.55 & .75 & 1.87 & .98 & $(-0.40 /-0.25)^{*}$ & .33 \\
\hline $\begin{array}{l}\text { 7. SP simulates physical complaints } \\
\text { unrealistically. }\end{array}$ & 1.51 & .77 & 1.67 & .83 & $(-0.25 /-0.08)^{*}$ & .19 \\
\hline 8. SP's appearance fits the role. & 3.66 & .55 & 3.59 & .60 & $(0.02 / 0.12)^{*}$ & .12 \\
\hline 9. SP answers questions in a natural manner. & 3.68 & .54 & 3.57 & .61 & $(0.07 / 0.17)^{*}$ & .18 \\
\hline $\begin{array}{l}\text { 10. Number of times SP starts conversation with } \\
\text { student(s) during time-out. }\end{array}$ & & & & & $*$ & .00 \\
\hline \multicolumn{7}{|l|}{ Feedback after the consultation } \\
\hline & Mean & SD & Mean & SD & $(95 \%$ CI) & ES \\
\hline $\begin{array}{l}\text { 11. Number of times SP leaves the room between } \\
\text { consultation and feedback. }\end{array}$ & \multicolumn{2}{|c|}{$97.30 \%$} & \multicolumn{2}{|c|}{$97.95 \%$} & & \\
\hline 12. SP stimulates student to ask questions. & 2.89 & .83 & 2.81 & .87 & $(0.00 / 0.15)^{*}$ & .09 \\
\hline $\begin{array}{l}\text { 13. I can judge from the reactions of the SP } \\
\text { whether or not (s)he is listening to the student. }\end{array}$ & 3.54 & .58 & 3.47 & .62 & $(0.02 / 0.12)^{*}$ & .11 \\
\hline $\begin{array}{l}\text { 14. SP communicates how (s)he felt during the } \\
\text { consultation. }\end{array}$ & 3.52 & .68 & 3.43 & .71 & $(0.03 / 0.15)^{*}$ & .13 \\
\hline 15. SP gives feedback about medical issues. & 1.75 & .87 & 1.52 & .78 & $(0.16 / 0.30)^{*}$ & .29 \\
\hline 16. SP gives examples from the consultation. & 3.08 & .89 & 3.13 & .88 & $(-0.12 / 0.03)$ & \\
\hline $\begin{array}{l}\text { 17. SP speaks about his/her role in the first person } \\
\text { ("I"). }\end{array}$ & 3.52 & .73 & 3.54 & .69 & $(-0.08 / 0.04)$ & \\
\hline 18. SP gives constructive criticism. & 3.26 & .71 & 3.16 & .82 & $(0.03 / 0.16)^{*}$ & .12 \\
\hline 19. SP compares student to other students. & 1.31 & .68 & 1.28 & 67 & $(-0.02 / 0.09)$ & \\
\hline 20. SP acts in a friendly manner. & 3.76 & .50 & 3.70 & .52 & $(0.02 / 0.10)^{*}$ & .12 \\
\hline $\begin{array}{l}\text { Overall rating of the SP encounter on } 10 \text { point } \\
\text { scale. }\end{array}$ & 7.68 & .78 & 7.54 & .89 & $(0.07 / 0.21)^{*}$ & .16 \\
\hline
\end{tabular}

* Significant difference MaSP scores between years 
Furthermore, students valued the overall performance of SPs in the longitudinal program more compared to the performance of SPs in the single-case program. However, effect sizes of all differences were small, indicating a small difference of negligible practical importance. ${ }^{17}$

\section{Feasibility}

The largest difficulty that was encountered at the introduction of the longitudinal SP program concerned the commitment of the faculty indirectly involved in the program, for example the faculty coordinating the clusters. It turned out to be very hard to get all faculty staff ready to cooperate with the program. In 2005-2006, the year after the introduction of the longitudinal SP program, two of the four Year 3 clusters did not want to participate in the SP program anymore. They felt the SP encounters took too much time in the busy schedules of the clusters. The longitudinal SP program was then discontinued in all clusters and replaced by the regular, single-case SP program in two clusters.

Secondly, the organization and planning of the longitudinal SP program was highly time-consuming. For faculty, the workload of the longitudinal SP program was tremendous compared to the single-case SP program as a result of the "individual management plans" that were kept for each of the 272 students and the SP instructions that were made in response to the individual student's management plan. Since the longitudinal SP roles were more complex compared to the single-case roles, the training of SPs was also highly timeconsuming. SPs have also indicated that the workload of the longitudinal program was larger than that of the single-case program. ${ }^{12}$

A third difficulty that was encountered concerned the use of the opportunities offered by the longitudinal SP program. At the start of the program, teachers and students were told about its content and specific set-up. During the program, however, it became clear from reports of SPs that some students did not make full use of the opportunities to practice continuity of care. ${ }^{12}$ For example, some students handled each new problem the SP presented with on top of his/her chronic health problem as a separate problem. These students did not go back on the previous SP encounter and did not pay attention to the SP's chronic health problem as a result of which the longitudinal SP encounters effectively became single-case encounters. 


\section{Discussion}

This is the first study to compare student evaluations regarding a longitudinal SP program with those regarding a regular, single-case SP program. In general, students and teachers were positive about the longitudinal SP program. Students indicated preferring the longitudinal SP program to the single-case SP program, but to a moderate degree ( 3.43 on a 5 point scale) and with large dispersion. There are several significant differences between student evaluations regarding the longitudinal SP program and those regarding the single-case program. However, none are of practical importance. So, in contrast to what we hypothesized, students seem to think the longitudinal SP program is as good as the single-case SP program. This might be explained by the fact that some students did not make full use of the opportunities to practice continuity of care offered by the longitudinal program, effectively turning the longitudinal SP encounters into single-case SP encounters. After all, it is the continuity of care character of the longitudinal program that sets it apart from the single-case program. Since both students and teachers were only familiar with the single-case SP program, we possibly should have given more emphasis to the specific set-up of the new, longitudinal program at the introduction. However, the teachers indicated to be well aware of the aims of the program and the majority of the students reported to keep previous SP encounters in mind during successive encounters.

Another explanation for students not preferring the longitudinal SP program to the single-case SP program might be that students did not like the fact that the content of the longitudinal SP encounter was often not related to the cluster they were enrolled in. With exception of the first encounter, the health problem the SP presented with in a successive encounter was the same for each of the four clusters. Therefore, the content of the longitudinal SP encounter was often not related to the cluster, in contrast to the content of the regular, single-case SP encounters. Perhaps, we should have related the content of the longitudinal SP encounter more to the cluster the student was enrolled in at that time. However, this would have increased the workload of the program and would probably have made the program even less feasible.

Since we hypothesized students to prefer the longitudinal SP program to the single-case program on the basis of SP evaluations, it might be concluded that students and SPs have different views regarding the longitudinal SP program. However, the views of SPs have previously been assessed in a qualitative, focus group study whereas in this study we have assessed the views of students quantitatively. This might explain (part of) the difference. Further research on 
evaluations of longitudinal SP programs might provide us with more information regarding this issue.

The longitudinal SP program was valued by students and teachers and was considered instructive. As we had hoped, students and teachers thought the program offered enough training in continuity of care. However, some difficulties were encountered at the introduction of the longitudinal SP program. Especially cooperation of faculty staff and the huge workload of the program, with 272 students participating in it, were found to be a problem. In the currently used form, the longitudinal SP program did not appear to be feasible. A smaller scale set-up might be more feasible. Further studies with regard to the feasibility of longitudinal SP programs are needed.

There are some limitations to this study. First of all, the student and teacher questionnaires that were used were initially designed for program evaluation and not for this study. Although a large part of the items included in the questionnaires are relevant to our research questions, this might have biased our results. Furthermore, the low student response rate on the MaSP in 2004-2005, the year in which the longitudinal program was introduced, might also have biased our results. On the other hand, the absolute response on the MaSP is still very high.

In summary, the longitudinal SP program appears to be valued by students as well as teachers. In contrast to what we hypothesized, students think the longitudinal SP program is as good as the single-case SP program. In the current form, the longitudinal SP program did not appear to be feasible. Clearly, the search for an instructive, enjoyable and feasible SP program to teach students about continuity of care is to be continued. 


\section{References}

1. Barrows HS. An overview of the uses of standardized patients for teaching and evaluating clinical skills. AAMC. Acad Med. Jun 1993;68(6):443-451; discussion 451-443.

2. Barrows HS, Abrahamson S. The programmed patients: a technique for appraising student performance in clinical neurology. Journal of Medical Education. 1964;39:802-805.

3. Beullens J, Rethans JJ, Goedhuys J, Buntinx F. The use of standardized patients in research in general practice. Fam Pract. Feb 1997;14(1):58-62.

4. Darer JD, Hwang W, Pham HH, Bass EB, Anderson G. More training needed in chronic care: a survey of US physicians. Acad Med. Jun 2004;79(6):541-548.

5. Diederiks JP, Bosma H, van Eijk JT, van Santen M, Scherpbier A, van der Vleuten C. Chronic patients in undergraduate education: didactic value as perceived by students. Med Educ. Aug 2006;40(8):787-791.

6. Nieman LZ. A preclinical training model for chronic care education. Med Teach. May 2007;29(4):391-393.

7. Pham HH, Simonson L, Elnicki DM, Fried LP, Goroll AH, Bass EB. Training U.S. medical students to care for the chronically ill. Acad Med. Jan 2004;79(1):32-40.

8. Brown A, Anderson D, Szerlip HM. Using standardized patients to teach disease management skills to preclinical students: a pilot project. Teach Learn Med. Spring 2003;15(2):84-87.

9. Rull G, Rosher RB, McCann-Stone N, Robinson SB. A simulated couple aging across the four years of medical school. Teach Learn Med. Summer 2006;18(3):261-266.

10. Slavin SJ, Wilkes MS, Usatine R. Doctoring III: innovations in education in the clinical years. Acad Med. Dec 1995;70(12):1091-1095.

11. Wilkes MS, Usatine R, Slavin S, Hoffman JR. Doctoring: University of California, Los Angeles. Acad Med. Jan 1998;73(1):32-40.

12. Linssen T, van Dalen J, Rethans JJ. Simulating the longitudinal doctor-patient relationship: experiences of simulated patients in successive consultations. Med Educ. Sep 2007;41(9):873878.

13. Van Dalen J, Bartholomeus P, Kerkhofs E, et al. Teaching and assessing communication skills in Maastricht: the first twenty years. Med Teach. May 2001;23(3):245-251.

14. Diemers AD, Dolmans DH, Van Santen M, Van Luijk SJ, Janssen-Noordman AM, Scherpbier AJ. Students' perceptions of early patient encounters in a PBL curriculum: a first evaluation of the Maastricht experience. Med Teach. Mar 2007;29(2-3):135-142.

15. Diemers AD, Dolmans DH, Verwijnen MG, Heineman E, Scherpbier AJ. Students' opinions about the effects of preclinical patient contacts on their learning. Adv Health Sci Educ Theory Pract. Jul 2007 (Epub ahead of print).

16. Wind LA, Van Dalen J, Muijtjens AM, Rethans JJ. Assessing simulated patients in an educational setting: the MaSP (Maastricht Assessment of Simulated Patients). Med Educ. Jan 2004;38(1):39-44.

17. Hojat $\mathrm{M}, \mathrm{Xu} \mathrm{G}$. A visitor's guide to effect sizes: statistical significance versus practical (clinical) importance of research findings. Advances in Health Sciences Education 2004;9(3):241-249. 



\section{Chapter}

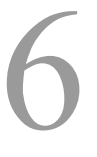

\section{Performance-related stress symptoms in simulated patients}

L. Bokken, J. van Dalen, JJ. Rethans

Medical Education 2004;38(10):1089-94 


\begin{abstract}
Introduction: During the first four years of the 6-year undergraduate medical curriculum at Maastricht University, the Netherlands, students practice clinical skills in simulated patient (SP) encounters at the Skillslab. Generally, these encounters are instructive and enjoyable for both students and SPs. However, in conversations with SP trainers some SPs have mentioned experiencing adverse symptoms due to performing a patient role. Some published studies have reported similar findings in SPs. We explored the seriousness of this problem by surveying SPs on the occurrence and severity of stress symptoms related to performing patient roles. We also examined by which variables the symptoms were influenced.

Methods: An anonymous questionnaire was developed to investigate factors related to stress symptoms and the frequency and severity of stress symptoms. A burnout scale was also included in the questionnaire. All SPs who had performed between March 2000 and March 2001 were asked to participate. Results: The response was $84 \%$. Of the SPs, $73 \%$ were found to have experienced stress symptoms, with a mean of 4 symptoms per SP. No significant correlations were found between the occurrence of symptoms on the one hand and factors that might influence symptoms or the burnout scale on the other hand.

Discussion: An unexpectedly high number of SPs reported symptoms. Fortunately, the symptoms were relatively mild ( 2.2 on a 5 -point scale). Future studies should address the connection between work as a SP and symptoms, and measures should be taken to prevent and treat the symptoms. Debriefing sessions might play a role in this respect.
\end{abstract}




\section{Introduction}

Since the introduction of simulated patients (SPs) by Barrows in 1964, SPs have been used extensively in medical education and assessment. ${ }^{1,2}$ Simulated patients are now recognized as a valid, accurate, feasible and acceptable educational and assessment tool. ${ }^{3-6}$ Since 1978 , SPs have contributed to the undergraduate clinical skills training program offered by the Skillslab of Maastricht University, the Netherlands. Every 6 weeks all 800 students in the preclinical curriculum (Years 1- 4 in a 6-year program) are offered the opportunity to play the role of the doctor in a simulated consultation with an SP, which includes an interview, physical examination and management plan. Students receive feedback from the SP immediately after the encounter. The videotaped consultation is watched by the other students and the tutor in the "doctor's" tutorial group, who give feedback to the "doctor" in a group session that takes place 1 week after the encounter. ${ }^{7}$

Formal evaluations generally show that both students and SPs regard the encounters as instructive and enjoyable. However, SPs have occasionally mentioned to SP trainers that their roles were heavy and that they sometimes experienced symptoms due to their performances as SPs. Few studies have focused on the possible effects that simulating a patient role may have on a person. ${ }^{8-13}$ McNaughton et al. used focus groups to explore the impact on SPs of performing highly affective psychiatric roles. ${ }^{8}$ The majority of the SPs mentioned negative effects, consisting predominantly of stress symptoms like exhaustion, irritability, sleeping problems and physical complaints. The likelihood of the occurrence of stress symptoms was found to be increased by the type of role and reduced by the type of motivation for being an SP. ${ }^{8}$ Woodward and Gliva-McConvey found that number of patient roles and amount of experience as an SP affected the probability of an SP experiencing symptoms. ${ }^{9,10}$ However, Naftulin and Andrew found no differences between experienced and inexperienced SPs in the likelihood of stress symptoms occurring. ${ }^{11}$

The acting style used by the SP also appeared to affect the probability of symptoms. $^{8-11}$

Two acting styles were distinguished. These were "method acting", in which the actor draws on his or her personal experience in portraying a role, and the more technical approach, where the actor maintains a greater personal distance from the role. At Maastricht Medical School method acting is used in training SPs, because it is thought that the role will gain credibility if it stays close to the SP's 
true situation and character. Method actors have been found to be more likely to develop stress symptoms than actors who use a more technical acting style. ${ }^{11}$ Some studies have addressed the effect on SPs of their contact with health care professionals. Woodward and Gliva-McConvey found that SPs developed a more balanced view of health care professionals, developed better communication skills and became more tolerant of others during the course of their contact with health care professionals. ${ }^{9,10}$ Wallach et al. reported that SPs had a better understanding of medical history taking and physical examination, showed improved communication with health care professionals and were more comfortable with health care visits, especially regarding physical examination. ${ }^{12}$ Gecht found improved interaction with health care professionals in patientinstructors. $^{13}$

The few studies conducted so far focused on emotionally complex roles or on long-term effects of contact with health care professionals. Moreover, the studies were conducted in the USA and Canada. Findings from published studies in combination with spontaneous remarks by SPs in Maastricht prompted us to explore the presence of stress symptoms in SPs in the clinical skills program of the Maastricht Skillslab. We focused on direct, negative, stressrelated effects immediately following performance of a patient role in an educational setting. More specifically, we wanted to examine which stress symptoms occurred, the severity of the symptoms and by which factors the symptoms were affected.

\section{Methods}

\section{Instrument}

We designed a questionnaire especially for this study. One part of the questionnaire consisted of an existing questionnaire, whilst the other parts were newly written. The questionnaire was anonymized so that SPs could feel free to report any symptom. First, a draft questionnaire was compiled by one of the authors on the basis of a literature study of stress symptoms. Comments on the draft by several experts in the field of stress (including psychologists, a sociologist and a general practitioner) were used to adjust the questionnaire and the revised version was presented to the same experts for approval. 
The final questionnaire consisted of 3 parts. The first part contained questions about factors which previous studies had shown to affect the likelihood of stress symptoms as well as questions about sex, age, number of years of experience as an SP, work as an SP outside the Skillslab, number of different SP roles performed per year and acting style. We did not ask which patient roles the SPs performed, so as not to jeopardize anonymity.

The second part of the questionnaire asked SPs to indicate on a 5-point scale ( $1=$ no symptoms; $5=$ severe symptoms) the severity of each of 54 stress symptoms experienced as a result of student-SP encounters. The symptoms comprised physical symptoms (e.g. sleeping problems, headaches), psychological symptoms (e.g. anxiety, worrying about a role or a performance) and behavioral symptoms (e.g. increased smoking and alcohol consumption), which were presented in random order. By way of illustration, Table 1 shows part of the list. The SPs were instructed to report only those stress symptoms that they felt were related to performing as an SP in the simulated consultations in the Skillslab. This teaching situation was further specified in guidelines that the respondents received together with the questionnaire.

The third part of the questionnaire consisted of Schmidt's burnout symptoms questionnaire. ${ }^{14}$ This instrument, which was developed and validated at the University of Maastricht, was included to determine whether a high score on stress symptoms was associated with a high burnout score and might thus be related to burnout rather than performing as an SP. Respondents were asked to answer questions about symptoms on a 5 -point Likert scale (1=no symptoms, $5=$ severe symptoms).

\section{Table 1. Example of a part of the questionnaire}

Please indicate to what extent you have experienced the following symptoms due to performing a patient role.

\begin{tabular}{|l|l|l|l|l|l|}
\hline & No symptoms & & & & $\begin{array}{l}\text { Severe } \\
\text { symptoms }\end{array}$ \\
\hline Exhaustion & 1 & & & 4 & 5 \\
\hline Being anxious & 1 & 2 & 3 & 4 & 5 \\
\hline Eating more & 1 & 2 & 3 & 4 & 5 \\
\hline Back pain & 1 & 2 & 3 & 4 & 5 \\
\hline Perspiring & 1 & 2 & 3 & 4 & 5 \\
\hline
\end{tabular}




\section{Subjects}

The Skillslab of the University of Maastricht has at its disposal a pool of about 100 SPs, who collectively perform 4000 times per year. Of the SPs, about 70\% performs at least 1 role a year, with an average of 3-4 repetitions per SP. Each role is performed by 6-7 SPs during 3 days. The SPs perform 6-9 times for 30minutes a day, with a 30-minute break after 3 performances.

We sent the questionnaire to the 70 SPs who contributed to the Skillslab program between 1 March 2000 and 1 March 2001.

\section{Analysis}

For the statistical analysis we used SPSS Version 10.0 for Windows. Cronbach's alpha was calculated to estimate the internal consistency of the questionnaire. Non-parametric tests were used to examine the relationship between the variables in the first part of the questionnaire and reported stress symptoms. Relationships between gender and reported stress symptoms were estimated using the Mann-Whitney test. The Kruskall-Wallis test was used to determine relationships between age, years of experience as an SP, work as an SP outside the Skillslab, number of SP roles performed per year and acting style on the one hand, and reported stress symptoms on the other hand. The correlation between the number and severity of stress symptoms (Likert scale) reported for the second part of the questionnaire and the number and severity of stress symptoms reported for the burnout questionnaire was estimated using the Spearman correlation coefficient.

\section{Results}

The internal consistency of the questionnaire was 0.91 (Cronbach's alpha).

Of 70 SPs, 59 (84\%) completed and returned the questionnaire. Forty respondents were female and 19 were male. The mean age of the respondents was 58 years (range 29-77 years) and the mean number of years of working as an SP was 6 years (range 1.5-25 years). Of the respondents 12\%,15\%,10\%, 10\%, 5\% and $41 \%$ reported performing an average of $1,2,3,4,5$ and $>5$ roles, respectively. A total of 56 respondents $(95 \%)$ reported predominant use of the method acting style. Of the respondents, 30 (51\%) reported also performing as an SP 
outside the Skillslab, usually at the Maastricht Faculty of Health Sciences. The SPs reported various motivations for working as an SP (Table 2).

Table 2. Motivation for being SP

\begin{tabular}{|l|l|l|}
\hline & \multicolumn{2}{|c|}{ Number of SPs (N=59) } \\
\hline Feeling useful & 22 & $(37.3 \%)$ \\
\hline Educational aspect & 14 & $(23.7 \%)$ \\
\hline More than 1 motivation & 8 & $(13.6 \%)$ \\
\hline Contact with others & 7 & $(11.9 \%)$ \\
\hline Money & 3 & $(5.1 \%)$ \\
\hline Miscellaneous & 3 & $(5.1 \%)$ \\
\hline Feeling valued & 1 & $(1.6 \%)$ \\
\hline Acting & 1 & $(1.6 \%)$ \\
\hline
\end{tabular}

Only 16 (27\%) SPs reported experiencing no stress symptoms due to performing a patient role in the past year (score 1 on all items). Table 3 shows the number and severity of physical, psychological and behavioral symptoms reported by the SPs. The 5 most frequently reported symptoms were fatigue (reported by $49.2 \%$ of the respondents), dissatisfaction with own or others' performance (28.8\%), nervousness $(23.7 \%)$, anxiety about things that might happen during the performance $(23.7 \%)$ and anxiety about the patient role $(20.3 \%)$.

The results of the Mann-Whitney test and the Kruskall-Wallis tests demonstrated no significant relationships. No significant correlation was found between number and severity of symptoms and response to the burnout questionnaire. The average score on that questionnaire was 2.5 (SD 0.4). 
Table 3. Number of symptoms reported by SPs

\begin{tabular}{|c|c|c|c|}
\hline SPs with symptoms $(\mathrm{N}=43)$ & Mean & Range & $1 / 4-3 / 4$ \\
\hline Number of reported symptoms & 4 & $1-29$ & $2-7$ \\
\hline Score on $5 p$-scale & 2.2 & $2-3.7$ & $2-2.7$ \\
\hline \multicolumn{4}{|l|}{ SPs with physical symptoms $(\mathrm{N}=36)$} \\
\hline Number of reported symptoms & 2 & $1-11$ & $1-4$ \\
\hline Score on $5 \mathrm{p}$-scale & 2.3 & $2-4$ & $2-3$ \\
\hline \multicolumn{4}{|c|}{ SPs with psychological symptoms $(\mathrm{N}=34)$} \\
\hline Number of reported symptoms & 2 & $1-18$ & $1-3$ \\
\hline Score on $5 p$-scale & 2 & $2-3.2$ & $2-2.5$ \\
\hline \multicolumn{4}{|c|}{ SPs with behavioral symptoms $(\mathrm{N}=23)$} \\
\hline Number of reported symptoms & 1 & $1-6$ & $1-2$ \\
\hline Score on $5 p$-scale & 2 & $2-4$ & $2-2.7$ \\
\hline
\end{tabular}

$1 / 4=25^{\text {th }}$ percentile score; $3 / 4=75^{\text {th }}$ percentile score

\section{Discussion}

Overall $73 \%$ of the respondents reported stress symptoms as a result of performing a patient role in a simulated consultation at the Skillslab at the University of Maastricht. This percentage and the mean number of symptoms (4) are much higher than expected, despite the occasional spontaneous remarks about symptoms made by SPs to SP trainers. A reassuring finding was that the severity of the symptoms appeared to be moderate ( 2.2 on a 5 -point scale). The 5 most frequently reported symptoms correspond to symptoms that were mentioned in previous studies. ${ }^{8-11}$

The motivations SPs reported for working as an SP were similar to those described in previous studies. ${ }^{8,15}$

The majority of the SPs reported using method acting in performing the patient role. This was expected because of the way the SPs are trained to perform their roles.

The score on the burnout questionnaire $(2.5 \pm 0.4)$ corresponds to an average level of burnout symptoms. ${ }^{14}$ How this burnout level relates to the burnout level of other occupations is not known. We found no correlation between number and severity of stress symptoms and the variables that previous studies described as affecting the likelihood of stress symptoms. It should be noted, 
however, that the previous results were found in focus group studies and not in questionnaire surveys like the present study.

A limitation of this study is that the questionnaire was administered to all SPs at the same time. As a consequence, the time between the last performance as an $\mathrm{SP}$ and responding to the questionnaire varied among the respondents. For some SPs the most recent performance might have been as long as 1 year before they completed the questionnaire. A long time gap may affect recollection of stress symptoms. Although $41 \%$ of the SPs performed more than 5 roles per year, the results might have been more reliable if the questionnaire had been administered at different moments, preferably immediately following role performance. Another limitation is that the design did not allow examination of a relationship between particular SP roles and stress symptoms, because anonymity would have been jeopardized if SPs had been asked to state which roles they had performed. Previous studies showed that stress symptoms were more likely to occur with emotionally and psychologically demanding roles. A possible explanation for this finding is that such roles are mainly performed by persons who are prone to stress symptoms. However, it is unlikely that this explanation applied in our study, as more than half of the SPs reported stress symptoms and only a few of them performed emotionally and psychologically complex roles. Moreover, not all SPs perceive a role as equally heavy. Obviously, stress symptoms can occur after performing a less heavy and complex patient role. The anonymous questionnaire also prevented investigation of a possible connection between reported and simulated symptoms, such as headaches due to simulating a patient presenting with headaches.

In conclusion, the large number of reported symptoms gives cause for concern. We recommend that staff should be alert to symptoms of stress in SPs. Future studies should address the causes, prevention and management of this phenomenon. Simulated patients may benefit from post-performance debriefing and an opportunity to share experiences with fellow SPs and with Skillslab staff. It is imperative that we should take measures to prevent the possibility that performing a patient role turns a simulated patient into a real one. 


\section{References}

1. Barrows HS, Abrahamson S. The programmed patients: a technique for appraising student performance in clinical neurology. Journal of Medical Education. 1964;39:802-805.

2. Barrows HS. An overview of the uses of standardized patients for teaching and evaluating clinical skills. Academic Medicine. 1993;68(6):443-451.

3. Rethans JJ. Needs assessment in continuing medical education through standardized patients. J Cont Educ Health Prof. 1998;18:172-178.

4. Stillman PL, Regan MD, Philbin M, Haley HL. Results of a survey on the use of standardized patients to teach and evaluate clinical skills. Academic Medicine. 1990;65(5):288-292.

5. Van der Vleuten CPM, Swanson DB. Assessment of clinical skills with standardized patients: state of the art. Teach Learn Med. 1990;2:58-76.

6. $\mathrm{Vu} \mathrm{NV}$, Barrows HS. Use of standardized patients in clinical assessments: recent developments and measurement findings. Educational Res. 1994;23(3):23-30.

7. Van Dalen J, Bartholomeus P, Kerkhofs E, et al. Teaching and assessing communication skills in Maastricht: the first twenty years. Medical Teacher. May 2001;23(3):245-251.

8. McNaughton N, Tiberius R, Hodges B. Effects of portraying psychologically and emotionally complex standardized patient roles. Teach Learn Med. 1999;11(3):135-141.

9. Woodward CA, Gliva-McConvey G. The effect of simulating on standardized patients. Academic Medicine. 1995;70(5):418-420.

10. Woodward CA. Standardized patients: a fixed role therapy experience in normal individuals. J Constructivist Psychol. 1998;11:33-48.

11. Naftulin DH, Andrew BJ. The effects of patient simulations on actors. J Med Educ. 1975;50:87-89.

12. Wallach PM, Elnick M, Bognar B, et al. Standardized patients' perceptions about their own health care. Teach Learn Med. Fall 2001;13(4):227-231.

13. Gecht MR. What happens to patients who teach? Teach Learn Med. Fall 2000;12(4):171-175.

14. Schmidt AJM. De psychologie van overspanning, Theorie en Praktijk [The psychology of nervous strain, Theory and Practice]. Amsterdam: Uitgeverij Boom; 2000.

15. Van Dalen J, Eekers P, Peerden M. Oordelen over simulatiepatientcontacten [Evaluating SP contacts]. From: Houtkoop E, Pols J, Pollemans M, Scherpbier A, Verwijnen M, Redactie Gezond Onderwijs-3. 's Gravenhage: Haagse Hogeschool; 1994. 


\section{Chapter 7}

\section{The impact of simulation on people who act as simulated patients: A focus group study}




\begin{abstract}
Objective: Previous studies have shown that people who act as simulated patients (SPs) experience negative effects caused by performing patient roles. This study was performed to further explore the impact of simulation and the factors that might affect this impact. The aim was to find ways of preventing negative effects of simulation impacting on our SPs.

Methods: Focus groups interviews were conducted among 35 SPs at Skillslab, University of Maastricht. The discussion was guided by 6 pre-established items. Results: The majority of the SPs appeared to experience negative effects of performing a patient role. The effects were considered as inherent to acting as an SP or due to simulation being a strenuous activity. The impact was shortlived and did not affect SPs' enjoyment of their work. Factors that appeared to affect the impact of performing included: the type of role (whether it is emotionally complex or not); the number of consecutive performances; the length of time between performances; the giving of feedback; the amount of experience, and students.

Discussion: Although the SPs were found to experience negative effects caused by playing patient roles, the frequency and intensity of the negative effects were minor. The focus group discussions led to various suggestions for measures to reduce the impact of simulation.
\end{abstract}




\section{Introduction}

The emphasis in research into simulated patients (SPs) has mostly concerned the validity, reliability, consistency, feasibility and costs of the use of SPs. ${ }^{1-6}$ Only few studies have focused on the impact that performing a patient role may have on the people who act as SPs. ${ }^{7-11}$ These studies show that role playing has negative effects. Most of them, however, concentrate on specific cases that are known to be difficult to portray, such as psychiatric roles. ${ }^{7}$ They are, moreover, qualitative studies, and therefore do not provide conclusive evidence of the frequency of occurrence of negative effects.

Simulated patients have been employed for more than 25 years at Skillslab, University of Maastricht, the Netherlands, which now has a pool of about 100 SPs. Over 4000 individual student-SP encounters take place every academic year. ${ }^{12}$ The vast majority of SP contacts take place in a teaching setting, which includes the provision of feedback. Simulated patient training at Skillslab is based on the "method acting" approach. A recent anonymous quantitative survey among SPs at the Skillslab showed that $73 \%$ of our SPs experience negative effects caused by performing patient roles. ${ }^{11}$ The most frequently reported effects were fatigue, dissatisfaction about the performance, nervousness and anxiety about the performance or the patient role. The mean number of effects experienced by SPs was 4 . The impact of the effects appeared to be mild, with a mean of 2.2 on a 5 -point Likert scale ( $1=$ no effects at all, $5=$ severe effects). The number and degree of impact of the effects were not affected by any of the factors described in previous studies, such as previous experience as an SP or acting style. We were surprised by the large number of SPs who reported experiencing negative effects caused by performing patient roles and by the absence of any correlation between the number and degree of impact of the effects and the factors identified in other studies as affecting such effects. These puzzling findings, coupled with the fact that the earlier studies had been conducted in non-European settings (the USA and Canada), fuelled our interest in further exploration of the impact on our SPs of performing patient roles and of factors that might affect the impact, either positively or negatively. Our aim was to find ways of preventing the occurrence of negative effects on SPs. 


\section{Method}

\section{Subjects}

All SPs who had performed at least 1 patient role in a teaching situation in the period between 1 March 2002 and 1 March 2003 were invited by letter to participate in a focus group interview. It was explained that the purpose of the focus groups was to obtain insight into both the type of impact the performance of a patient role might have and factors that might increase or reduce the impact. Seventy SPs were invited. They were asked to return the letter, indicating whether they were interested in attending a focus group and if so, which of 4 dates and times they preferred. The reply was pre-paid.

\section{Focus group sessions}

The focus group sessions followed the guidelines described by Morgan and Krueger. ${ }^{13}$ Four focus group meetings, lasting 1-1.5 hours, were held at Skillslab. With the consent of the SPs, the meetings were audio- and videotaped for later transcription. It was explained to the SPs that we were interested in all kinds of views and ideas and that there were no correct or incorrect answers. The interview was structured according to 6 pre-established items: types of impact of performing a patient role; duration of the impact; strategies to prevent or reduce negative effects; consequences on enjoyment of working as an SP; factors that increase or reduce impact, and suggestions for improvement. The item on "factors that increase or reduce impact" was subdivided into 7 items, such as type of role, number of performances per day, and breaks between performances. All items were based on findings from previous studies.

\section{Analysis}

The tapes of the 4 focus groups were transcribed and the transcripts reviewed and coded by 1 reviewer (who had served as an assistant in all 4 focus group meetings). The codes served to summarize the transcripts. As a form of triangulation, 1 transcript was reviewed by an independent reviewer, upon which the 2 reviewers were found to agree on $81 \%$ of coded items. Since the content of the 
four focus groups was quite similar, we valued this $81 \%$ as an acceptable level of agreement. Disagreement occurred when a comment could be fitted into more than 1 category. However, as the content of the 4 focus groups was quite similar, we deemed this $81 \%$ to represent an acceptable level of agreement and did not use a second reviewer for the other transcripts. Participating SPs were sent a summary of their respective group meeting and asked to comment on it. The summaries were adjusted on the basis of the SPs' comments to achieve the final version.

\section{Results}

Of the 70 SPs who were invited to participate in a focus group, 48 (69\%) were interested in attending a focus group and $10(14 \%)$ were not. Of those who were not interested, $4(6 \%)$ had previous (work) engagements, $2(3 \%)$ said they did not experience any negative effects of performing a patient role and $4(6 \%)$ did not give a reason. The remaining $12(17 \%)$ SPs did not respond at all. Of the 48 SPs who were prepared to attend a focus group, we selected the first 40 for participation in 1 of 4 groups. Of these 40 SPs, $4(6 \%)$ were unable to attend because of other commitments (e.g. work, SP obligations, hospital appointment) and $3(4 \%)$ failed to attend the focus group. Of the 8 SPs who were initially not selected to participate in a focus group, 2 did eventually attend a focus group session. Four focus groups were held with a total of $35(50 \%)$ participating SPs. Compared with the non-participating SPs, participants had portrayed significantly more patient roles between 1 March 2002 and 1 March 2003 (the mean number of performances was 4.2 for participants and 2.6 for non-participants; $\mathrm{p}=0.012)$. The groups did not differ with regard to age $(\mathrm{p}=0.72)$.

\section{Impact of simulation}

At the beginning of the discussion many SPs said that they did not experience any negative effects caused by performing patient roles. However, as the discussion progressed, the majority of the SPs did report effects, mostly to a minor extent. Most SPs said that they thought experiencing such effects was inherent to working as an SP, as illustrated by the following remark: 
"For example, in breast examination, when there are 8 fellows feeling and prodding, well, you sort of expect it, you think it's normal [to experience some breast pain]."

Only a few SPs reported that they did not experience any effects at all due to role performance. The effects that were mentioned were, in descending order of frequency: exhaustion; dissatisfaction with one's performance; physical complaints due to the performance; continuing to feel or act like the person portrayed, and experiencing real symptoms that interfered with the simulation. Exhaustion was not attributed to the performance as such, but rather to the fact that simulating a patient role combined with giving feedback to students is a strenuous activity. The SPs reported feelings of dissatisfaction with their performance regarding both the role played and the feedback given to students: "I'm not sure if I've given good feedback, especially when I think it didn't go well",

"I don't think its negative [to be dissatisfied with one's performance], for me it is a learning moment"

"It's more like a feeling of frustration, you think, oh what a pity, perhaps I didn't give good feedback. You don't want to put the students at a disadvantage [with regard to other students]"

and

"I feel guilty towards the students [when I'm tired] because I'm no longer able to concentrate properly."

The performance-related physical complaints mentioned by the SPs were: abdominal pain due to abdominal examination as part of the performance; breast pain due to breast examination; headache due to reading without reading glasses during performance; backache due to uncomfortable positions while simulating radicular compression syndrome and worsening of eczema due to performing "bad news" roles. The SPs also said that they sometimes continued to feel and act like the patients they had been simulating, for example:

"I once portrayed a manic patient . . . and after the performance I was talking to a colleague at work and he said, "What's the matter with you?" I was talking like this [makes wild gestures], I mean even though the role is finished, the locomotion persists."

Describing a role in which a miscarriage featured, an SP said:

"It does definitely affect you. . . I must say it affected me in the same way as if I had seen it on $T V$."

Interference by the simulation with real-life complaints experienced by the people who act as SPs was noted in statements such as: 
"I caught myself recently when I saw my doctor for complaints that were similar to the ones in the patient role I had to portray and I really had to be careful not to play that patient role."

The SPs reported that a trigger had to be present for effects to occur and that effects were triggered more easily on some days than on others, depending on how they felt. Most of the effects reported by the SPs lasted only a short time, such as only during the performance or for only a short time afterwards. Physical complaints due to a role sometimes lasted longer, from a few hours after the performance to the rest of the day. Some SPs began to engage in the simulation the day before the performance, by way of preparation. In no way did the occurrence of effects due to performing a patient role appear to affect the SPs' enjoyment of their work as SPs.

\section{Type of role}

The SPs said that they suffered from exhaustion more often after simulating an emotional role than after other roles. However, they also expressed a preference for complex (emotional) roles:

"The heavier the role, the more psychologically complex, the more I enjoy playing it." The SPs said that the type of role had a greater impact than the logistics of the performance. According to the SPs, the closer a role resembled their personal life, the harder it was to portray that role and the greater the impact of the performance. By contrast, the SPs also said that a role became more difficult to play when it was too far removed from their personal experience, because such a role might cause them to feel awkward and dissatisfied. One SP said:

"I think it has to do with resistance, if a role is too far removed from your personal life, you feel a lot of resistance to portraying that role, which causes exhaustion and loss of concentration, but there's also a lot of resistance if a role is too close to your personal life."

\section{Number of performances}

The first contact of the day was described as usually difficult, with subsequent contacts becoming easier as the day went on. The SPs found it hard to maintain the same level of concentration from the first to the last performance. The 
optimal number of performances per day mentioned by SPs varied from 4 to 7 and depended on the type of role and the type of interaction with students. The SPs preferred working half a day to working a full day. More than 7 performances a day, with an extra break, were considered possible, but the SPs indicated that such a long day increased the effects of performing, especially exhaustion: "When you perform a role for a whole day, at the end of it you're worn out." They also stated a preference for having most of the performances scheduled before the main break.

\section{Intervals between performances}

Some SPs indicated that it was important for them to have a break between performances to be able to move out of their roles. They very much appreciated being able to relax and talk with other SPs in order to exchange experiences and put the performance into perspective. Other SPs, however, preferred to continue without breaks in order in role. Some SPs felt uncomfortable if disorganization ensued during short breaks between performances:

"There's a lot of walking in and out of rooms, I mean one SP returns [from a performance] while you're being collected [by the student at the start of the consultation], and it all gets rather chaotic, there's a lot of noise. I have noticed that when something like that happens a lot during a day, it definitely increases my feelings of exhaustion and everything related to that."

\section{Feedback}

Most SPs were more relaxed, if they did not have to give feedback to the student at the end of the consultation, as is the case in examinations. The SPs said they often thought on a dual level during performances when they have to give feedback, because while they were concentrating on the patient role, they also had to monitor the student's reactions in order to be able to give good feedback. It was considered important to maintain concentration, especially during the last performance(s). The SPs found this very tiring:

"It's much easier to just play the role and walk away, like you do in examinations, and not have to think about it, because when you're giving feedback, it's your responsibility to tell the student something useful and that takes extra energy." 
In contrast, other SPs said they found it satisfying to give feedback to the student at the end of a performance because it allowed them to wind up the consultation and put it behind them.

\section{Experience}

The SPs indicated that the first performance of a new role was difficult. After the first time the role would become easier as they came to know how to portray it and how the students would react. Some SPs said they preferred to continue portraying the same role. Other SPs did not like to play a role more than 4 years in a row. One SP observed:

"The first year Mrs. L [name of a patient role] is difficult because you don't really know how the role ... the second year Mrs. L is a piece of cake, the third year Mrs. L same thing, but the fourth year of doing Mrs. L it's getting to be like, I've had it with Mrs. L."

Other SPs said that each performance was different, because each of them took place with a different student. The SPs said that some aspects of working as an SP became easier with experience, such as giving feedback, dual thinking during a performance and moving out of a role. Other aspects remained difficult, however, including uncertainty about one's performance and exhaustion: "every time you give 100\%."

\section{Students}

The SPs indicated that, to a great extent, how they felt after a performance was determined by the student:

"Often it depends on the student, if you don't get much co-operation or response, it is often hard to do a good job"

\section{Discussion}

We found that the majority of the SPs experienced negative effects from performing patient roles. However, most SPs only experienced these negative effects to a mild degree. The SPs regarded negative effects as being inherent to the performance of patient roles and in working as an SP. This probably ex- 
plains why many SPs initially said that they did not experience any impact of simulation and only realized in the course of discussion in the focus groups that they actually did experience some. Of the reported negative effects 4 (exhaustion, dissatisfaction with the performance, physical complaints due to the performance and continuing to feel or act like the character in the patient role) were similar to the effects described in previous studies. ${ }^{7,11}$ Most effects were only of short duration and limited to the duration of the performance. The impact of performing in no way diminished SPs' enjoyment of their work. This is probably attributable to the fact that the SPs experienced negative effects only to a limited degree and the effects are short-lived. Various factors appeared to affect the impact, including the type of role, number of consecutive performances, time between performances, the giving of feedback, the amount of experience, and students. This is contradictory to our findings in a previous study. ${ }^{11}$ Possibly, these factors only have a moderate effect on the impact of performing. Moreover, focus groups may be a more sensitive way of demonstrating a weak correlation than the questionnaire used in our previous study. As method-acting techniques are used in training the SPs and method acting increases the likelihood of effects, we had expected to find that role training increased the likelihood of negative effects. However, this was not among our findings.

Our results may be regarded by some as relevant only to our unique setting in Maastricht. However, we believe the results of this study are transferable to SPs in other educational settings, although they are, of course, less valid when it comes to use of SP in high-stake examinations.

Figure 1 provides an overview of measures that might reduce the impact of portraying a patient role. As the SPs see effects on them as being inherent to performing patient roles, any efforts to reduce the impact of such effects should focus on the variables that increase or reduce the likelihood of effects rather than on the performance itself. The type of role has a greater impact than the logistics involved, such as the number of performances and length of time between them. Emotional roles are more likely to give rise to negative effects than other roles. People who act as SPs find it difficult to portray a role that is too close to or too far removed from their personal life. Therefore, it is important that SPs are able to turn down roles they do not feel comfortable with. A reduction in the number of performances per day to a maximum of 7 could decrease the impact of performing. Having (short) breaks between performances decreases the probability of effects in most SPs, but increases it in others. This seems to make it difficult to reduce the likelihood of effects by altering the 
intervals between performances. We could, however, attempt to improve the scheduling of breaks. More frequent or improved feedback training might increase SPs' confidence in their feedback skills and thus decrease the impact of the performance. The remaining variables affecting the probability of effects (i.e. experience and students) are probably difficult to alter. As SPs do not like portraying a particular patient role for more than 4 years in a row, perhaps patient roles could be adjusted or reallocated more frequently, and definitely after 4 years. These are relatively small adaptations that are easy to achieve. This appears to be a small price to pay for reducing the impact of simulating on the people who act as simulated patients.

\section{Figure 1. Overview of measures to reduce the impact of portraying a patient role}

- Maximum of 7 performances a day, including a 30 minute break after a few performances.

- Highest number of performances to be scheduled before the break.

- More short breaks to be scheduled between each performance.

- A standby SP who can stand in when other SPs need a break.

- Encourage SPs to turn down roles they do not feel comfortable with.

- Change or adjust a patient role after four years.

- More frequent or improved feedback training to make SPs more confident in giving feedback to students.

\section{References}

1. Barrows HS, Abrahamson S. The programmed patients: a technique for appraising student performance in clinical neurology. Journal of Medical Education. 1964;39:802-805.

2. Barrows HS. An overview of the uses of standardized patients for teaching and evaluating clinical skills. Academic Medicine. 1993;68(6):443-451.

3. Stillman PL, Regan MD, Philbin M, Haley HL. Results of a survey on the use of standardized patients to teach and evaluate clinical skills. Academic Medicine. 1990;65(5):288-292.

4. Van der Vleuten CPM, Swanson DB. Assessment of clinical skills with standardized patients: state of the art. Teach Learn Med. 1990;2:58-76.

5. $\mathrm{Vu} \mathrm{NV}$, Barrows HS. Use of standardized patients in clinical assessments: recent developments and measurement findings. Educational Res. 1994;23(3):23-30.

6. Rethans JJ. Needs assessment in continuing medical education through standardized patients. J Cont Educ Health Prof. 1998;18:172-178.

7. McNaughton N, Tiberius R, Hodges B. Effects of portraying psychologically and emotionally complex standardized patient roles. Teach Learn Med. 1999;11(3):135-141.

8. Woodward CA, Gliva-McConvey G. The effect of simulating on standardized patients. Academic Medicine. 1995;70(5):418-420. 
9. Woodward CA. Standardized patients: a fixed role therapy experience in normal individuals. J Constructivist Psychol. 1998;11:33-48.

10. Naftulin DH, Andrew BJ. The effects of patient simulations on actors. J Med Educ. 1975;50:87-89.

11. Bokken L, van Dalen J, Rethans JJ. Performance-related stress symptoms in simulated patients. Med Educ. Oct 2004;38(10):1089-1094.

12. Van Dalen J, Bartholomeus P, Kerkhofs E, et al. Teaching and assessing communication skills in Maastricht: the first twenty years. Medical Teacher. May 2001;23(3):245-251.

13. Morgan DL, Krueger RA. The focus group kit. Vol 1-6. London, New Delhi: Sage Publications; 1998. 


\section{Chapter}

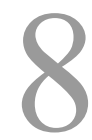

\section{Strengths and weaknesses of simulated and real patients in the teaching of skills to medical students: A review}

L. Bokken, JJ. Rethans, A. Scherpbier, C. van der Vleuten

Simulation in Health Care 2008;3(3):161-9 


\begin{abstract}
The aim of this review was to identify the strengths and weaknesses of the roles of real and simulated patients (SPs) in undergraduate medical education. The literature was reviewed in relation to four patient roles: real patients as educational "resource" (passive role), real patients as teachers (active role) and SPs as educational resource and teachers.

Each of the four patient roles was found to have specific advantages and disadvantages from the perspectives of teachers, students and patients. For example, advantages of real patients as educational resource were patientcentered learning and high patient satisfaction. Disadvantages were their limited availability and the variability in learning experiences among students. Despite the considerable amount of literature we found, many gaps in knowledge about patient roles in medical education remain and should be addressed by future studies.
\end{abstract}




\section{Introduction}

Patient contacts have always been an integral part of undergraduate medical education. Early patient contacts have been recommended by the Association of American Medical Colleges and the UK General Medical Council. ${ }^{1}$ A recent review identified several positive effects of early patient contacts: they increased student motivation, taught students "things that cannot be learned from books", increased students' confidence to interview patients and eased the transition from preclinical to clinical training. ${ }^{2,3}$ Furthermore, patient contacts enhanced students' feelings of empathy and responsibility towards patients and fostered their professional identity. ${ }^{2-4}$ Patient contacts also help students build integrated skills for clinical reasoning, communication, history taking and physical examination..$^{1-3,5}$ In his review, Aspegren found that experiential methods such as patient contacts with immediate feedback from teachers were more instructive in the teaching of communication skills to medical students than traditional methods such as lectures. ${ }^{6}$

Patient contacts also help students develop "illness scripts". Illness scripts are cognitive structures containing features of prototypical or real patients together with clinically relevant information about diseases. ${ }^{7}$ Patient contacts may supply content for illness scripts and thus help students develop their ability to handle clinical problems.

Patient contacts in medical education may involve real patients or simulated patients (SP). The role of patients in education may be passive, i.e. limited to presentation of complaints and symptoms, or it may be active as when the patient actually takes on the role of the teacher. In situations, such as assessments, where repeated identical role performance is required, SPs are also referred to as standardized patients.

Although the importance of patient contacts is generally recognized, we know little about the various roles of both real patients and SPs in undergraduate medical education and their value from the perspectives of students, teachers and patients. ${ }^{1}$

We reviewed the literature to identify the different roles of real patients and SPs in undergraduate medical education and the benefits and limitations of these roles. We were particularly interested in how the roles relate to each other. In this review we did not consider the role of patients in assessment, because we were specifically interested in the contribution of patients to teaching. 


\section{Methods}

We searched the Pubmed and Eric databases using the search terms: (real or active) patients, patient partners or instructors, patient simulation, standardized or simulated patients and undergraduate medical education or teaching. The databases were searched from their onset throughout March 2006. Additionally, we searched the references of articles to identify relevant papers that we might have missed. Papers were selected for inclusion in the review by one of the authors (LB). Articles were selected on the basis of the abstract or the full paper if the abstract was absent or did not provide sufficient information. We included all retrieved research papers and descriptive papers published in English on the subject of real patients or SPs involved in undergraduate medical education. Even though real patients and SPs are also used in graduate and postgraduate medical education, we concentrated on undergraduate medical education to define the sphere of the review. Although assessment is an important part of education, we did not include papers dealing with assessment.

We categorized the selected articles on the basis of four types of patient roles derived from the literature: real patients as an educational resource (passive role); real patients as teachers (active role); SPs as an educational resource; and SPs as teachers. The patient role was categorized as active when real patients or SPs were actively involved in teaching. This meant that the patient had the teacher's role, preferably in the absence of other teachers.

The aim of this review was to identify strengths and limitations of the four types of patient roles from the perspectives of students, teachers and patients.

\section{Real patients as an educational resource}

Patients as educational resource are used in many different educational settings, for example in bedside teaching. Generally, this is considered a valuable method for teaching skills, such as physical examination, history taking, communication and procedural skills. ${ }^{8-10}$ The opportunity for students to observe skill performance by experienced clinicians and the fact that the patient is at the centre of teaching are perceived as beneficial. ${ }^{10}$

We found two comparative studies on the effectiveness of bedside teaching in the teaching of skills, in terms of student scores on an objective structured clinical examination (OSCE) ${ }^{11,12}$ These studies are summarized in Table 1. 
Table 1. Comparative studies on the effectiveness of real patients as an educational resource (Bedside teaching)

\begin{tabular}{|c|c|c|c|c|c|}
\hline Reference & Participants & Control & Intervention & Outcome & Conclusion \\
\hline $\begin{array}{l}\text { Cooper } \\
(1983)^{11}\end{array}$ & $\begin{array}{l}64 \text { fourth-year } \\
\text { medical } \\
\text { students, } 32 \text { in } \\
\text { control group, } \\
32 \text { in } \\
\text { intervention } \\
\text { group. }\end{array}$ & $\begin{array}{l}1 \text { week, } \\
\text { morning: } \\
\text { demonstration } \\
\text { of videotaped } \\
\text { GI physical } \\
\text { examination } \\
\text { and practice } \\
\text { on healthy } \\
\text { subjects, } \\
\text { supervised by } \\
\text { teacher. } \\
\text { Afternoon: } \\
\text { teaching in } \\
\text { history taking. }\end{array}$ & $\begin{array}{l}1 \text { week, } \\
\text { morning: like } \\
\text { the control } \\
\text { group. } \\
\text { Afternoon: } \\
\text { bedside } \\
\text { teaching } \\
\text { sessions on GI } \\
\text { physical } \\
\text { examination } \\
\text { techniques } \\
\text { (hospitalized } \\
\text { patients). }\end{array}$ & $\begin{array}{l}\text { Assessment } \\
\text { on GI physical } \\
\text { examination } \\
\text { skills (OSCE), } \\
\text { evaluators } \\
\text { blinded. } \\
\text { Intervention } \\
\text { group } \\
\text { performed } \\
\text { better. }\end{array}$ & $\begin{array}{l}\text { Bedside } \\
\text { teaching in } \\
\text { addition to } \\
\text { instruction } \\
\text { and practice } \\
\text { sessions is } \\
\text { more effective } \\
\text { than instruc- } \\
\text { tion and } \\
\text { practice } \\
\text { sessions alone } \\
\text { in the teaching } \\
\text { of GI physical } \\
\text { examination. }\end{array}$ \\
\hline Hill $(1991)^{12}$ & $\begin{array}{l}66 \text { third-year } \\
\text { medical } \\
\text { students. }\end{array}$ & $\begin{array}{l}11 \text { 2-hour } \\
\text { bedside } \\
\text { teaching } \\
\text { sessions on } \\
\text { physical } \\
\text { examination } \\
\text { and history } \\
\text { taking skills, } \\
\text { cross-over to } \\
\text { intervention } \\
\text { group after } \\
\text { assessment. }\end{array}$ & $\begin{array}{l}112 \text {-hour } \\
\text { structured } \\
\text { clinical } \\
\text { teaching } \\
\text { sessions } \\
\text { (lecture and } \\
\text { small group } \\
\text { teaching) on } \\
\text { physical } \\
\text { examination } \\
\text { and history } \\
\text { taking skills, } \\
\text { cross-over to } \\
\text { control group } \\
\text { after assess- } \\
\text { ment. }\end{array}$ & $\begin{array}{l}2 \text { assessments } \\
\text { on physical } \\
\text { examination } \\
\text { and history } \\
\text { taking skills } \\
\text { (MCQ and } \\
\text { OSCE), } 1 \text { at } \\
\text { the end of the } \\
\text { first series of } \\
\text { sessions and } 1 \\
\text { after cross- } \\
\text { over. No } \\
\text { difference was } \\
\text { found. }\end{array}$ & $\begin{array}{l}\text { Traditional } \\
\text { bedside } \\
\text { teaching is as } \\
\text { effective as } \\
\text { structured } \\
\text { clinical } \\
\text { teaching in the } \\
\text { teaching of } \\
\text { physical } \\
\text { examination } \\
\text { and history } \\
\text { taking skills. }\end{array}$ \\
\hline
\end{tabular}

GI: Gastro-intestinal; MCQ: Multiple choice questions; OSCE: Objective structured clinical examination

Bedside teaching was found to be effective in comparison with instruction and practice sessions or structured clinical teaching.

Two studies reported on students valuing bedside teaching and considering it an effective educational method. ${ }^{13,14}$ A large majority of students considered bedside teaching an effective way to develop physical examination, history 
taking and communication skills. ${ }^{14}$ Particularly feedback at the bedside was perceived as high-quality teaching by students. ${ }^{13}$

Most studies show that patients feel very positive about their participation in bedside teaching. ${ }^{14-19}$ Nair et al. found that $77 \%$ of patients enjoyed bedside teaching, with $84 \%$ saying they would recommend it to others. ${ }^{14}$

One of the limitations of patients as an educational resource is concern among students and faculty about patients' comfort $^{18}$ and concern about bedside teaching being stressful to patients. ${ }^{20}$ However, no physiological signs of stress (changes in heart rate, blood pressure or plasma norepinephrine levels) were found in patients during bedside teaching. ${ }^{16}$ Furthermore, patients reported bedside teaching not being stressful. ${ }^{15-17}$ Many even found bedside teaching a reassuring experience which helped them understand their illness. Patient satisfaction with bedside teaching may be further improved, for instance by paying more attention to consent and confidentiality. ${ }^{17,19}$

Another limitation of bedside teaching is variability due to differences between individual clinical teachers and the uncertain availability of suitable patients. ${ }^{14}$, ${ }^{21-24}$ Patients may be too ill or their condition too complicated to participate in bedside teaching. In addition, bedside teaching is affected by reductions in inpatient beds, shorter hospital stays, and reductions in the number of faculty teachers, ${ }^{21,24,25}$ whilst increasing numbers of students, such as medical students, nursing students and physician assistants in training, require patient contacts. ${ }^{22}$ These limitations might have contributed to the decline in bedside teaching from $75 \%$ of clinical teaching in the 1960 s to an estimated less than $16 \%$ today. ${ }^{26}$ In a study using direct observation, the median time spent at the bedside during teaching rounds was much less compared to the time spent in the classroom (2.5 minutes and 69 minutes respectively). ${ }^{27}$ Waterbury suggested that SPs might compensate for the limitations of bedside teaching. ${ }^{24}$

In summary, the use of patients as an educational resource in bedside teaching is considered valuable and effective in the teaching of skills to undergraduate medical students, in comparison to other teaching methods such as structured clinical teaching as well as from the perceptions of students. Although students and teachers worry about patients' comfort, patients were reported to enjoy bedside teaching. There are limitations of bedside teaching, such as the unpredictable availability of suitable patients and the high variability in learning experiences. 

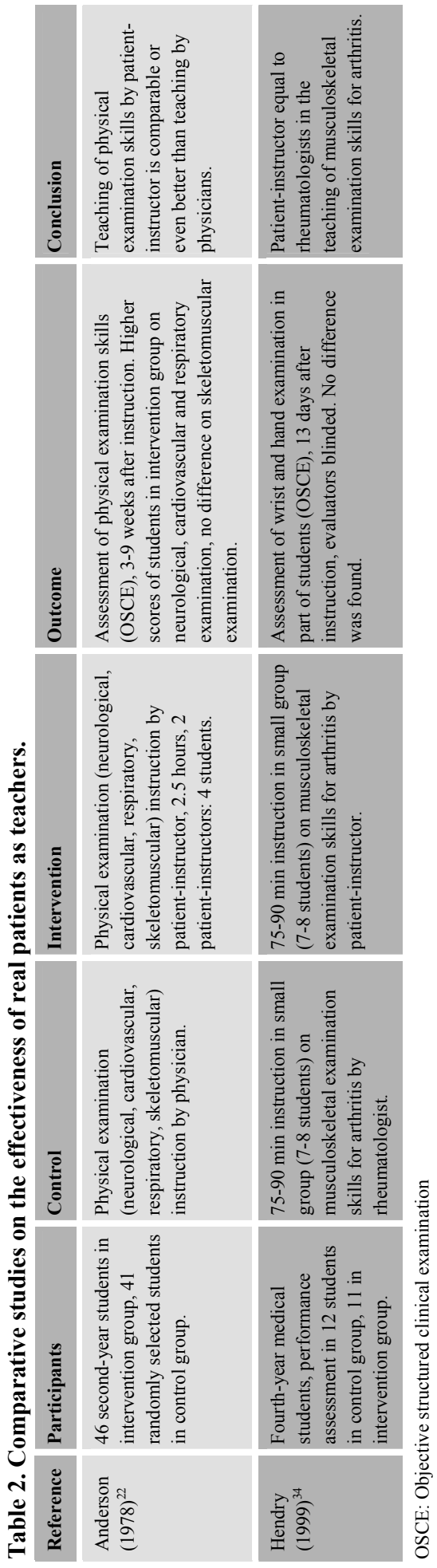
Real patients are increasingly fulfilling active teaching roles in undergraduate medical education. ${ }^{28}$ In most studies, patient-instructors are used to actively teach skills such as physical examination and communication skills..$^{22,29-36}$ They have also been used in the teaching of factors and circumstances affecting health and health care. ${ }^{37}$

We found two comparative studies on the effectiveness of patient-instructors in the teaching of skills, in terms of student scores on an OSCE. ${ }^{22,34}$ In these studies, summarized in Table 2, patient-instructors were compared to physicians in the teaching of physical examination skills to students. Patient-instructors were found to be at least as effective as physicians. Studies comparing the teaching by patient-instructors to other teaching methods have not been found.

Studies on patients' views show that patients value their active teaching role. . $^{2,35,37,38}$ They regard themselves as important contributors to medical education as experts and exemplars of their particular medical condition and as facilitators of the development of students' professional skills and attitudes. ${ }^{38}$ Plymale et al. found that cancer survivors enjoyed participating in a clinical teaching course, were willing to participate in future courses and perceived their role as an important and effective part of the course. ${ }^{35}$ Patients appreciate the opportunity to talk and learn about their condition. ${ }^{28,38}$ Furthermore, contributing to the training of future doctors gives them a sense of empowerment. ${ }^{28,35}$ Evaluations of students with regard to teaching by patient-instructors are positive. ${ }^{22,28,31-35}$ Instruction on joint examination by patients with arthritis was rated as beneficial by $93 \%$ of the students. ${ }^{33}$ Students valued the direct feedback on their skill performance provided by patient-instructors as it helped them in identifying their strengths and weaknesses. ${ }^{28,31}$ Furthermore, teaching by patient-instructors increased students' confidence in physical examination skills and reduced anxiety. ${ }^{22,28}$ Stillman et al. suggested patient-instructors enhance the integration of technical and interpersonal skills. ${ }^{31}$ They also suggested patient-instructors are better able than teachers to highlight the patient's perspective and give feedback on subjective aspects of physical examination. ${ }^{31}$ Therefore their expertise may complement that of teachers. ${ }^{37}$

There are limitations too, however. Being patient-instructor demands a great deal from patients. Some patients found it tiring, especially when they were ill. ${ }^{32}$ Stillman et al. developed criteria for patient-instructors: their physical findings must be evident, their physical condition must allow repeated examination, and they should be able and willing to learn about their disease. ${ }^{31}$ Another limitation 
is that of costs in terms of faculty time spent on training and maintaining the skills of patient-instructors. ${ }^{32}$ However, this investment may be worthwhile since trained patient-instructors are 50 to 75 per cent less expensive than faculty teachers. ${ }^{31}$ In one study, the use of real patients (as opposed to SPs) reduced training time since real patients required no training in simulating physical findings. ${ }^{36}$

In summary, although there are few comparative studies on the effectiveness of patient-instructors, patients-instructors are suggested to be equally effective as physicians in the teaching of specific physical examination skills to undergraduate medical students. Students value being taught by patient-instructors. Skills can be practiced and physical abnormalities can be found in a low anxiety setting. In addition to the teaching of skills, patient-instructors are trained to give constructive feedback to the student. This is a considerable advantage of patient-instructors as opposed to patients. An active role in the teaching of students is also enjoyed by patients. A limitation of this teaching method for teachers is the extensive training time needed. In addition, only a select group of patients, for example those with stable physical findings who are not too ill, can be trained to teach.

\section{SPs as educational resource}

SPs are individuals trained to perform the role of a patient realistically and consistently. SPs were introduced by Barrows in 1964 and they have been extensively used in medical education ever since. ${ }^{39-41}$ Studies have suggested SPs being a valuable complement to real patients. ${ }^{21,23,42}$ We found only one study directly comparing the effectiveness of SPs as educational resource to real patients in the same role. ${ }^{21}$ This study, summarized in Table 3, found skills teaching with SPs is as effective as skills teaching with inpatients, in terms of student scores on an OSCE. Student evaluations showed a non-significant trend towards greater satisfaction with the SP encounters, especially with the feedback provided to the students. ${ }^{21}$ Other advantages of SPs over real patients, portrayed by Barrows, are that they are available, safe, adaptable to students' learning needs and minimize variability in learning experiences between students. ${ }^{41}$ SP encounters can be arranged at any time and in any setting, unlike encounters with real patients whose presence in hospital or general practice is difficult to control. SPs offer safety, because students need not feel embarrassed if their interviewing and physical examination skills are imperfect. Mistakes are 
Table 3. Comparative study on the effectiveness of SPs as an educational resource

\begin{tabular}{|c|c|c|c|c|c|}
\hline Reference & Participants & Control & Intervention & Outcome & Conclusion \\
\hline $\begin{array}{l}\text { McGraw } \\
(1999)^{21}\end{array}$ & $\begin{array}{l}75 \text { first-year } \\
\text { medical } \\
\text { students, } 20 \\
\text { randomly } \\
\text { selected } \\
\text { students in } \\
\text { intervention } \\
\text { group, } 55 \text { in } \\
\text { control group. }\end{array}$ & $\begin{array}{l}5 \text { inpatient } \\
\text { contacts (+ } 1 \\
\text { SP contact } \\
\text { and } 1 \\
\text { videotaped } \\
\text { encounter), } 2 \\
\text { students per } \\
\text { patient, } 90 \\
\text { min, history } \\
\text { and physical } \\
\text { examination, } \\
\text { feedback from } \\
\text { tutor and } \\
\text { peers. }\end{array}$ & $\begin{array}{l}7 \text { SP contacts, } \\
2 \text { students per } \\
\text { SP, } 60 \\
\text { minutes, } \\
\text { history and } \\
\text { physical } \\
\text { examination, } \\
\text { feedback from } \\
\text { tutor, peers } \\
\text { and SP. }\end{array}$ & $\begin{array}{l}\text { Assessment of } \\
\text { clinical skills } \\
\text { (OSCE). No } \\
\text { difference was } \\
\text { found. }\end{array}$ & $\begin{array}{l}\text { SP contacts } \\
\text { are equally } \\
\text { effective as } \\
\text { inpatient } \\
\text { contacts in } \\
\text { acquiring } \\
\text { clinical skills. }\end{array}$ \\
\hline
\end{tabular}

OSCE: Objective structured clinical examination

acceptable, even in difficult and sensitive situations, such as the pelvic examination or breaking bad news. SP performance can be adapted to specific educational purposes. For example, an SP encounter can be interrupted to discuss the case or give tips to the student and SPs can be examined repeatedly to perfect students' examination techniques. Also, the difficulty of the patient encounter can be adapted to match a student's competence level. Variability in learning can be minimized by allowing each student to question and examine an SP who is simulating the same medical problem in the same way. SPs can simulate a wide range of physical findings, for example wheezing, abdominal tenderness, muscle weakness and tremor. ${ }^{41}$ Furthermore, SPs are easy to train and can contribute to training a variety of skills. ${ }^{23,40,41}$ People of various age groups may be SPs. For example, adolescent girls have been reported to highly value their performance in a patient role. $^{43}$ SPs reported being strongly motivated and greatly enjoying their encounters with students. ${ }^{44}$

Students enjoyed workshops with SPs in which they learned about basic interviewing skills and interview challenges, such as breaking bad news. ${ }^{42}$ They considered the workshops effective and valued the realistic learning with immediate feedback from the SP, without having to worry about harming real patients.

One study suggested that students prefer real patients to SPs because of their authenticity. ${ }^{45}$ This might be a limitation of SPs. However, a recent systematic review on incognito SPs visiting practicing physicians (who do not know when 
they are visited by SPs) showed SPs were detected in less than $15 \%$ of the cases. ${ }^{46}$ Detection rates of even less than $1 \%$ were found. These findings suggest SPs can be very authentic.

As with the real patients, SPs may also experience negative effects of their role. In a recent study $73 \%$ of SPs reported negative effects of patient role performance, for example fatigue and dissatisfaction with their performance. ${ }^{47}$ However, a subsequent study showed that the frequency and intensity of these negative effects were minor. ${ }^{48}$

In summary, in addition to real patients SPs are considered valuable educational instruments. SPs generally enjoy their work despite some minor negative effects of performing a patient role. SPs have considerable advantages compared to real patients used as an educational resource, including their availability and flexibility. Also, SPs can be trained to provide students with feedback, which is valued by the students.

SPs as teachers: SP-teachers

With additional training SPs can undertake active teaching roles. To avoid confusion with real patients in the patient-instructor role, we will use the term SP-teacher to refer to SPs who teach.

Several comparative studies have assessed the effectiveness of SP-teachers in the teaching of skills, in terms of student scores on an OSCE. These studies are summarized in Table 4. Most studies show SP-teachers are effective in the teaching of skills to medical students. Students who were taught skills, such as communication and pelvic examination skills, by SP-teachers had similar or even better OSCE scores compared to those taught by physicians or faculty teachers. Furthermore, students taught by SP-teachers performed at least equally as those taught by traditional teaching methods, such as lectures, role playing or instruction on (plastic) models, in the teaching of skills. Three studies showed retention of skills over a longer period of time in students taught by SPteachers. ${ }^{49-51}$ Some comparative studies also reported views of students on the instruction they had. ${ }^{52-54}$ All of these studies showed students preferred instruction by SP-teachers to teaching by physicians or to traditional teaching methods such as role playing.

Several studies primarily focused on student evaluations with regard to instruction by SP-teachers. Most studies found students highly value the teaching of skills, particularly pelvic examination skills, by SPs. ${ }^{55-60}$ Students felt calmer, 
more secure and more confident about performing a pelvic examination after instruction by SP-teachers. ${ }^{55,58,60}$ Students also valued the ability of SP-teachers to provide feedback. ${ }^{55,59}$ Levenkron et al. reported students considered direct feedback from SP-teachers on behavioral counseling skills more effective than feedback from a faculty member on a videotaped SP encounter. ${ }^{61}$ Two studies suggested SP-teachers are better able to give feedback on certain parts of the students' pelvic examination, for example on the gentleness of the examination and on palpation of the ovaries, as opposed to traditional teachers. ${ }^{56,57}$

A limitation of the use of SP-teachers is the time and effort required to train SPs in their role of both patient and teacher. Davidson et al., however, reported considerable cost savings due to teaching by SP-teachers. ${ }^{62}$ Although most studies reported students preferring instruction by SP-teachers to teaching by physicians or role playing, two did not. ${ }^{63,64}$ In these studies, student evaluations regarding a didactic lecture on appendicitis or peripheral vascular disease were compared to student evaluations regarding an instructional SP interaction on the same subject. Overall, students preferred the didactic lecture, although they evaluated the SP interaction more favorably when it was preceded by the lecture. . $^{63,64}$

Only few studies, summarized in Table 5, have compared real patients to SPs in the teaching of skills to medical students. Most studies found real patient encounters are comparable to SP encounters. One study, however, found that communication skills training by real patients led to a stronger focus on the psychosocial content of the medical interview, whereas training by SPs resulted in significantly better verbal skills, such as summarization. ${ }^{45}$ On the basis of these findings, it was suggested to use SPs in the early stages of communication skills training and real patients in later stages when students have mastered the basic interviewing skills.

In summary: SP-teachers are effective in teaching communication skills and physical examination skills such as pelvic examination skills. SP-teachers are at least as effective as traditional teaching methods such as didactic lectures, use of plastic models and teaching by physicians or faculty teachers. In general, students value the teaching by SP-teachers and regard it more effective than traditional teaching methods. However, in two studies students valued didactic lectures more than the teaching by SPs. The literature suggests real patients and SPs are useful for teaching different parts of communication skills.

The advantages and disadvantages of the different roles of patients in teaching skills to medical students are summarized in Table 6. 
Table 4. Comparative studies on the effectiveness of SPs as teachers

Study comparing SP teachers to no instruction

\begin{tabular}{|c|c|c|c|c|c|}
\hline Reference & Participants & Control & Intervention & Outcome & Conclusion \\
\hline $\begin{array}{l}\text { Colletti } \\
(2001)^{65}\end{array}$ & $\begin{array}{l}21 \text { randomly } \\
\text { assigned junior } \\
\text { medical } \\
\text { students in } \\
\text { intervention } \\
\text { group, } 17 \text { in } \\
\text { control group. }\end{array}$ & $\begin{array}{l}\text { No instruction } \\
\text { on breaking bad } \\
\text { news. }\end{array}$ & $\begin{array}{l}\text { Practice session } \\
\text { on breaking bad } \\
\text { news with SP- } \\
\text { teacher. }\end{array}$ & $\begin{array}{l}\text { Assessment of } \\
\text { breaking bad } \\
\text { news skills } \\
\text { (OSCE), } \\
\text { evaluators } \\
\text { blinded. Better } \\
\text { performance of } \\
\text { students in } \\
\text { intervention } \\
\text { group. }\end{array}$ & $\begin{array}{l}\text { SP-teachers are } \\
\text { effective in } \\
\text { teaching } \\
\text { students to } \\
\text { break bad } \\
\text { news. }\end{array}$ \\
\hline
\end{tabular}

Studies comparing SP teachers to physicians

\begin{tabular}{|c|c|c|c|c|c|}
\hline Reference & Participants & Control & Intervention & Outcome & Conclusion \\
\hline $\begin{array}{l}\text { Vannatta } \\
(1996)^{66}\end{array}$ & $\begin{array}{l}154 \text { first-year } \\
\text { students, } 43 \\
\text { students } \\
\text { randomly } \\
\text { assigned to } \\
\text { intervention } \\
\text { group, } 41 \text { and } \\
36 \text { students to } \\
\text { control groups. }\end{array}$ & $\begin{array}{l}\text { Group 1: } 8 \\
\text { hours, } \\
\text { instruction by } \\
\text { faculty, } \\
\text { practicing } \\
\text { interviewing } \\
\text { skills with SPs, } \\
\text { feedback from } \\
\text { faculty and } \\
\text { peers. } \\
\text { Group 2: } 8 \\
\text { hours, role play } \\
\text { with feedback } \\
\text { from faculty } \\
\text { and peers. }\end{array}$ & $\begin{array}{l}8 \text { hours, } \\
\text { instruction by } \\
\text { faculty, } \\
\text { practicing } \\
\text { interviewing } \\
\text { skills with SPs, } \\
\text { feedback from } \\
\text { SPs and peers. }\end{array}$ & $\begin{array}{l}\text { Assessment of } \\
\text { interviewing } \\
\text { skills (OSCE) } \\
\text { before and after } \\
\text { instruction, } \\
\text { evaluators } \\
\text { blinded. Higher } \\
\text { scores on open- } \\
\text { ended questions } \\
\text { and empathy in } \\
\text { intervention } \\
\text { group, no } \\
\text { difference on } \\
\text { other items. }\end{array}$ & $\begin{array}{l}\text { SPs are at least } \\
\text { as effective as } \\
\text { faculty in } \\
\text { teaching } \\
\text { interviewing } \\
\text { skills to } \\
\text { medical } \\
\text { students. }\end{array}$ \\
\hline $\begin{array}{l}\text { Davidson } \\
(2001)^{62}\end{array}$ & $\begin{array}{l}83 \text { first-year } \\
\text { students in } \\
\text { intervention } \\
\text { group, } 118 \\
\text { second-year } \\
\text { students in } \\
\text { control group. }\end{array}$ & $\begin{array}{l}\text { Instruction on } \\
\text { physical } \\
\text { examination by } \\
\text { faculty and } \\
\text { practice on } \\
\text { each other and } \\
\text { inpatients } \\
\text { supervised by } \\
\text { faculty. }\end{array}$ & $\begin{array}{l}\text { Introduction on } \\
\text { physical } \\
\text { examination by } \\
\text { faculty and } \\
\text { practice on } \\
\text { each other } \\
\text { supervised by } \\
\text { SPs. }\end{array}$ & & $\begin{array}{l}\text { SPs can } \\
\text { effectively } \\
\text { teach physical } \\
\text { examination to } \\
\text { medical } \\
\text { students. }\end{array}$ \\
\hline
\end{tabular}




\begin{tabular}{|c|c|c|c|c|c|}
\hline Reference & Participants & Control & Intervention & Outcome & Conclusion \\
\hline $\begin{array}{l}\text { Holzman } \\
(1977)^{67}\end{array}$ & $\begin{array}{l}38 \text { second-year } \\
\text { students, } 14 \\
\text { and } 14 \text { students } \\
\text { randomly } \\
\text { assigned to } \\
\text { experimental } \\
\text { groups, } 10 \text { to } \\
\text { control group. }\end{array}$ & $\begin{array}{l}\text { Instruction on } \\
\text { pelvic } \\
\text { examination by } \\
\text { gynecologist, } \\
\text { practice on } \\
\text { patient } \\
\text { supervised by } \\
\text { gynecologist. }\end{array}$ & $\begin{array}{l}\text { Group 1: } \\
\text { instruction by } \\
\text { physician and } \\
\text { practice on SP, } \\
\text { supervised by } \\
\text { SP. } \\
\text { Group 2: } \\
\text { instruction by } \\
\text { and practice on } \\
\text { SP. }\end{array}$ & $\begin{array}{l}\text { Assessment of } \\
\text { pelvic } \\
\text { examination } \\
\text { skills (OSCE, } \\
\text { interpersonal } \\
\text { and technical } \\
\text { skills), } \\
\text { evaluators } \\
\text { blinded. Higher } \\
\text { scores of } \\
\text { students trained } \\
\text { by SPs, in both } \\
\text { intervention } \\
\text { groups. }\end{array}$ & $\begin{array}{l}\text { SPs are } \\
\text { effective in the } \\
\text { teaching of } \\
\text { pelvic } \\
\text { examination } \\
\text { skills to } \\
\text { medical } \\
\text { students. }\end{array}$ \\
\hline $\begin{array}{l}\text { Kleinman } \\
(1996)^{51}\end{array}$ & $\begin{array}{l}33 \text { second-year } \\
\text { students of one } \\
\text { medical school } \\
\text { in control } \\
\text { group, } 48 \text { third- } \\
\text { year students of } \\
\text { another medical } \\
\text { school in } \\
\text { intervention } \\
\text { group. }\end{array}$ & $\begin{array}{l}\text { Instruction on } \\
\text { pelvic } \\
\text { examination by } \\
\text { physician, } \\
\text { practice on SP } \\
\text { supervised by } \\
\text { physician, in } \\
\text { pre-clinical } \\
\text { course. }\end{array}$ & $\begin{array}{l}\text { Instruction by } \\
\text { SP and practice } \\
\text { on SP in pre- } \\
\text { clinical course. }\end{array}$ & $\begin{array}{l}\text { Assessment of } \\
\text { pelvic exami- } \\
\text { nation skills } \\
\text { (OSCE inter- } \\
\text { personal and } \\
\text { technical skills) } \\
\text { after gynecol- } \\
\text { ogy clerkship. } \\
\text { Higher scores } \\
\text { on interper- } \\
\text { sonal skills in } \\
\text { intervention } \\
\text { group, no } \\
\text { difference on } \\
\text { technical skills. }\end{array}$ & $\begin{array}{l}\text { Effects of SPs } \\
\text { teaching } \\
\text { interpersonal } \\
\text { skills related to } \\
\text { pelvic } \\
\text { examination } \\
\text { persist after } \\
\text { exposure of } \\
\text { students to } \\
\text { clinical } \\
\text { clerkship. }\end{array}$ \\
\hline $\begin{array}{l}\text { Livingstone } \\
(1978, \\
1980)^{50,52}\end{array}$ & $\begin{array}{l}100 \text { second- } \\
\text { year students, } \\
50 \text { randomly } \\
\text { selected } \\
\text { students in } \\
\text { intervention } \\
\text { group, } 50 \text { in } \\
\text { control group. }\end{array}$ & $\begin{array}{l}\text { Instruction on } \\
\text { gynecologic } \\
\text { history and } \\
\text { pelvic } \\
\text { examination } \\
\text { (lecture and } \\
\text { video), } \\
\text { practical } \\
\text { instruction by } \\
\text { physician (on } \\
\text { real patient). }\end{array}$ & $\begin{array}{l}\text { Instruction on } \\
\text { gynecologic } \\
\text { history and } \\
\text { pelvic } \\
\text { examination } \\
\text { (lecture and } \\
\text { video), } \\
\text { practical } \\
\text { instruction by } \\
\text { SPs. }\end{array}$ & $\begin{array}{l}\text { Assessment of } \\
\text { pelvic exami- } \\
\text { nation skills } \\
\text { (OSCE, } \\
\text { communication } \\
\text { and technical } \\
\text { skills) } \\
\text { immediately } \\
\text { after and } 1 \text { year } \\
\text { after instruc- } \\
\text { tion, evaluators } \\
\text { blinded. Better } \\
\text { performance of } \\
\text { students taught } \\
\text { by SPs. }\end{array}$ & $\begin{array}{l}\text { SPs are more } \\
\text { effective in } \\
\text { teaching pelvic } \\
\text { examination } \\
\text { compared to } \\
\text { physicians } \\
\text { using real } \\
\text { patients, even } \\
\text { at } 1 \text { year after } \\
\text { teaching. }\end{array}$ \\
\hline
\end{tabular}




\begin{tabular}{|c|c|c|c|c|c|}
\hline \multicolumn{6}{|c|}{ Studies comparing SP teachers to traditional teaching methods } \\
\hline Reference & Participants & Control & Intervention & Outcome & Conclusion \\
\hline $\begin{array}{l}\text { Levenkron } \\
(1990)^{68}\end{array}$ & $\begin{array}{l}\text { Second-year } \\
\text { students, class } \\
1985 \text { control } \\
\text { group, class } \\
1986 \text { interven- } \\
\text { tion group. }\end{array}$ & $\begin{array}{l}\text { Instruction on } \\
\text { risk-factor } \\
\text { counseling } \\
\text { skills by } \\
\text { lectures and } \\
\text { small group } \\
\text { sessions with } \\
\text { patient in } \\
\text { group. }\end{array}$ & $\begin{array}{l}\text { Instruction on } \\
\text { risk-factor } \\
\text { counseling } \\
\text { skills by SP- } \\
\text { teacher } \\
\text { (individual } \\
\text { student). }\end{array}$ & $\begin{array}{l}\text { Assessment of } \\
\text { risk-factor } \\
\text { counseling } \\
\text { skills (OSCE), } \\
6 \text { months after } \\
\text { instruction, } \\
\text { evaluators } \\
\text { blinded. Better } \\
\text { performance of } \\
\text { students in } \\
\text { intervention } \\
\text { group. }\end{array}$ & $\begin{array}{l}\text { SPs are more } \\
\text { effective in } \\
\text { teaching risk- } \\
\text { factor counsel- } \\
\text { ing skills } \\
\text { compared to } \\
\text { lectures } \\
\text { combined with } \\
\text { small group } \\
\text { sessions. }\end{array}$ \\
\hline $\begin{array}{l}\text { Fletcher } \\
(2004)^{49}\end{array}$ & $\begin{array}{l}\text { Second-year } \\
\text { students, } \\
\text { performance } \\
\text { assessment in } \\
38 \text { students of } \\
\text { control group } \\
\text { (class 2001), } \\
166 \text { students in } \\
\text { intervention } \\
\text { group (class } \\
2002 \text { ). }\end{array}$ & $\begin{array}{l}\text { Lecture on } \\
\text { examination of } \\
\text { patients with } \\
\text { abdominal pain. }\end{array}$ & $\begin{array}{l}\text { Lecture on } \\
\text { examination of } \\
\text { patients with } \\
\text { abdominal pain } \\
\text { and practice } \\
\text { session with } \\
\text { SP-teacher. }\end{array}$ & $\begin{array}{l}\text { Assessments of } \\
\text { history taking } \\
\text { and physical } \\
\text { examination } \\
\text { skills (OSCE) } \\
18 \text { months after } \\
\text { instruction. } \\
\text { Better } \\
\text { performance in } \\
\text { intervention } \\
\text { group. }\end{array}$ & $\begin{array}{l}\text { Adding a } \\
\text { practice session } \\
\text { with SP- } \\
\text { teachers to a } \\
\text { lecture is more } \\
\text { effective than a } \\
\text { lecture alone in } \\
\text { teaching history } \\
\text { and physical } \\
\text { examination at } \\
18 \text { months after } \\
\text { intervention. }\end{array}$ \\
\hline $\begin{array}{l}\text { Sachdeva } \\
(1997)^{54}\end{array}$ & $\begin{array}{l}153 \text { third-year } \\
\text { medical } \\
\text { students } \\
\text { randomly } \\
\text { assigned to } \\
\text { control group } \\
\text { and interven- } \\
\text { tion group. }\end{array}$ & $\begin{array}{l}\text { Traditional } \\
\text { clerkship } \\
\text { teaching. }\end{array}$ & $\begin{array}{l}\text { Traditional } \\
\text { clerkship } \\
\text { teaching and } \\
\text { instruction and } \\
\text { practice session } \\
\text { by SP on breast } \\
\text { and abdominal } \\
\text { examination, } \\
\text { small group and } \\
\text { one-to-one. }\end{array}$ & $\begin{array}{l}\text { Assessment of } \\
\text { breast and } \\
\text { abdominal } \\
\text { examination } \\
\text { skills and } \\
\text { professionalism } \\
\text { during } \\
\text { examination } \\
\text { (OSCE). Better } \\
\text { performance of } \\
\text { students in } \\
\text { intervention } \\
\text { group. }\end{array}$ & $\begin{array}{l}\text { A single } \\
\text { instruction } \\
\text { session by SP- } \\
\text { teachers is } \\
\text { effective in the } \\
\text { teaching of } \\
\text { breast and } \\
\text { abdominal } \\
\text { examination } \\
\text { skills. }\end{array}$ \\
\hline
\end{tabular}




\begin{tabular}{|c|c|c|c|c|c|}
\hline Reference & Participants & Control & Intervention & Outcome & Conclusion \\
\hline $\begin{array}{l}\text { Papadakis } \\
(1997)^{53}\end{array}$ & $\begin{array}{l}\text { First-year } \\
\text { students, } 35 \\
\text { randomly } \\
\text { assigned to } \\
\text { intervention } \\
\text { group, } 37 \text { to } \\
\text { control group. }\end{array}$ & $\begin{array}{l}\text { Lecture on } \\
\text { smoking- } \\
\text { cessation } \\
\text { techniques and } \\
\text { practice with } \\
\text { role playing. }\end{array}$ & $\begin{array}{l}\text { Lecture on } \\
\text { smoking- } \\
\text { cessation } \\
\text { techniques and } \\
\text { practice with } \\
\text { SP-teachers. }\end{array}$ & $\begin{array}{l}\text { Assessment of } \\
\text { smoking- } \\
\text { cessation skills } \\
\text { (OSCE), } 2 \\
\text { weeks after } \\
\text { practice. No } \\
\text { difference was } \\
\text { found. }\end{array}$ & $\begin{array}{l}\text { SP teachers are } \\
\text { as effective as } \\
\text { role playing in } \\
\text { the teaching of } \\
\text { smoking- } \\
\text { cessation } \\
\text { techniques. }\end{array}$ \\
\hline
\end{tabular}

\begin{tabular}{|c|c|c|c|c|c|}
\hline \multicolumn{6}{|c|}{ Study comparing SP teachers to instruction on models } \\
\hline Reference & Participants & Control & Intervention & Outcome & Conclusion \\
\hline Nelson $(1978)^{69}$ & $\begin{array}{l}\text { Second-year } \\
\text { medical } \\
\text { students, } 15 \\
\text { assessed in } \\
\text { intervention } \\
\text { group, } 15 \\
\text { assessed in } \\
\text { control group. }\end{array}$ & $\begin{array}{l}\text { Instruction and } \\
\text { practice of } \\
\text { pelvic } \\
\text { examination } \\
\text { skills on plastic } \\
\text { model. }\end{array}$ & $\begin{array}{l}\text { Instruction by } \\
\text { SP, practice on } \\
\text { SP. }\end{array}$ & $\begin{array}{l}\text { Assessment of } \\
\text { pelvic } \\
\text { examination } \\
\text { skills (OSCE), } \\
\text { evaluators } \\
\text { blinded. } \\
\text { Students } \\
\text { trained by SPs } \\
\text { performed } \\
\text { better on } \\
\text { palpation of } \\
\text { ovaries. }\end{array}$ & $\begin{array}{l}\text { SP teachers are } \\
\text { more effective } \\
\text { in teaching } \\
\text { palpation of } \\
\text { ovaries } \\
\text { compared to } \\
\text { instruction on } \\
\text { plastic models. }\end{array}$ \\
\hline
\end{tabular}

OSCE: Objective structured clinical examination 
Table 5. Studies comparing real patients to SPs in the teaching of skills to students

\begin{tabular}{|c|c|c|c|c|c|}
\hline Reference & Participants & Control & Intervention & Outcome & Conclusion \\
\hline Helfer $(1975)^{70}$ & $\begin{array}{l}22 \text { third-year } \\
\text { medical } \\
\text { students. }\end{array}$ & $\begin{array}{l}\text { See interven- } \\
\text { tion. }\end{array}$ & $\begin{array}{l}2 \text { encounters } \\
\text { per student, } 11 \\
\text { students real } \\
\text { mother } \\
\text { followed by } \\
\text { simulated } \\
\text { mother, } 11 \\
\text { students vice } \\
\text { versa, randomly } \\
\text { assigned. Half } \\
\text { of mothers } \\
\text { presented to } \\
\text { students as } \\
\text { opposite of } \\
\text { what they were } \\
\text { (real or } \\
\text { simulated). }\end{array}$ & $\begin{array}{l}\text { Scores of } \\
\text { students on } \\
\text { history content } \\
\text { and interaction } \\
\text { checklists. No } \\
\text { difference was } \\
\text { found between } \\
\text { groups. }\end{array}$ & $\begin{array}{l}\text { Students' } \\
\text { pediatric } \\
\text { interviewing } \\
\text { skills in SPs } \\
\text { encounters are } \\
\text { equal to skills } \\
\text { in real patient } \\
\text { encounters. }\end{array}$ \\
\hline $\begin{array}{l}\text { Sanson-Fisher } \\
(1980)^{71}\end{array}$ & $\begin{array}{l}40 \text { second-year } \\
\text { students, } \\
\text { randomly } \\
\text { selected, } 10 \\
\text { students per } \\
\text { group. Students } \\
\text { unaware of } \\
\text { having a real } \\
\text { patient or SP } \\
\text { encounter. }\end{array}$ & $\begin{array}{l}\text { Group 1: } 2 \text { real } \\
\text { patient } \\
\text { encounters } \\
\text { Group 2: real } \\
\text { patient } \\
\text { encounter } \\
\text { followed by SP } \\
\text { encounter. }\end{array}$ & $\begin{array}{l}\text { Group 3: } 2 \text { SP } \\
\text { encounters } \\
\text { Group 4: SP } \\
\text { encounter } \\
\text { followed by } \\
\text { real patient } \\
\text { encounter. }\end{array}$ & $\begin{array}{l}\text { Scores of } \\
\text { students on } \\
\text { empathy scale, } \\
\text { evaluators } \\
\text { blinded. No } \\
\text { difference was } \\
\text { found between } \\
\text { groups. }\end{array}$ & $\begin{array}{l}\text { Empathy } \\
\text { portrayed by } \\
\text { students in real } \\
\text { patient } \\
\text { encounters is } \\
\text { similar to } \\
\text { empathy } \\
\text { portrayed in SP } \\
\text { encounters. }\end{array}$ \\
\hline $\begin{array}{l}\text { Simek- } \\
\text { Downing } \\
(1986)^{45}\end{array}$ & $\begin{array}{l}64 \text { third and } \\
\text { fourth-year } \\
\text { medical } \\
\text { students, } 41 \text { in } \\
\text { intervention } \\
\text { group, } 23 \text { in } \\
\text { control group. }\end{array}$ & $\begin{array}{l}\text { Interview with } \\
\text { real patient, } \\
\text { instruction and } \\
\text { feedback on } \\
\text { communication } \\
\text { skills by patient } \\
\text { and teacher. }\end{array}$ & $\begin{array}{l}\text { Interview with } \\
\text { SP, instruction } \\
\text { and feedback } \\
\text { on communica- } \\
\text { tion skills by } \\
\text { SP and teacher. }\end{array}$ & $\begin{array}{l}\text { Assessment of } \\
\text { communication } \\
\text { skills (OSCE, } \\
\text { verbal skills } \\
\text { and content) } 6 \\
\text { weeks after } \\
\text { instruction. } \\
\text { Control group } \\
\text { showed better } \\
\text { psychosocial } \\
\text { content, } \\
\text { intervention } \\
\text { group showed } \\
\text { better summa- } \\
\text { rization. }\end{array}$ & $\begin{array}{l}\text { SPs are most } \\
\text { valuable in } \\
\text { teaching verbal } \\
\text { interviewing } \\
\text { skills and real } \\
\text { patients are } \\
\text { most valuable } \\
\text { in teaching } \\
\text { focal content of } \\
\text { the interview. }\end{array}$ \\
\hline
\end{tabular}




\begin{tabular}{|c|c|c|c|c|c|}
\hline Reference & Participants & Control & Intervention & Outcome & Conclusion \\
\hline $\begin{array}{l}\text { Gilliland } \\
(2006)^{72}\end{array}$ & $\begin{array}{l}323 \text { second- } \\
\text { year students, } \\
183 \text { self- } \\
\text { selected } \\
\text { students in } \\
\text { control group, } \\
140 \text { in } \\
\text { intervention } \\
\text { group. }\end{array}$ & $\begin{array}{l}\text { Instruction on } \\
\text { history taking } \\
\text { and physical } \\
\text { examination } \\
\text { with real } \\
\text { patients. }\end{array}$ & $\begin{array}{l}\text { Instruction on } \\
\text { history taking } \\
\text { and physical } \\
\text { examination } \\
\text { with SPs. }\end{array}$ & $\begin{array}{l}\text { Assessment of } \\
\text { history taking } \\
\text { and physical } \\
\text { examination } \\
\text { skills, multiple } \\
\text { instruments } \\
\text { (e.g. OSCE, } \\
\text { teachers' } \\
\text { evaluations, } \\
\text { MCQ). No } \\
\text { difference was } \\
\text { found. }\end{array}$ & $\begin{array}{l}\text { SPs are as } \\
\text { effective as real } \\
\text { patients in the } \\
\text { teaching of } \\
\text { history taking } \\
\text { and physical } \\
\text { examination. }\end{array}$ \\
\hline
\end{tabular}

OSCE: Objective structured clinical examination MCQ: Multiple choice questions 
Table 6. Advantages and disadvantages of different patient roles

\begin{tabular}{|c|c|c|}
\hline Patient roles & Advantages & Disadvantages \\
\hline $\begin{array}{l}\text { Bedside } \\
\text { teaching }\end{array}$ & $\begin{array}{l}\text { Teaching of many different skills. } \\
\text { Patient-centered learning. } \\
\text { High patient satisfaction. }\end{array}$ & $\begin{array}{l}\text { Limited availability of patients. } \\
\text { Concerns for patients comfort and } \\
\text { confidentiality. } \\
\text { High variability in students' learning. } \\
\text { Difficult to maintain with fewer } \\
\text { available patients in hospital. }\end{array}$ \\
\hline $\begin{array}{l}\text { Patients as } \\
\text { teachers }\end{array}$ & $\begin{array}{l}\text { Effective teaching method for many } \\
\text { different skills. } \\
\text { Direct feedback from patient. } \\
\text { Enjoyed by students and patients. } \\
\text { Offers a unique insight from the } \\
\text { patient's perspective. } \\
\text { Less expensive than faculty teachers } \\
\text { once trained. }\end{array}$ & $\begin{array}{l}\text { Takes considerable training time and } \\
\text { faculty investment. } \\
\text { Only selective patient groups can be } \\
\text { trained. }\end{array}$ \\
\hline $\begin{array}{l}\text { SPs as } \\
\text { educational } \\
\text { resource }\end{array}$ & $\begin{array}{l}\text { Direct feedback from SP. } \\
\text { Available at various times and in } \\
\text { various settings. } \\
\text { Teaching of many different skills in } \\
\text { a safe environment. } \\
\text { SP interaction can be manipulated } \\
\text { for educational purposes. } \\
\text { Minimizes variability in learning. }\end{array}$ & $\begin{array}{l}\text { Negative effects of SP performance for } \\
\text { SPs. } \\
\text { Investment in training SPs. }\end{array}$ \\
\hline SPs as teachers & $\begin{array}{l}\text { Effective teaching method for many } \\
\text { different skills. } \\
\text { Safe learning environment. } \\
\text { Direct feedback from SP. } \\
\text { Available at various times and in } \\
\text { various settings. }\end{array}$ & $\begin{array}{l}\text { Students not always perceive it as } \\
\text { effective compared to lectures. } \\
\text { Time for training SPs. }\end{array}$ \\
\hline
\end{tabular}




\section{Discussion}

Most of the studies in our review suggest that real patients and SPs make a highly valued and indispensable contribution to undergraduate medical education in passive and active roles. Simulated and real patients, the latter especially in their teaching role, provide a safe, low anxiety learning environment where students can learn from immediate feedback and their own mistakes and build their competence and confidence.

The key aspects of educational experiences with real patients appear to be the presentation of actual abnormal physical findings and unique insights from the patient's perspective. The advantages of SPs are that they are controllable and flexible. They are available when needed, adaptable to students' needs, offer uniformity of educational experiences across students and enable repeated practice of skills. They also have an excellent track record for teaching related to sensitive areas, such as breaking bad news and pelvic examination.

Real patients have limitations that place restrictions on their use however desirable it may be deemed to be. There are fewer available and suitable patients due to changes in health care and there are concerns about the patient's comfort and confidentiality.

A possible limitation of the use of SP-teachers might be their costs in terms of faculty time required for training. However, real patients also require training for their teaching roles and once trained, both SP-teachers and patientinstructors appear to be less expensive than faculty teachers. We feel patient contacts remain essential in medical education, even with the rapid development of realistic simulation techniques. Initiatives to integrate (simulated) patient contacts and simulation techniques are therefore highly welcomed by us. In addition, we feel that both real patients and SPs should not be burdened excessively by their educational roles. Their health and well-being should be a strong concern for program directors and teachers.

Our review has some limitations. Only one researcher searched the databases and selected studies for inclusion in the review. Therefore the review was not systematic. Although we made every effort to make our searches as thorough as possible, selection bias cannot be ruled out. Furthermore, relatively few comparative studies were found in our review. Although the majority of these studies used high-quality experimental designs, many used rather small populations. Many studies in our review were descriptive in nature. This may have influenced our results. Finally, for some studies in our review the distinction between the four patient roles turned out to be somewhat artificial as a small 
amount of overlap was found between the roles in these studies, for example, real patients who simulated some aspects of their role or SPs who had actual findings on physical examination. Although most studies were clear on whether real patients or SPs were used, as educational resource or as teachers, this might have influenced our results.

Further research should compare the effectiveness of real patients in the role of teachers to other teaching methods such as instruction on hospitalized patients or models. The role of patient-instructors in the teaching of skills in addition to physical examination skills, such as history taking and communication skills, is another area for future research. In addition, further research is needed with regard to the comparison of real patients to SPs. Despite the considerable amount of literature we found, many gaps in knowledge about patient roles in medical education remain and should be addressed by future studies.

\section{References}

1. Spencer J, Blackmore D, Heard S, et al. Patient-oriented learning: a review of the role of the patients in the education of medical students. Medical Education. 2000;34(10):851-857.

2. Littlewood S, Ypinazar V, Margolis SA, Scherpbier A, Spencer J, Dornan T. Early practical experience and the social responsiveness of clinical education: systematic review. British Medical Journal. 2005;331(7513):387-391.

3. Dornan T, Littlewood S, Margolis SA, Scherpbier A, Spencer J, Ypinazar V. How can experience in clinical and community settings contribute to early medical education? A BEME systematic review. Med Teach. Feb 2006;28(1):3-18.

4. Dammers J, Spencer J, Thomas M. Using real patients in problem-based learning: students' comments on the value of using real, as opposed to paper cases, in a problem-based learning module in general practice. Medical Education. 2001;35(1):27-34.

5. Howe A, Dagley V, Hopayian K, Lillicrap M. Patient contact in the first year of basic medical training--feasible, educational, acceptable? Med Teach. Mar 2007;29(2-3):237-245.

6. Aspegren K. BEME Guide No. 2: Teaching and learning communication skills in medicine - a review with quality grading of articles. Medical Teacher. 1999;21(6):563-570.

7. Schmidt HG, Rikers RM. How expertise develops in medicine: knowledge encapsulation and illness script formation. Med Educ. Dec 2007;41(12):1133-1139.

8. Janicik RW, Fletcher KE. Teaching at bedside: a new model. Medical Teacher. 2003;25(2):127-130.

9. Kroenke K, Omori DM, Landry FM, Lucey CR. Bedside teaching. Southern Medical Journal. 1997;90(11):1069-1074.

10. Fitzgerald FT. Bedside teaching. The Western Journal of Medicine. 1993;158(4):418-420.

11. Cooper D, Beswick W, Whelan G. Intensive bedside teaching of physical examination to medical undergraduates: evaluation including the effect of group size. Med Educ. Sep 1983;17(5):311-315. 
12. Hill DA, Lord RS. Complementary value of traditional bedside teaching and structured clinical teaching in introductory surgical studies. Med Educ. Nov 1991;25(6):471-474.

13. Torre DM, Simpson D, Sebastian JL, Elnicki DM. Learning/feedback activities and highquality teaching: perceptions of third-year medical students during an inpatient rotation. Academic Medicine. 2005;80(10):950-954.

14. Nair BR, Coughlan JL, Hensley MJ. Student and patient perspectives on bedside teaching. Medical Education. 1997;31(5):341-346.

15. Linfors EW, Neelon FA. The case for bedside rounds. New England Journal of Medicine. 1980;303(21):1230-1233.

16. Simons RJ, Baily RG, Zelis R, Zwillich CW. The physiologic and psychological effects of the bedside presentation. New England Journal of Medicine. 1989;321(18):1273-1275.

17. Lehmann LS, Brancati FL, Chen M, Roter D, Dobs AS. The effect of bedside case presentations on patients' perceptions of their medical care. New England Journal of Medicine. 1997;336(16):1150-1155.

18. Wang-Cheng RM, Barnas GP, Sigmann P, Riendl PA, Young MJ. Bedside case presentation: why patients like them but learners don't. Journal of General Internal Medicine. 1989;4(4):284-287.

19. Howe A, Anderson J. Involving patients in medical education. British Medical Journal. Aug 9 2003;327(7410):326-328.

20. Hodgson H. Teaching and the patient. British Medical Journal. 1975;1(5958):628.

21. McGraw RC, O'Conner HM. Standardized patients in the early acquisition of clinical skills. Medical Education. 1999;33(8):572-578.

22. Anderson KK, Meyer TC. The use of instructor-patients to teach physical examination techniques. Journal of Medical Education. 1978;53(10):831-836.

23. Stillman PL, Swanson DB. Ensuring the clinical competence of medical school graduates through standardized patients. Archives of Internal Medicine. 1987;147(6):1049-1052.

24. Waterbury JT. Refuting patients' obligations to clinical training: a critical analysis of the arguments for an obligation of patients to participate in the clinical education of medical students. Medical Education. 2001;35(3):286-294.

25. Farquhar D. Reducing reliance in hospitalized patients for undergraduate clinical skills teaching in internal medicine. Academic Medicine. 2000;75(5):537.

26. LaCombe M. On bedside teaching. Annals of Internal Medicine. 1997;126(3):217-220.

27. Tremonti LP, Biddle WB. Teaching behaviors of residents and faculty members. J Med Educ. Nov 1982;57(11):854-859.

28. Wykurz G, Kelly D. Developing the role of patients as teachers: literature review. British Medical Journal. 2002;325(7368):818-821.

29. Frazer NB, Miller RH. Training practical instructors (programmed patients) to teach basic physicial examination. J Med Educ. Feb 1977;52(2):149-151.

30. Guttman HA, Paris J. Using nonpsychiatric patients to teach medical students about psychiatry. Journal of Medical Education. 1978;53(2):147-149.

31. Stillman PL, Ruggill JS, Rutala PJ, Sabers DL. Patient instructors as teachers and evaluators. Journal of Medical Education. 1980;55(3):186-193.

32. Gall EP, Meredith KE, Stillman PL, et al. The use of trained patient instructors for teaching and assessing rheumatologic care. Arthritis and Rheumatism. 1984;27(5):557-563.

33. Lindsley HB, Welch KE, Bonaminio G. Using patients to teach functional assessment of patients with arthritis. Academic Medicine. 1998;73(5):583. 
34. Hendry GD, Schrieber L, Bryce D. Patients teach students: partners in arthritis education. Medical Education. 1999;33(9):674-677.

35. Plymale MA, Witzke DB, Sloan PA. Cancer survivors as standardized patients: an innovative program integrating cancer survivors into structures clinical reaching. Journal of Cancer Education. 1999;14(2):67-71.

36. Coletta EM, Murphy JB. Using elderly disabled patients to teach history taking and physical examination. Academic Medicine. 1993;68(12):901.

37. Kelly D, Wykurz G. Patients as teachers: a new perspective in medical education. Education for Health. 1998;11(3):369-377.

38. Stacy R, Spencer J. Patients as teachers: a qualitative study of patients' views on their role in a community-based undergraduate project. Medical Education. 1999;33(9):688-694.

39. Barrows HS, Abrahamson S. The programmed patients: a technique for appraising student performance in clinical neurology. Journal of Medical Education. 1964;39:802-805.

40. Stillman PL, Regan MD, Philbin M, Haley HL. Results of a survey on the use of standardized patients to teach and evaluate clinical skills. Academic Medicine. 1990;65(5):288-292.

41. Barrows HS. An overview of the uses of standardized patients for teaching and evaluating clinical skills. Academic Medicine. 1993;68(6):443-451.

42. Fortin AH, Haeseler FD, Angoff N, et al. Teaching pre-clinical medical students an integrated approach to medical interviewing: half-day workshops using actors. Journal of General Internal Medicine. 2002;17(9):704-708.

43. Blake K, Gusella J, Greaven S, Wakefield S. The risks and benefits of being a young female adolescent standardized patient. Medical Education. Jan 2006;40(1):26-35.

44. Davies M. The way ahead: teaching with simulated patients. Medical Teacher. 1989;11(3/4):315-320.

45. Simek-Downing L, Quirk ME, Letendre AJ. Simulated versus actual patients in teaching medical interviewing. Family Medicine. 1986;18(6):358-360.

46. Rethans JJ, Gorter S, Bokken L, Morrison L. Unannounced standardized patients in real practice: a systematic literature review. Med Educ. Jun 2007;41(6):537-549.

47. Bokken L, Van Dalen J, Rethans JJ. Performance-related stress symptoms in simulated patients. Medical Education. 2004;38(10):1089-1094.

48. Bokken L, Van Dalen J, Rethans JJ. The impact of simulation on simulated patients: a focus group study. Medical Education. 2006;40(8):781-786.

49. Fletcher KE, Stern DT, White C, Gruppen LD, Oh MS, Cimmino VM. The physical examination of patients with abdominal pain: the long-term effect of adding standardized patients and small-group feedback to a lecture presentation. Teach Learn Med. Spring 2004;16(2):171174.

50. Livingstone RA, Moodie PF, Ostrow DN. A follow-up study of patient-instructors who teach the pelvic examination. Journal of Medical Education. 1980;55(8):715-717.

51. Kleinman DE, Hage ML, Hoole AJ, Kowlowitz V. Pelvic examination instruction and experience: a comparison of laywoman-trained and physician-trained students. Acad Med. Nov 1996;71(11):1239-1243.

52. Livingstone RA, Ostrow DN. Professional patient-instructors in the teaching of the pelvic examination. American Journal of obstetrics and gynecology. 1978;132(1):64-67.

53. Papadakis MA, Croughan-Minihane M, Fromm LJ, Wilkie HA, Ernster VL. A comparison of two methods to teach smoking-cessation techniques to medical students. Acad Med. Aug 1997;72(8):725-727. 
54. Sachdeva AK, Wolfson PJ, Gabler Blair P, Gillum DR, Gracely EJ, Friedman M. Impact of a standardized patient intervention to teach breast and abdominal examination skills to thirdyear medical students at two institutions. The American Journal of Surgery. 1997;173(4):320325.

55. Beckmann CR, Sharf BF, Barzansky BM, Spellacy WN. Student response to gynecologic teaching associates. Am J Obstet Gynecol. Aug 1986;155(2):301-306.

56. Johnson GH, Brown TC, Stenchever MA, Gabert HA, Poulson AM, Warenski JC. Teaching pelvic examination to second-year medical students using programmed patients. American Journal of obstetrics and gynecology. 1975;121(5):714-717.

57. Kretzschmar RM. Evolution of the Gynecology Teaching Associate: An education specialist. American Journal of obstetrics and gynecology. 1978;131(4):367-372.

58. Wånggren K, Pettersson G, Csemiczky G, Gemzell-Danielsson K. Teaching medical students gynaecological examination using professional patients' evaluation of students' skills and feelings. Medical Teacher. 2005;27(2):130-135.

59. Plauche WC, Baugniet-Nebrija W. Students' and physicians' evaluations of gynecologic teaching associate program. J Med Educ. Nov 1985;60(11):870-875.

60. Wallis LA, Tardiff K, Deane K. Changes in students' attitudes following a pelvic teaching associate program. J Am Med Womens Assoc. Mar-Apr 1984;39(2):46-48.

61. Levenkron JC, Greenland P, Bowley N. Using patient instructors to teach behavioral counseling skills. Journal of Medical Education. 1987;62(8):665-672.

62. Davidson R, Duerson M, Rathe R, Pauly R, Watson RT. Using standardized patients as teachers: a concurrent controlled trial. Academic Medicine. 2001;76(8):840-843.

63. Carter MB, Wesley G, Larson GM. Didactic lecture versus instructional standardized patients interaction in the surgical clerkship. The American Journal of Surgery. 2005;189(2):243-248.

64. Carter MB, Wesley G, Larson GM. Lecture versus standardized patient interaction in the surgical clerkship: a randomized prospective cross-over study. The American Journal of Surgery. 2006;191(2):262-267.

65. Colletti L, Gruppen L, Barclay M, Stern D. Teaching students to break bad news. The American Journal of Surgery. 2001;182(1):20-23.

66. Vannatta JB, Smith KR, Crandall S, Fischer PC, Williams K. Comparison of standardized patients and faculty in teaching medical interviewing. Academic Medicine. 1996;71(12):13601362.

67. Holzman GB, Singleton D, Holmes TF, Maatsch JL. Initial pelvic examination instruction: the effectiveness of three contemporary approaches. Am J Obstet Gynecol. Sep 15 1977;129(2):124-129.

68. Levenkron JC, Greenland P, Bowley N. Teaching risk-factor counseling skills: a comparison of two instructional methods. Am J Prev Med. 1990;6(2 Suppl):29-34.

69. Nelson LH. Use of professional patients in teaching pelvic examinations. Obstet Gynecol. Nov 1978;52(5):630-633.

70. Helfer RE, Black MA, Teitelbaum H. A comparison of pediatric interviewing skills using real and simulated mothers. Pediatrics. Mar 1975;55(3):397-400.

71. Sanson-Fisher RW, Poole AD. Simulated patients and the assessment of medical students' interpersonal skills. Med Educ. Jul 1980;14(4):249-253.

72. Gilliland WR, Pangaro LN, Downing S, et al. Standardized versus real hospitalized patients to teach history-taking and physical examination skills. Teach Learn Med. 2006;18(3):188-195. 


\section{Chapter}

\section{Students' views on the use of real patients and simulated patients in undergraduate medical education}

L. Bokken, JJ. Rethans, L. van Heurn, R. Duvivier, A. Scherpbier, C. van der Vleuten Accepted by Academic Medicine 


\begin{abstract}
Purpose: Although it has been recognized as an important research area, there is paucity of literature on the value of real patient contacts as opposed to simulated patient (SP) contacts from the perspectives of students. Students' views with regard to the strengths and weaknesses of real patient contacts as opposed to SP contacts in the undergraduate medical curriculum were explored. The aim was to evaluate how their strengths can be optimally used and weaknesses remedied. Method: Five focus group interviews were conducted among 38 fourth and fifth year medical students at Maastricht University in 2007, using a pre-established interview guide. The interviews were recorded, transcribed and analyzed using qualitative methods.

Results: In general, students considered real patient contacts more instructive and more authentic than SP contacts. However, students identified several strengths of SP contacts compared to real patient contacts. For example, SP contacts were helpful in preparing students for real patient contacts (particularly with regard to communication skills and self-confidence), in the teaching of "intimate" physical examination skills, such as gynecological examination skills, and in giving constructive feedback on communication skills. In contrast to what we had anticipated, taking a time-out was considered easier in real patient contacts.

Conclusions: Both real patient contacts and SP contacts are considered indispensable to undergraduate medical education. Each contact has unique strengths and weaknesses from the perspectives of students. On the basis of strengths and weaknesses that were identified, suggestions were made for the use of real patients and SPs in undergraduate medical education.
\end{abstract}




\section{Introduction}

Patient contacts have always been an integral part of undergraduate medical education. Early patient contacts increase student motivation, ease the transition from preclinical to clinical training and teach students "things that cannot be learned from books", such as empathy, responsibility towards patients and professional identity. ${ }^{1-3}$ Patient contacts also help students build integrated skills for clinical reasoning, communication, history taking and physical examination. ${ }^{1,2,4,5}$

Patient contacts in medical education may involve real patients or simulated patients (SPs). Barrows described several advantages of SPs compared to real patients, for example their availability, flexibility and standardization. ${ }^{6}$ The safe learning environment offered by SPs and the feedback provided by SPs have been described as important advantages from the perspective of students. ${ }^{6-8}$ Students highly value SPs in the learning of clinical skills, for example pelvic examination skills. ${ }^{9-11}$ In real patients, safe learning environment and feedback have also been reported as important advantages for students, particularly in patients taking on the role of teacher. ${ }^{8,12,13}$ Students have been suggested to prefer real patients to SPs because of their authenticity. ${ }^{14}$ This might be an important advantage of real patients since authenticity is a key aspect in contextual learning; the closer the learning is to real life, the more quickly and effectively skills can be learned. ${ }^{15,16}$ Studies on incognito SPs visiting practicing doctors (who do not know when they are visited by SPs) have reported low detection rates. ${ }^{17}$ This suggests SPs can be very authentic.

The differential value of real patients as opposed to SPs, has been recognized as an important research area. ${ }^{5,8}$ Nevertheless, there is paucity of comparative studies in this field. We found only two studies in which students' views on real patient contacts and SP contacts were compared. ${ }^{18,19}$ McGraw et al. found no significant difference with regard to student satisfaction with both contacts whereas Eagles et al. found students preferred SP contacts to real patient contacts for learning interview skills. ${ }^{18,19}$

Since we wanted to further explore the differential value of real patients and SPs in undergraduate medical education from the students' perspective, we performed the study presented in this paper. The aims of this study were 1) to evaluate the points of view of students with regard to the strengths and weaknesses of real patient contacts as opposed to SP contacts in the undergraduate medical curriculum and 2) to evaluate how the strengths of real patient contacts 
and SP contacts can be optimally used and weaknesses remedied. We performed a qualitative study using focus group interviews involving students who have experienced both real patient contacts and SP contacts.

\section{Study context}

At Maastricht University, students in the preclinical years of the six-year medical curriculum of Maastricht University (Years 1-3) have the opportunity to practice communication and physical examination skills in contacts with SPs in the Skillslab once every three weeks. ${ }^{20}$ These contacts consist of simulated consultations in which two students, one in the role of the doctor and the other as observer, see an SP and take a history and/or perform a physical examination. The SPs provide the "student-doctor" with feedback afterwards. The sessions are recorded on DVD and discussed in tutorial groups composed of 10 students and one tutor who is a medical doctor or a behavioral scientist. This SP program is developed and organized by the Skillslab and is fully integrated with the preclinical medical curriculum at Maastricht University.

Alongside the SP encounters, students of the last preclinical year (Year 3) have regular contacts with real patients at the outpatient clinic of the Maastricht University Hospital and in general practice. ${ }^{21,22}$ These real patient contacts are used as triggers for learning (as opposed to paper patients used in Years 1-2).

\section{Methods}

\section{Subjects}

All fourth and fifth year students who were scheduled for an introduction week of the clinical clerkships internal medicine, surgery, pediatrics or ENT in July and August $2007(\mathrm{~N}=80)$, were invited to participate in a focus group interview. We invited students of Year 4 and 5 since they recently experienced SP contacts (Year 1-3) and real patient contacts (Year 3 and clerkships). Therefore, we expected the fourth and fifth year students to be well able to reflect on these experiences. During the introduction weeks of the clinical clerkships internal medicine, surgery, pediatrics and ENT, which are held at the university, students are offered skills training at the Skillslab. Since we intended to schedule 
the focus group interviews immediately before or after skills training at the Skillslab, we invited the students participating in the introduction weeks of one of these clerkships. An email was sent to the students, explaining the purpose and procedure of the study and inviting the students to participate. Two weeks later a reminder email was sent to the students who had not responded to the initial email. Furthermore, all students were personally invited to participate in the focus group interviews during a group meeting at the start of the clerkship. Students were invited by one of the authors (LB) who is an independent researcher not involved in any teaching activities. Students were offered a lunch and were paid $\$ 23$ for participation. Five focus groups were composed on the basis of the students interested in participating.

\section{Focus group sessions}

The focus group sessions followed the guidelines offered by Morgan and Krueger. ${ }^{23}$ Each focus group interview, lasting 1-1.5 hours, was held at the Skillslab or at a tutorial group room at the university. With consent of the students, the meetings were audio taped with a digital recording system for later transcription. The focus group interviews were guided by an independent moderator (LvH). The assistant moderator (LB) observed, took notes and audio taped the interviews. It was explained to the students that we were interested in all kinds of views and ideas, that there were no correct or incorrect answers and that the analysis and the reporting of the results would be anonymous. The interview was semi-structured on the basis of a pre-established interview guide. List 1 provides an overview of the interview guide.

\section{Analysis}

The recordings of the five focus groups were transcribed by one of the authors (LB). The transcripts were summarized and the summaries were sent to the participants of the respective focus group for approval. The students were asked whether the summary gave a complete and truthful impression of the focus group discussion they had participated in. The summaries were adjusted on the basis of the students' comments and finally approved by all students. The transcripts of the interviews were imported into the software program ATLASti. The transcripts were reviewed and coded by two reviewers independently 
(LB and $\mathrm{RD}$ ). When the two reviewers disagreed, the codes were discussed until agreement was reached. The main codes corresponded with the questions discussed in the focus groups (List 1). Additional codes were used for new themes raised by the participants during the discussions.

\section{List 1. Interview guide}

What type of encounter have you learnt most from: a real patient contact or an SP contact?
Do you prepare differently for an encounter with a real patient compared to an encounter with
an SP? How do you prepare?
What type of encounter provides a stronger motivation for self-study: a real patient contact or an
SP contact? Why?
What are the advantages of real patient contacts as opposed to SP contacts in the learning of
communication skills?
What are the disadvantages of real patient contacts as opposed to SP contacts in the learning of
communication skills?
Does the phase of the curriculum affect the effectiveness of real patient contacts or SP contacts?
What type of encounter is most effective in the learning of physical examination skills: a real
patient contact or an SP contact?
Does feedback by the (simulated) patient affect the effectiveness of real patient contacts or SP
contacts?
What should be changed in the use of real patients and SP?

\section{Results}

Of the 80 fourth and fifth year students who were invited to participate in the focus groups, 38 (48\%) participated. The number of participants per group ranged from 5 to 10 participants. The majority of the participants were fourth year students. The final focus groups yielded no new information, i.e. saturation was reached. Therefore no additional focus groups or additional meetings with the same groups were planned.

We present the results for the main themes discussed in the focus groups: instructiveness, preparation and motivation for self-study, phase of the curriculum, advantages and disadvantages of real patient contacts in learning communication skills, physical examination skills and feedback. 
Instructiveness

In general, students considered real patient contacts more instructive than SP contacts. However, the majority of students found SPs useful in preparation for real patient contacts.

"In the first year you don't know how to behave in front of a patient, you're nervous and don't know what to say and then, with the help of SPs, you cross a barrier and it becomes easier and it helps you when you eventually see a real patient you feel more self-assured."

"I think it's very useful to have practiced this [communication skills] and now you're seeing real patients you can forget about that a little and be less consciously engaged in it."

Students indicated learning different things from real patients and SPs. In SP contacts the emphasis is mostly on learning communication skills whereas in real patient contacts the emphasis is mostly on medical aspects and on learning about the disease from the perspective of the patient.

\section{Preparation and motivation for self-study}

Most students prepared themselves better for real patient encounters than for SP encounters. Students were more serious in their preparation for real patient contacts and felt more responsible towards real patients.

"With real patients it's more exciting and subconsciously you work harder because you know it's a patient seeking help, you have to offer help, you can't say to a patient I don't know."

In their preparation for real patient encounters, students focused on medical aspects, for example by studying PBL cases related to the patient's problem.

Students prepared themselves better for real patient contacts to feel more confident during the consultation. Some students also prepared themselves better for consultations with real patient since there might be a doctor present at the consultation who might ask the student questions about the patient's medical problem afterwards. Some students did not prepare at all for consultations with real patients and SPs, mostly since they did not know beforehand what the consultation would be about.

Most students indicated real patient contacts provided a stronger motivation for self-study than SP contacts, particularly since the emphasis in real patient 
contacts is on learning medical aspects. Some students commented on feeling responsible towards real patients.

"After a real patient contact, sometimes you know very little and you make quite a few mistakes and then at home you are supposed to look it up and you will look it up because you don't want it to go wrong again with a real patient whereas in SPs it's not about the clinical presentation, it's about the communication skills and you don't come back to that."

Some students were more impressed by real patient encounters and seeing a real patient provided a frame for learning.

"When I see something in clinical practice, in reality, it's easier for me to place it."

"It comes to life and therefore I find it more enjoyable than a written case and that motivates me more to be at my books."

Phase of the curriculum

The majority of students considered SP encounters useful until the introduction of real patient encounters in the curriculum, in the third year.

"In Year 3 when we were having real patient encounters, I could not take the SPs seriously anymore, then you notice what kind of performance it really is."

Students indicated SP contacts have little additional value after the third year, during the clinical clerkships.

"Now we're working with real patients day in day out, it's really weird to go back to SPs, it is a step back."

"I think you have enough baggage from the first three years, you know what it's about."

Some students prefer a gradual increase in learning medical aspects in SP encounters in the first two years, in addition to learning communication skills. This would ease the transition to real patient encounters in the third year and the clerkships.

"The change from just the conversation to thinking about differential diagnoses is too big, first you should just train communication skills in Year 1 and then in Year 2 you should practice differential diagnostic thinking."

"...and then in Year 3 real patient contacts, again a step forward, and then in Year 4 you enter clinical practice, that is a very smooth transition."

Most students enjoyed practicing "difficult cases" such as breaking bad news or dealing with angry patients in consultations with SPs, although some students 
found these consultations unrealistic. Some students would like to practice more "difficult cases" in the third year.

Advantages of real patient contacts in learning communication skills

Compared to SP contacts, students considered real patient contacts to be more natural. Students felt SPs were often deliberately withholding information.

"If you're dealing with a real patient it's more action and reaction, what I say, how I say it reflects on how someone responds to it, whereas in SPs I often felt they already had in mind what they were going to do during the conversation." "I think SPs are often play-acting too much, they stick too much to the role imposed on them."

Students also indicated real patient contacts are more diverse and the setting of the real patient contacts is more authentic.

"Often, patients have had their blood drawn or X-rays made and you were supposed to look at the results, it's more natural, it's what you miss in the SP consultations."

The extent to which SP encounters felt artificial depended largely on the performance of the individual SP.

Most students reported real patient encounters are easier as the emphasis is less on the students' communication skills. Real patient contacts were also regarded as easier since real patients talk more spontaneously.

"Real patients usually give you the story for free, you ask them what is going on and there comes a bunch of information and most of the time you just have to fill the gaps, but with SPs you have to keep asking questions."

Some students reported additional advantages of real patient contacts as opposed to SP contacts such as learning to break off the conversation in very wordy people and learning to work under the pressure of time.

Most students considered taking a time-out easier and more natural in real patient encounters than in SP encounters.

"In an SP encounters you want to do well and you don't want to tell the patient you've lost it or don't know what to say unlike in clinical practice when I see a patient and I don't know I just say I don't know."

In real patient encounters students take a time-out, for example, by summarizing or writing down their findings or by consulting their supervisor. 
Disadvantages of real patient contacts in learning communication skills

For most students, an important disadvantage of real patient contacts was learning less about communication skills since the emphasis is mostly on medical aspects and since the contacts are easier with regard to communication. Some students indicated there is less room to experiment in real patient contacts as opposed to SP contacts.

"With real patients you allow yourself fewer mistakes."

Another disadvantage of real patients might be their unwillingness to participate in medical education.

"Sometimes real patients have no need at all to talk to you; they've come to see their doctor, not you."

Most students indicated they would feel more insecure if they would start practicing their communication skills in consultations with real patients. Students indicated this would also be unpleasant for the real patients.

\section{Physical examination skills}

In general, students preferred learning physical examination skills on peers, followed by practice on real patients.

"Whether you practice [on someone else] or someone else practices on you, you learn a lot from it, I think [practicing] on each other is better than practicing on SPs."

"It's enough to practice on each other and then in clinical practice, you don't need to listen to heart and lungs in an SP as well."

Some students liked practicing on SPs as a transitional stage between examining peers and examining real patients.

"If you practice on a fellow student you know each other but in an SP the jitters more or less come in, it's a rather different concept. Just an extra repetition, to become more certain."

All students considered SPs very useful in learning "intimate" examinations such as gynecological examination, urogenital examination and breast examination.

"...so you have just already taken that step in a safe environment and you then come across more certain in front of a patient and your uncertainty is eventually gone." 
SP encounters were also considered useful to practice introducing the physical examination in the consultation and to practice giving instructions to the patient with regard to the physical examination.

Students indicated little attention was paid to their physical examination skills in encounters with SPs.

"I did not have the feeling that it was about the physical examination in SP encounters, it was just about the communication skills, you were never judged on your physical examination."

The majority of the students considered clinical practice the best place to learn physical examination skills.

"I think you don't really learn your physical examination until you practice on real patients, because these people suffer from something."

"In clinical practice you perform the examinations everyday and that's when you learn them."

Students were more curious to find abnormalities in real patients. Some students suggested integrating more real patients in the learning of physical examination skills to learn to distinguish normal and abnormal physical findings.

\section{Feedback}

Most students found feedback provided by SPs more useful than feedback from real patients.

"I think an SP is more honest than a real patient."

"People [real patients] often don't go beyond yes it was alright, it was pleasant."

Real patients gave little feedback to students, although students also rarely asked for feedback in clinical practice. Some students would like to receive more feedback on their communication skills in encounters with real patients.

Students disagreed with regard to the quality of the feedback provided by SPs. Some students felt SPs held on too strict to a fixed structure in the consultation and went too much into details when providing feedback.

"I thought it was pushed a little bit too far about how you were sitting or what word you said exactly on what moment."

Some students commented on the difference between SPs and real patients with regard to providing feedback. 
"An SP much more looks out for extremes and that is quite useful to know and a real patient reflects more on his own interest, if his requests are not granted he will respond differently."

In addition to the feedback from SPs, students also receive feedback on the SP encounter from peers and a tutor. Students considered this feedback very important for the usefulness of the SP encounters.

"The feedback from the tutor was more useful to me than the feedback from the $S P . "$

\section{Discussion}

In this study, we explored the strengths and weaknesses of real patient contacts and SP contacts in undergraduate medical education from the perspectives of students. On the basis of the strengths and weaknesses found, several suggestions for the use of real patients and SPs were made. The suggestions are included in List 2.

\section{List 2. Suggestions for use of real patients and SPs in medical education}

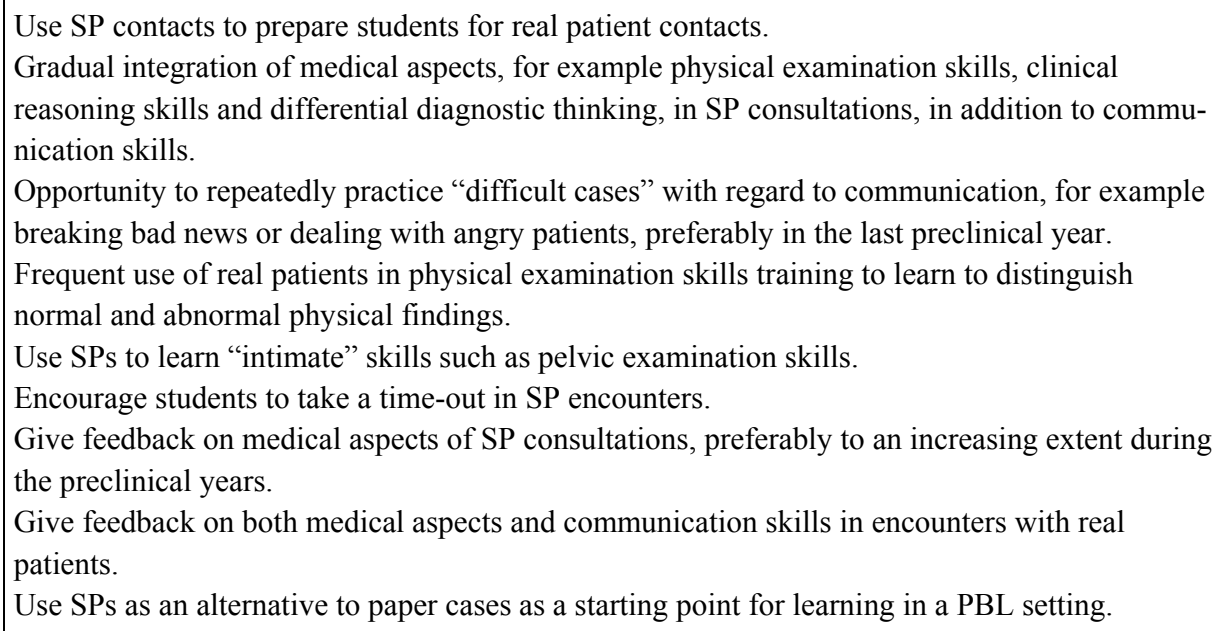

We found that, in general, students considered real patient contacts more instructive than SP contacts. However, students identified several strengths of SPs as opposed to real patients. An important strength found is that SP contacts prepare students for real patient contacts, especially with regard to communica- 
tion skills and self-confidence. SPs were also considered useful in providing constructive feedback on communication skills. Furthermore, students considered SPs useful in teaching "intimate" physical examination skills, which corresponds to previous findings. ${ }^{9-11}$ The finding that students prefer learning non-intimate physical examination skills on peers is also consistent with findings from previous studies, reporting high student acceptance for peer physical examination. ${ }^{24,25}$ Compared to SPs, peers have been found to give more valuable feedback. ${ }^{25}$

Students reported the emphasis in SP contacts mostly being on learning communication skills. Students regarded this as both strength and weakness of SP contacts. Since students have learned their communication skills in SP contacts, they can be less consciously engaged in communication skills in real patient encounters. Consequently, real patient encounters become easier. On the other hand, students learn less about medical aspects in SP contacts. This affects students' preparation and motivation for self-study. At Maastricht University, SP encounters are predominately used for teaching communication skills. Perhaps, the use of SPs should be extended to the teaching of medical aspects, for example clinical reasoning skills including differential diagnostic thinking. This might be particularly important in the second and third preclinical year when most students feel they have mastered the basic communication skills. Cases with a gradually increasing focus on clinical reasoning skills might be presented to students. SPs could also be introduced as an alternative to paper cases as a starting point for learning in a PBL setting, analogously to the use of real patients in PBL settings. ${ }^{21,22}$

Students found it easier to take a time-out in real patient contacts than in SP contacts. This is a remarkable finding, especially since the ability to take a timeout is considered an important strength of SP contacts in literature. ${ }^{8}$ Taking a time-out might become easier as students generally become more confident during later years of the medical curriculum, when real patients are introduced. Furthermore, although SP contacts in our setting are primarily used for teaching purposes, students might have experienced SP contacts as (formative) assessments. This might have influenced their views on taking a time-out. Perhaps we should encourage students more to take a time-out during SP encounters.

Students considered authenticity an important strength of real patients as opposed to SPs. This finding is inconsistent with findings from studies on incognito SPs. ${ }^{17}$ Expectations of students with regard to having a real patient contact or an SP contacts might have influenced their perception of the authenticity of the contact. Consequently, the students' views on the strengths and 
weaknesses of real patients and SPs might have been biased. Future research is needed to address this, for example by making use of incognito SPs in undergraduate medical education. In addition, the views of students with regard to the strengths and weaknesses of real patients and SPs might further be explored, for example by using grounded theory approach. This might be helpful in identifying the nuance of why students feel the way they do and what aspects of real patient and SP encounters contribute to students' perceptions. The fourth and fifth year students participating in our study all had SP contacts prior to having real patient contacts. This might have biased their perspectives as it might be hard for students to distinguish to what extend SP contacts have influenced their real patient contacts. Therefore, studies on the strengths and weaknesses of real patients and SPs from the perspectives of students who have not been previously biased, for example first year students, are needed.

There are some limitations to this study. First of all, this study was conducted in the specific setting of Maastricht Medical School, which differs from many US medical schools with regard to the use of real patients and SPs. For example, in many US medical schools real patients and SPs are introduced simultaneously in the first year of the curriculum. Also, in many US medical schools SPs are trained to give feedback on students' physical examination skills. Because of these differences, some of the results might not be generalizable to US settings. Furthermore, only half of the students who were invited to participate in the focus groups actually participated and all of the participants were self-selected. This might also have biased our results. Finally, the wording of questions 4 and 5 in the interview guide (List 1) might have introduced bias since we asked after the advantages and disadvantages of real patients as opposed to SPs and not the opposite (advantages and disadvantages of SPs as opposed to real patients).

In summary, this study identified several strengths and weaknesses of real patient contacts and SP contacts in undergraduate medical education from the perspectives of students. On the basis of the strengths and weaknesses found, suggestions were made for the use of real patients and SPs. Although further research is needed, students in our study considered both real patient contacts and SP contacts indispensable to undergraduate medical education. 


\section{References}

1. Littlewood S, Ypinazar V, Margolis SA, Scherpbier A, Spencer J, Dornan T. Early practical experience and the social responsiveness of clinical education: systematic review. British Medical Journal. 2005;331(7513):387-391.

2. Dornan T, Littlewood S, Margolis SA, Scherpbier A, Spencer J, Ypinazar V. How can experience in clinical and community settings contribute to early medical education? A BEME systematic review. Med Teach. Feb 2006;28(1):3-18.

3. Dammers J, Spencer J, Thomas M. Using real patients in problem-based learning: students' comments on the value of using real, as opposed to paper cases, in a problem-based learning module in general practice. Medical Education. 2001;35(1):27-34.

4. Howe A, Anderson J. Involving patients in medical education. British Medical Journal. Aug 9 2003;327(7410):326-328.

5. Spencer J, Blackmore D, Heard S, et al. Patient-oriented learning: a review of the role of the patients in the education of medical students. Medical Education. 2000;34(10):851-857.

6. Barrows HS. An overview of the uses of standardized patients for teaching and evaluating clinical skills. Academic Medicine. 1993;68(6):443-451.

7. Fortin AH, Haeseler FD, Angoff N, et al. Teaching pre-clinical medical students an integrated approach to medical interviewing: half-day workshops using actors. Journal of General Internal Medicine. 2002;17(9):704-708.

8. Bokken L, Rethans JJ, Scherpbier A, Van Der Vleuten C. Strengths and weaknesses of simulated and real patients in the teaching of skills to medical students: a review. Simulation in Health Care. 2008;3(3):161-9.

9. Beckmann CR, Sharf BF, Barzansky BM, Spellacy WN. Student response to gynecologic teaching associates. Am J Obstet Gynecol. 1986;155(2):301-306.

10. Plauche WC, Baugniet-Nebrija W. Students' and physicians' evaluations of gynecologic teaching associate program. J Med Educ. 1985;60(11):870-875.

11. Wånggren K, Pettersson G, Csemiczky G, Gemzell-Danielsson K. Teaching medical students gynaecological examination using professional patients' evaluation of students' skills and feelings. Medical Teacher. 2005;27(2):130-135.

12. Wykurz G, Kelly D. Developing the role of patients as teachers: literature review. British Medical Journal. 2002;325(7368):818-821.

13. Stillman PL, Ruggill JS, Rutala PJ, Sabers DL. Patient instructors as teachers and evaluators. Journal of Medical Education. 1980;55(3):186-193.

14. Simek-Downing L, Quirk ME, Letendre AJ. Simulated versus actual patients in teaching medical interviewing. Family Medicine. 1986;18(6):358-360.

15. Kneebone R, Nestel D, Wetzel C, et al. The human face of simulation: patient-focused simulation training. Acad Med. Oct 2006;81(10):919-924.

16. Lane C, Rollnick S. The use of simulated patients and role-play in communication skills training: a review of the literature to August 2005. Patient Educ Couns. Jul 2007;67(1-2):1320.

17. Rethans JJ, Gorter S, Bokken L, Morrison L. Unannounced standardized patients in real practice: a systematic literature review. Med Educ. Jun 2007;41(6):537-549.

18. McGraw RC, O'Conner HM. Standardized patients in the early acquisition of clinical skills. Medical Education. 1999;33(8):572-578. 
19. Eagles JM, Calder SA, Nioll KS, Walker LG. A comparison of real patients, simulated patients and videotaped interview in teaching medical students about alcohol misuse. Teach Learn Med. 2001;23(5):490-3.

20. Van Dalen J, Bartholomeus P, Kerkhofs E, et al. Teaching and assessing communication skills in Maastricht: the first twenty years. Medical Teacher. May 2001;23(3):245-251.

21. Diemers AD, Dolmans DH, Verwijnen MG, Heineman E, Scherpbier AJ. Students' opinions about the effects of preclinical patient contacts on their learning. Adv Health Sci Educ Theory Pract. Jul 2007 (Epub ahead of print).

22. Diemers AD, Dolmans DH, Van Santen M, Van Luijk SJ, Janssen-Noordman AM, Scherpbier AJ. Students' perceptions of early patient encounters in a PBL curriculum: a first evaluation of the Maastricht experience. Med Teach. Mar 2007;29(2-3):135-142.

23. Morgan DL, Krueger RA. The focus group kit. Vol 1-6. London, New Delhi: Sage Publications; 1998.

24. Rees CE, Wearn AM, Vnuk AK, Sato TJ. Medical students' attitudes towards peer physical examination: findings from an international cross-sectional and longitudinal study. $A d v$ Health Sci Educ. 2008; 1

25. Power DV, Center BA. Examining the medical student body: peer physical exams and genital, rectal or breast exams. Teach Learn Med. 2005;17(4):337-343. 


\section{Chapter 10}

\section{Instructiveness of real patients}

and simulated patients in undergraduate medical education: A randomized experiment

L. Bokken, JJ. Rethans, Q. Jöbsis, R. Duvivier, A. Scherpbier, C. van der Vleuten Submitted 


\begin{abstract}
Objective: Few studies have compared the instructiveness of real patient contacts with SP contacts. Although most of these studies found no difference, students often commented on the instructiveness of both encounters being dissimilar. The aims of this study were to evaluate which contact (real patient contact or SP contact) is perceived as most instructive by students and which variables contribute to this.

Method: We performed an experiment involving 163 first-year medical students, randomized to having a real patient contact $(\mathrm{N}=61)$ or SP contact $(\mathrm{N}=102)$. Both quantitative (questionnaires) and qualitative (focus groups) methods were used to evaluate the perceived instructiveness of the contact. Results: The general instructiveness of both real patient contacts and SP contacts was marked high. Several differences between the evaluations of real patient contacts and SP contacts were found. For example, students considered real patient contacts less helpful in practicing communication skills and considered the real patients' feedback less relevant. The focus group interviews yielded explanations for many of the differences found. Students regarded real patients as more authentic. However, SPs were better informed about the routine of the consultation and provided the student with more specific feedback.

Discussion: Students consider authenticity an important advantage of real patients. Their difficult recruitment is an important disadvantage. SPs have important advantages compared to real patients, for example their feedback. The choice of real patient contacts or SP contacts for medical education depends on factors like the phase of the curriculum and the aim of the encounter.
\end{abstract}




\section{Introduction}

Patient contacts have always been an integral part of undergraduate medical education. Early patient contacts increase student motivation, ease the transition from preclinical to clinical training and teach students "things that cannot be learned from books", such as empathy, responsibility towards patients and professional identity. ${ }^{1-3}$ Patient contacts also help students build integrated skills for clinical reasoning, communication, history taking and physical examination. ${ }^{1,2,45}$ Patient contacts in medical education may involve real patients or simulated patients (SPs). Both contacts make unique contributions to medical education. ${ }^{6}$ Although many studies have compared the instructiveness of encounters with real patients or SPs with more traditional teaching methods, such as lectures or instruction by faculty teachers in the teaching of skills to medical students, only a few studies have compared the instructiveness of real patient contacts with SP contacts in the teaching of clinical skills. ${ }^{6-10}$ With regard to the outcome variables, all of these studies focused on the performance of students in the domain of clinical skills, for example student scores on an objective structured clinical examination (OSCE). Most of the studies found no difference between the performance of students taught by real patient contacts and those of students taught by SP contacts. Nevertheless, our students often comment on the instructiveness of real patient contacts and SP contacts being dissimilar. Perhaps, student performance as an outcome variable is not sufficiently sensitive to find differences between the instructiveness of real patient contacts and SP contacts. Perceived instructiveness might be a more sensitive outcome variable.

We performed an experiment in which first year medical students were randomized to having a real patient contact or an SP contact. The aims of this experiment were 1) to evaluate which contact (real patient or SP), is perceived as most instructive by the students and 2) to evaluate what variables contribute to the perceived instructiveness. A mixed method evaluation approach was used with quantitative (questionnaires) and qualitative (focus groups) evaluations of perceived instructiveness. 


\section{Methods}

\section{Setting}

Once every three weeks undergraduate students (Year 1-3) of the Maastricht Medical School have the opportunity to practice communication and physical examination skills in encounters with SPs. ${ }^{11}$ These simulated doctor-patient encounters involve one SP and two students, one student in the role of doctor and a second student observing. The students change roles for each SP encounter. After the encounter, SPs provide the "student-doctor" with feedback. SP encounters are recorded on DVD and discussed one week later in a tutorial group composed of ten students and a teacher. The SP program is fully integrated with the undergraduate curriculum of the Maastricht Medical School. ${ }^{11}$ For this experiment, encounters with real patients were organized within the structure of a regular SP encounter on asthma in Year 1. The experiment was performed during this SP encounter since the recruitment of real asthma patients seemed relatively easy and since students were offered the opportunity to practice a full consultation (including physical examination) during the encounter.

\section{Students}

All first year students were informed about the experiment by an announcement on the electronic learning environment of the Maastricht University. The students registered to perform the consultation in the role of student-doctor $(\mathrm{N}=163)$ were randomized to having a real patient encounter or an SP encounter. The students were informed about the encounter, specifically about the type of patient (real or simulated) assigned to them, by means of an email a few days before the consultation. A comparable preparation advice for both encounters was offered. The students were all involved in a module in which asthma was addressed. Students should therefore be able to manage a consultation with a patient suffering from asthma. 
For the experiment, adult patients with asthma were recruited via general practitioners (GPs) practices in Maastricht since we thought it was important to have the GPs' approval for participation of their patients. Several criteria were laid down for the selection of real patients (List 1). The recruitment and selection of patients turned out to be very difficult. In only one practice GPs were able to recruit patients themselves and one practice agreed on recruitment by the main researcher (LB). In total, nine patients were recruited and selected. All patients were informed about the encounters with the students. Similar to the SPs, the real patients were paid $\$ 13$ per hour for their participation.

\section{List 1. Selection criteria for real patients}

- Patients should use inhalation steroids to ensure the patient suffered from chronic intermittent asthma.

- Patients should not be currently treated by a pulmonologist to avoid the medical histories of the patients to be too complex for first year students.

- Patients should be available during at least one of the scheduled sessions.

- Patients should feel comfortable with having a consultation (including physical examination) with a first year medical student.

\section{Instruments}

\section{Questionnaires}

A questionnaire regarding the perceived instructiveness of real patient encounters and SP encounters was developed on the basis of literature and previous qualitative research. ${ }^{12}$ The draft questionnaire was revised based on comments of several experts in the field of medical education, second year medical students and teachers. The final questionnaire consisted of two parts. The first part contained general questions with regard to the patient encounter such as position of the student during the encounter (student-doctor or observer) and type of patient encounter (real patient encounter or SP encounter). The second part, shown in Table 1, contained statements on seven aspects of the patient encounter: preparation, authenticity of the consultation, content of the consultation (learning communication, history taking and physical examination skills), safety during the consultation, feedback provided by the patient, difficulty of the encounter, impact of the encounter (on learning in general). The students were asked to indicate their agreement with the statements on a four-point 
Likert scale $(1=$ complete disagreement, $4=$ complete agreement $)$. In addition, students could assign a general mark (on a 10 point scale) for the perceived instructiveness of the patient encounter and could make free comments. The questionnaire was anonymous, so students would feel free to report their views. To explore the views of teachers of the groups in which the patient encounters were discussed, a second questionnaire was developed. This questionnaire, shown in Table 2, was intended for teachers of groups in which students had had encounters with real patients and SPs. Teachers could also make free comments. 
Table 1. Evaluations of student-doctors and observers with regard to real patient encounters and simulated patient encounters

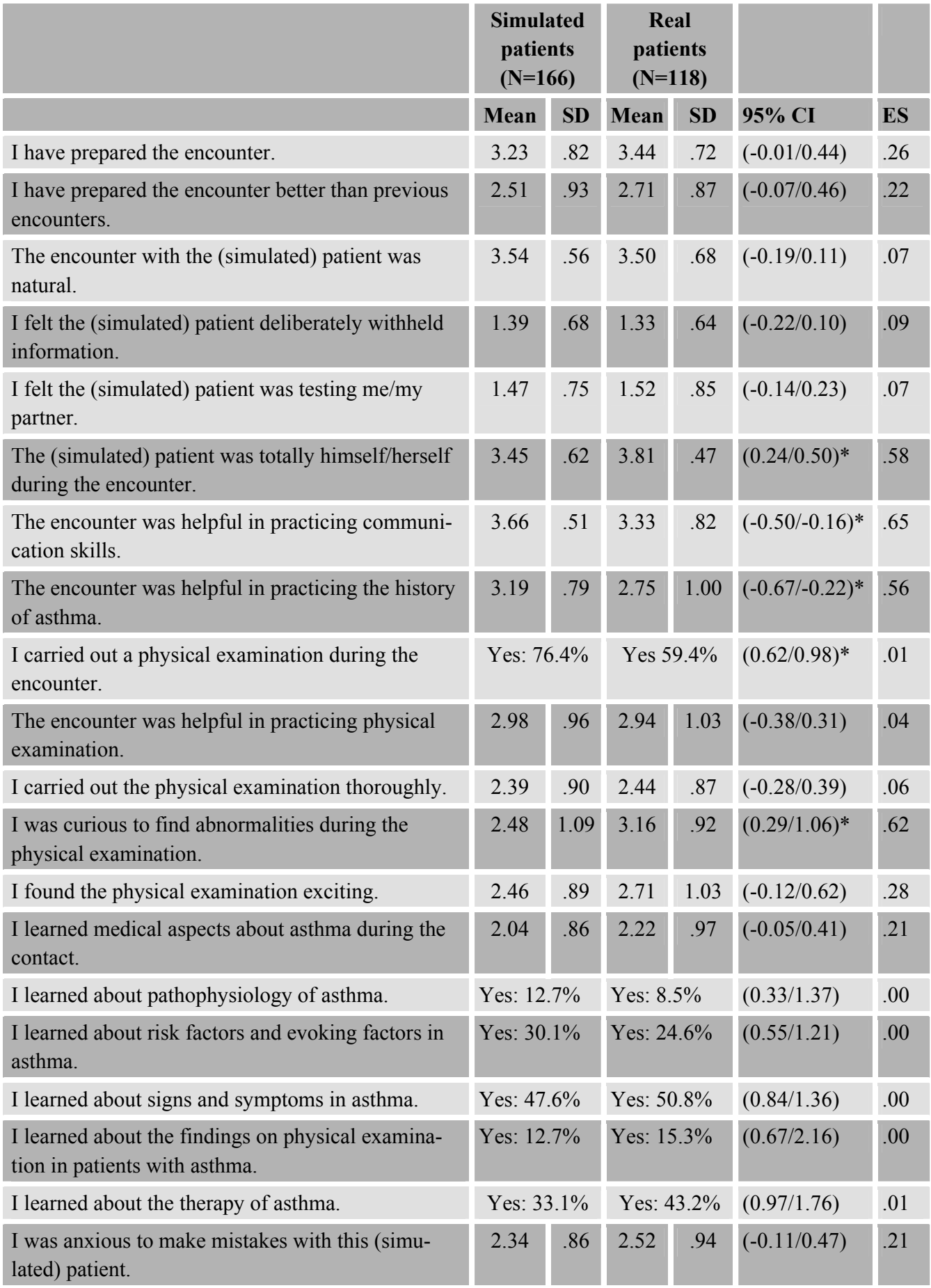




\begin{tabular}{|c|c|c|c|c|c|c|}
\hline & \multicolumn{2}{|c|}{$\begin{array}{c}\text { Simulated } \\
\text { patients } \\
(\mathrm{N}=166)\end{array}$} & \multicolumn{2}{|c|}{$\begin{array}{c}\text { Real } \\
\text { patients } \\
(\mathrm{N}=118)\end{array}$} & \multirow[b]{2}{*}{$95 \%$ CI } & \multirow[b]{2}{*}{ ES } \\
\hline & Mean & SD & Mean & SD & & \\
\hline $\begin{array}{l}\text { I felt comfortable during the encounter with the } \\
\text { (simulated) patient. }\end{array}$ & 3.25 & .70 & 3.12 & .78 & $(-0.36 / 0.10)$ & .19 \\
\hline $\begin{array}{l}\text { I felt insecure during the encounter with the } \\
\text { (simulated) patient. }\end{array}$ & 2.26 & .81 & 2.27 & .94 & $(-0.27 / 0.29)$ & .01 \\
\hline $\begin{array}{l}\text { I dared to ask all questions with this (simulated) } \\
\text { patient. }\end{array}$ & 3.61 & .67 & 3.48 & .64 & $(-0.35 / 0.08)$ & .19 \\
\hline I felt free to practice my learning goals. & 3.38 & .67 & 3.13 & .85 & $(-0.50 /-0.01)^{*}$ & .37 \\
\hline I find it important to receive feedback. & 3.89 & .37 & 3.84 & .37 & $(-0.14 / 0.04)$ & .14 \\
\hline $\begin{array}{l}\text { I received feedback that was relevant to me from } \\
\text { the (simulated) patient. }\end{array}$ & 3.50 & .65 & 3.05 & .94 & $(-0.72 /-0.19)^{*}$ & .69 \\
\hline $\begin{array}{l}\text { I take the feedback I received from the (simulated) } \\
\text { patient seriously. }\end{array}$ & 3.85 & .39 & 3.79 & .41 & $(-0.19 / 0.06)$ & .15 \\
\hline $\begin{array}{l}\text { The (simulated) patient dilated upon small things in } \\
\text { the provision of feedback. }\end{array}$ & 1.40 & .63 & 1.51 & .73 & $(-0.05 / 0.28)$ & .17 \\
\hline $\begin{array}{l}\text { The (simulated) patient gave feedback spontane- } \\
\text { ously. }\end{array}$ & 2.48 & 1.01 & 2.72 & .95 & $(-0.01 / 0.48)$ & .24 \\
\hline $\begin{array}{l}\text { The (simulated) patient gave feedback after } \\
\text { concrete questions from me/my partner. }\end{array}$ & 3.05 & .88 & 2.45 & .92 & $(-0.82 /-0.38)^{*}$ & .68 \\
\hline $\begin{array}{l}\text { The feedback of the (simulated) patient helped me } \\
\text { to make new learning goals. }\end{array}$ & 3.08 & .86 & 2.52 & .98 & $(-0.86 /-0.25)^{*}$ & .65 \\
\hline The encounter fitted in with the block "Dyspnoea". & 3.62 & .51 & 3.34 & .75 & $(-0.44 /-0.13)^{*}$ & .55 \\
\hline $\begin{array}{l}\text { The (simulated) patient encounter was hard for me } \\
\text { as a first year medical student. }\end{array}$ & 2.29 & .88 & 2.54 & .97 & $(0.02 / 0.48)^{*}$ & .28 \\
\hline The contact has made an impression. & 2.67 & .74 & 2.97 & .79 & $(0.13 / 0.49)^{*}$ & .41 \\
\hline The contact motivates to me for further study. & 3.24 & .74 & 3.22 & .73 & $(-0.19 / 0.16)$ & \\
\hline $\begin{array}{l}\text { The contact provides a clear understanding of the } \\
\text { meaning of this disease for a patient. }\end{array}$ & 2.71 & .84 & 3.03 & .85 & $(0.12 / 0.53)^{*}$ & .38 \\
\hline $\begin{array}{l}\text { The contact helps me in my professional training as } \\
\text { a doctor. }\end{array}$ & 3.25 & .61 & 3.30 & .69 & $(-0.11 / 0.20)$ & .08 \\
\hline General instructiveness of the encounter. & 7.43 & .75 & 7.22 & 1.30 & $(-0.48 / 0.05)$ & .28 \\
\hline
\end{tabular}


Table 2. Evaluations of teachers $(\mathrm{N}=21)$ with regard to real patient encounters and simulated patient encounters

\begin{tabular}{|c|c|c|c|}
\hline \multicolumn{4}{|c|}{$\begin{array}{l}\text { Were there any differences between student-real patient encounters and student-SP } \\
\text { encounters with regard to: }\end{array}$} \\
\hline & $\begin{array}{l}\text { Yes, better in real } \\
\text { patient encoun- } \\
\text { ters }\end{array}$ & $\begin{array}{l}\text { Yes, better in SP } \\
\text { encounters }\end{array}$ & No, no differences \\
\hline $\begin{array}{l}\text { students' communication } \\
\text { skills. }\end{array}$ & $1(4.8 \%)$ & $9(42.9 \%)$ & $8(38.1 \%)$ \\
\hline $\begin{array}{l}\text { students' history taking } \\
\text { skills. }\end{array}$ & 0 & $11(52.4 \%)$ & $8(38.1 \%)$ \\
\hline $\begin{array}{l}\text { students' physical } \\
\text { examination skills. }\end{array}$ & $2(9.5 \%)$ & $3(14.3 \%)$ & $12(57.1 \%)$ \\
\hline $\begin{array}{l}\text { students' patient manage- } \\
\text { ment skills. }\end{array}$ & 0 & $11(52.4 \%)$ & $9(42.9 \%)$ \\
\hline \multicolumn{4}{|c|}{ Were there any differences between reactions of students in the group with regard to: } \\
\hline $\begin{array}{l}\text { authenticity of the } \\
\text { encounter. }\end{array}$ & $5(23.8 \%)$ & $8(38.1 \%)$ & $6(28.6 \%)$ \\
\hline safety of the encounter. & 0 & $9(42.9 \%)$ & $11(52.4 \%)$ \\
\hline $\begin{array}{l}\text { feedback by the pa- } \\
\text { tient/SP. }\end{array}$ & $1(4.8 \%)$ & $12(57.1 \%)$ & $5(23.8 \%)$ \\
\hline difficulty of the encounter. & $16(76.2 \%)$ & 0 & $4(19 \%)$ \\
\hline $\begin{array}{l}\text { instructiveness of the } \\
\text { encounter. }\end{array}$ & $5(23.8 \%)$ & $6(28.6 \%)$ & $8(38.1 \%)$ \\
\hline \multicolumn{4}{|c|}{ What did you find the most instructive encounter? } \\
\hline $13(61.9 \%)$ SP encounter. & \multicolumn{3}{|c|}{$3(14.3 \%)$ real patient encounter. } \\
\hline
\end{tabular}

\section{Focus group sessions}

To gather qualitative information on the perceived instructiveness of the patient encounters and to elaborate on the results of the questionnaire, two focus group interviews, each lasting 1-1.5 hours, were held. All students who had performed the consultation in the role of student-doctor were sent an invitation to participate in a focus group session by email. Two focus groups were composed on the basis of students interested in participating ( $\mathrm{N}=17)$. Students were paid $\$ 22$ for participation. The focus group sessions followed the guidelines offered by Morgan and Krueger. ${ }^{13}$ The focus group interviews were audio taped for later transcription and guided by an independent moderator. It was explained to the 
students that the analysis and the reporting of the results would be anonymous. The interview was semi-structured on the basis of pre-established interview guide (List 2) which was based on the results of the questionnaire.

\section{List 2. Interview guide}

- How did you prepare for the encounter? Were there any differences in your tutorial group between preparation of students who had a real patient encounter and those who had an SP encounter?

- In retrospect, which type of encounter did you find most authentic/realistic? For example, real patients were found to be more themselves than SPs. Why?

- SP encounters were considered more instructive with regard to learning communication skills and history of asthma. Why?

- In retrospect, which encounter did you find more instructive in the learning of physical examination skills? For example, does the finding that you are more curious to find abnormalities in real patients play a part?

- Physical examination was performed less in real patients than in SPs. Why?

- We found you felt freer to practice your learning goals in SP encounters. Why?

- Which feedback did you find most instructive: feedback from real patient or from SP? Why? For example, does the finding that feedback by SPs is more relevant and more helpful in making new learning goals play a part?

- Real patient encounters were considered more impressive than SP encounters. Why? For example, does the finding that real patients provide a clear understanding of the meaning of a disease for a patient play a part?

- Real patient encounters were considered more difficult than SP encounters. Why?

- Do you have suggestions for the use of real patients and SPs in medical education? For example with regard to the phase of the curriculum? 
Analysis

\section{Questionnaires}

We analyzed the data with SPSS (15.0) for Windows, calculating frequencies for all items. Differences between evaluations of students who had an SP encounter and those of students who had an encounter with a real patient were calculated using the T-test for two independent samples. The T-test was used because the evaluations of students were normally distributed by approximation because of the large numbers of students. Whether the role of the student during the consultation (student-doctor or observer) had an effect on the difference between the evaluations of students who had an SP encounter and those of students who had real patient encounter, was tested with ANOVA. In case the role of the student appeared to be of influence, a simple effects analysis was carried out. Since scores on the items 9 and 15 to 19 of the questionnaire were nominal (Yes or No), differences with regard to these items were calculated using the Chi-Square test. Effect sizes were calculated following the guidelines described by Hojat and $\mathrm{Xu} .{ }^{14} \mathrm{~A}$ p-value smaller than 0.05 was considered to be statistically significant. Differences with effect sizes around 0.20 were considered to be of limited practical importance. Differences with effect sizes around 0.50 were considered to be of moderate practical importance and differences with effect sizes around 0.80 were considered to be of large practical importance.

\section{Focus group interviews}

The recordings of the two focus groups were transcribed by one of the authors (LB). The transcripts were summarized and sent to the students for approval. The transcripts were imported into the software program ATLAS-ti and were reviewed and coded by two reviewers independently (LB and RD). When the two reviewers disagreed, the codes were discussed until agreement was reached. The main codes corresponded with the questions discussed in the focus groups (List 2). Additional codes were used for new themes raised by the participants during the discussions. 


\section{Results}

\section{Questionnaires}

Of the 163 students registered to perform the consultation, 61 students (37\%) had encounters with real patients and 102 students $(63 \%)$ had the regular SP encounters. The total response on the student questionnaire was high (87\%).

Table 1 shows the evaluations of student-doctors and observers with regard to real patient encounters and SP encounters. There were several significant differences between the evaluations of students who had an SP contact and those of students who had a real patient contact. The effect sizes of most differences were considerable, indicating moderate to large practical importance. For example, compared to SP encounters, students considered real patient encounters less helpful in practicing communication skills (item 7). Students felt real patients were more themselves during the encounter (item 6) and students were more curious to find physical abnormalities in real patients (item 12). Furthermore, the feedback provided by SPs was considered more relevant compared to the feedback of real patients (item 26) and was more helpful in the making of new learning goals (item 31). The position of the student during the patient contact (student-doctor or observer) appeared not to influence the differences that were found, except for the difference found on item 7. Here, the evaluations of student-doctors were significantly different with regard to real patient encounters and SP encounters, but the evaluations of observers were not. The mean mark for the general instructiveness of real patient encounters and SP encounters was not significantly different (item 38).

The response on the teacher questionnaire was $67 \%$. In all groups students had had encounters with real patients and SPs, with a mean number of 3 SP encounters and 2 real patient encounters per group. The evaluations of teachers regarding real patient encounters and SP encounters are shown in Table 2. The majority of the teachers indicated students showed better skills in SP encounters or indicated that there was no difference. SP encounters were considered more instructive than real patient encounters. Several reasons were mentioned, for example:

"Because students can learn the basic skills in a safe environment, with rather trained SPS."

and 
"students have difficulty structuring [the consultation] and you can better practice this with an SP."

Most teachers preferred the feedback provided by SPs to the feedback provided by real patients and real patient encounters were considered more difficult than SP encounters. Many teachers felt the real patients did not know the purpose of the consultation which contributed to the difficulty of the consultation.

\section{Focus group interviews}

Compared to SP encounters, most students had better prepared the real patient encounters. A thorough preparation helped students to feel more self-assured.

"I was afraid I would otherwise say something wrong because a real patient knows a lot more about medical aspects than an SP."

Most students considered the real patient encounters to be more authentic as they felt some SPs were simply presenting pre-established symptoms or were deliberately withholding information.

"An SP just knows what I need to know to make a diagnosis and real patients don't."

"...Real patients talk more from themselves."

Because of their authenticity, real patient encounters made a more profound impression on the students.

Real patient encounters were considered less useful for practicing communication skills and learning goals related to communication skills. Students felt some real patients were ill-informed about the routine of the consultation and did not have a clear request for help.

"She said I don't have complaints, yes I do cough but that's not a problem, I just drink tea with honey and then it's done."

Some students also said the emphasis in the real patient encounters was less on communication skills and more on medical aspects.

"The fact that real patients have more medical knowledge and can judge you on this makes it very hard for me because I have to practice how to make a summary, ask open-ended questions and respond to the patient, instead of medical knowledge."

Many students felt that if the real patients would be better informed about the routine of the consultation, real patient encounters would be more useful than SP encounters to practice communication skills. 
"Because the real patient actually suffers from those symptoms and he knows what he is talking about."

Real patient encounters were considered more useful than SP encounters in practicing physical examination skills, mainly since real patients have actual abnormal physical findings. Consequently, students were more motivated and more directed at the physical examination. Students performed fewer physical examinations in real patient encounters since they felt the physical examination was less relevant to the real patient contact and some since they did not want to burden the patient.

Most students indicated the real patient encounters seemed more difficult beforehand.

"Because you just don't know what to expect."

However, some students said the real patient encounters appeared to be easier during the consultation since the real patients talked more spontaneously. Some students regarded the real patient encounters as more difficult since the emphasis was on medical aspects.

Students preferred the feedback from SPs to the feedback from real patients since the SPs' feedback was more specific.

"SPs know what they have to pay attention to."

However, students felt the feedback from SPs was often far-fetched.

The majority of students felt the real patient encounter was scheduled too early in the curriculum. Students preferred to have 3 to 4 regular SP encounters before the introduction of real patient encounters, although some students preferred to have real patient encounters from the start.

\section{Discussion}

On the questionnaire, the general instructiveness of the patient encounters was marked high by first-year students and the mean marks for the general instructiveness of real patient encounters and SP encounters were comparable. However, there were several significant and practically relevant differences between the evaluations of real patient encounters and SP encounters. The focus group sessions yielded explanations for many of the differences found. Studentdoctors considered the real patient encounters less useful for practicing communication skills. Students, as well as teachers, felt some of the real patients were ill-informed about the routine of the consultation and that real patient encounters focused more on medical aspects instead of on communication skills. 
Consequently, students had trouble practicing the learning goals related to communication skills. For student-observers, no significant difference was found between real patient encounters and SP encounters with regard to practicing communication skills. We think this may be due to the inherently different perspectives of the student roles, with student-doctors actually practicing their communication skills, in contrast to observers.

If real patients would be better informed about the routine of the consultation, many students would prefer real patient encounters to SP encounters for practicing communication skills, mainly because of their authenticity. Since the real patient encounters were regarded as more authentic they also made a more profound impression on the students. Authenticity is thus considered an important advantage of real patient encounters. However, an important disadvantage of real patients we encountered in this experiment is their difficult recruitment and selection.

Although many students would prefer real patient encounters, most students also preferred having several SP encounters prior to the real patient encounters. Teachers generally preferred SP encounters for teaching communication skills. The phase of the study and the aim of the consultation appear to be decisive in the use of real patients or simulated patients in medical education. Further research is needed on the phase of the curriculum in which real patient encounters can best be introduced. For example, a similar experiment in a later phase in the undergraduate curriculum or in a set-up in which several SP encounters prepare students for real patient encounters.

Both students and teachers considered feedback from SPs more instructive than the feedback from real patients. This is not surprising as the SPs in this study were extensively trained to provide feedback, in contrast to the real patients. We did not train the real patients to provide feedback since we wanted the encounters to be as authentic as possible.

This study has several limitations. Since the number of patients recruited for the experiment was smaller than we had expected, fewer students than we had initially planned were allocated to have an encounter with a real patient. Since the students in our study were previously informed about the type of encounter (real patient encounter or SP encounter) they were having, they might have been biased by their expectations regarding the encounter. However, in the practice of medical education, students know which patient (real or simulated) they are to encounter. For this reason, we chose to inform the students about the type of patient encounter they were having. Further research is needed to explore the role of expectations of students regarding a patient encounter. 
Furthermore, as mentioned earlier some of the real patients appeared not to understand the routine of the consultation with the student. This might have affected the perceived instructiveness of the encounter. Perhaps we should have made the routine of the encounter more clear to the real patients. Although we did not provide the patients with predetermined symptoms to keep them as authentic as possible, we might have been more guiding. Further research is needed to address these issues.

In conclusion, although both SP encounters and real patient encounters are perceived highly instructive, each encounter has specific advantages and disadvantages. For example, real patients are considered more authentic whereas their recruitment and selection is very difficult. Advantages of SPs are their usefulness in practicing communication skills and their feedback.

\section{References}

1. Littlewood S, Ypinazar V, Margolis SA, Scherpbier A, Spencer J, Dornan T. Early practical experience and the social responsiveness of clinical education: systematic review. British Medical Journal. 2005;331(7513):387-391.

2. Dornan T, Littlewood S, Margolis SA, Scherpbier A, Spencer J, Ypinazar V. How can experience in clinical and community settings contribute to early medical education? A BEME systematic review. Med Teach. Feb 2006;28(1):3-18.

3. Dammers J, Spencer J, Thomas M. Using real patients in problem-based learning: students' comments on the value of using real, as opposed to paper cases, in a problem-based learning module in general practice. Medical Education. 2001;35(1):27-34.

4. Howe A, Anderson J. Involving patients in medical education. British Medical Journal. Aug 9 2003;327(7410):326-328.

5. Spencer J, Blackmore D, Heard S, et al. Patient-oriented learning: a review of the role of the patients in the education of medical students. Medical Education. 2000;34(10):851-857.

6. Bokken L, Rethans JJ, Scherpbier A, Van Der Vleuten C. Strengths and weaknesses of simulated and real patients in the teaching of skills to medical students: a review. Simulation in Health Care. 2008;3(3):161-9.

7. Gilliland WR, Pangaro LN, Downing S, et al. Standardized versus real hospitalized patients to teach history-taking and physical examination skills. Teach Learn Med. 2006;18(3):188-195.

8. Helfer RE, Black MA, Teitelbaum H. A comparison of pediatric interviewing skills using real and simulated mothers. Pediatrics. Mar 1975;55(3):397-400.

9. Sanson-Fisher RW, Poole AD. Simulated patients and the assessment of medical students' interpersonal skills. Med Educ. Jul 1980;14(4):249-253.

10. Simek-Downing L, Quirk ME, Letendre AJ. Simulated versus actual patients in teaching medical interviewing. Family Medicine. 1986;18(6):358-360.

11. Van Dalen J, Bartholomeus P, Kerkhofs E, et al. Teaching and assessing communication skills in Maastricht: the first twenty years. Medical Teacher. May 2001;23(3):245-251. 
12. Bokken L, Rethans JJ, Van Heurn L, Duvivier R, Scherpbier A, Van Der Vleuten C. Student views on the use of real patients and simulated patients in undergraduate medical education. Accepted by Academic Medicine.

13. Morgan DL, Krueger RA. The focus group kit. Vol 1-6. London, New Delhi: Sage Publications; 1998 .

14. Hojat M, Xu G. A visitor's guide to effect sizes: statistical significance versus practical (clinical) importance of research findings. Advances in Health Sciences Education 2004;9(3):241-249. 



\section{Chapter 11}

\section{General discussion}




\section{Conclusions}

Research question 1: What are the practical implications of the perceived advantages and disadvantages of the use of SPs for teaching purposes in the undergraduate medical curriculum?

We explored the practical implications of key advantages of the use of SPs in medical education: SPs can give feedback to medical students (Chapter 2), SP roles can be performed by people of various age groups, including adolescents (Chapters 3 and 4), and SP roles can be adapted to specific educational needs, for example to enable students to conduct longitudinal SP encounters within a limited period of time (Chapter 5). We also explored the impact of role performance on SPs (Chapters 6 and 7), which may be an important disadvantage of the use of SPs.

In this chapter we present the conclusions of the studies in which the advantages and disadvantages of the use of SPs were explored.

\section{Feedback}

The aims of the study presented in Chapter 2 were to identify how SPs provide feedback to undergraduate medical students, the domains on which they provide feedback and how they are trained to provide feedback.

The ability of SPs to give feedback is considered an important advantage in the use of SPs for teaching purposes in undergraduate medical education. ${ }^{1,2}$ SPs provide feedback on a large scale in medical education. ${ }^{1}$ We were therefore surprised by the lack of comparative studies on effective methods to be used by SPs in providing feedback to medical students. In most of the studies included in our systematic review, feedback was not an object of study in itself but featured only as a tool for medical skills teaching. Considering that studies on feedback in general (not specifically on feedback by SPs) have yielded considerable evidence on how to provide feedback effectively, we expected that most of the feedback provided by SPs would be in line with these methods. This proved not to be the case, however. Also, the domains of SP feedback (clinical skills and communication skills) were inconsistent with the literature, where SPs are recommended to provide feedback from a patient's perspective. Fur- 
thermore, there was considerable heterogeneity with regard to methods and domains of SP feedback and feedback training.

In conclusion, methods and domains of SP feedback and feedback training are poorly supported by evidence and consensus on this topic appears to be lacking. In our opinion, the advantages of SP feedback are not being used to its full extent, which is disappointing considering the crucial role of effective feedback in clinical learning., ${ }^{2,3}$ In our opinion feedback from SPs is an important area for further research (see "Implications for further research"). In expectance of this research, we think SP feedback should be in accordance with evidence from studies on feedback in general (Box 2, Chapter 2). Furthermore, consistent with recommendations from the literature, SPs should give feedback from a patient's perspective.

\section{Adolescent SPS}

The study presented in Chapter 3 evaluated the quality of role play and feedback provided by adolescent SPs and the way role playing affected adolescents trained to perform an individualized simulated patient role (in contrast to a standardized patient role). The study presented in Chapter 4 examined the views of teachers, students and adolescent SPs on the adolescent SP program, the extent to which these views changed over a five-year period, and the lessons that were learned.

Since, with SP roles for teaching purposes, the emphasis is on authenticity and credibility, roles are generally kept close to SPs' personalities. ${ }^{4}$ SPs are trained to incorporate their personal backgrounds into the patient roles consistent with the method acting style. It is known that method actors are more susceptible to adverse effects from acting than technique actors, who keep a greater personal distance to the roles they perform. ${ }^{5} \mathrm{By}$ analogy, simulated patients whose training is consistent with method acting may be more likely than standardized patients to experience negative effects due to role playing. Furthermore, other studies in this thesis revealed that adult simulated patients experience negative effects due to role performance (Chapter 6 and 7). Fortunately, no negative effects were found in the adolescent simulated patients we studied. These results are consistent with results from other studies on adolescent standardized patients. ${ }^{6-9}$ Adolescent SPs considered role playing easier when the role was close to their personality. ${ }^{9}$ Taking this into account, as well as the importance of 
authentic and credible role performance, we recommend the use of adolescent simulated patients for teaching situations in medical education.

We believe the differences we found between adolescent SPs and adult SPs with regard to the impact of role playing (Chapter 6 and 7) are mainly attributable to the different research methods used in the respective studies. More comprehensive questionnaires to explore the impact of role performance on adolescent SPs or in-depth qualitative research using focus group interviews with adolescent SPs might have yielded different results.

Students and teachers were positive in their judgement of the quality of adolescent SPs' role performance and feedback. Students' judgements remained positive over several years. However, there were some matters of concern. First of all, the marks given by students for overall SP performance were higher during the first year of the adolescent SP program than four years later. In order to maintain the high quality of role performance, continuous attention should be paid to the adolescent SP program, particularly to recruitment, selection and training. Secondly, although students' evaluations of SP feedback became increasingly positive over the years, feedback remains an issue of concern, particularly since adolescent SPs have indicated that giving feedback is quite difficult for them. We feel that training adolescent SPs in providing feedback can improve the quality of the feedback and make SPs feel more comfortable with this task. Instruments like the structured communication adolescent guide (SCAG) can be helpful in this. ${ }^{10}$

\section{Longitudinal SP encounters}

The study described in Chapter 5 explored students' and teachers' views on a longitudinal SP program in which students had four consecutive encounters with the same SP during an 8-month period. We also compared students' judgements of this SP program with their evaluations of a single-case SP program and we explored the feasibility of the longitudinal SP program in terms of the difficulties encountered in running this program.

Students and teachers were positive in their judgement of the longitudinal SP program and considered it instructive. Similar results were found in other studies. ${ }^{11,12}$ We hypothesized that students would prefer the longitudinal SP program to the single-case SP program since in another study SPs had indicated that the encounters in the longitudinal program were more realistic and enabled more detailed feedback compared to the single-case encounters. ${ }^{13}$ However, the 
students were found to prefer the longitudinal program, although they considered it just as educationally rewarding as the single-case SP program. An explanation for this finding may be that some students did not take full advantage of the opportunities offered by the longitudinal SP program for practicing continuity of care. This may have mitigated the perceived difference between the longitudinal and the single-case SP programs. ${ }^{13}$ Another possible explanation is that students thought the SP encounters had little additional value compared to their experiences with real patients in year 3 (Chapter 9), despite the generally positive evaluations of the longitudinal program.

The longitudinal SP program proved not to be feasible due to lack of commitment from faculty and the huge workload involved in the program. A similar program but on a smaller scale may be more feasible. Nevertheless, we feel that longitudinal SP encounters have considerable educational potential in offering students experience with continuity of care within a limited period of time. The longitudinal SP encounters were evaluated positively by both students and teachers and appeared to offer the same advantages as single-case SP encounters, such as safety and feedback.

\section{Impact of role playing on SPS}

In Chapter 6 we described a quantitative study in which questionnaires were used to examine performance-related stress in SPs. In Chapter 7 we described a qualitative study in which focus groups were used to further explore the negative impact of performing patient roles on SPs and factors that might affect this, either negatively or positively. Our aim was to find ways to prevent negative effects due to role playing in SPs.

The majority of the SPs (73\%) reported role-related stress symptoms, with a mean number of 4 symptoms per SP. This was much higher than we had expected. Fortunately, the severity of the symptoms appeared to be moderate, with a mean score of 2.2 on a 5-point Likert scale. Similar results emerged from the focus group study. Of the five symptoms reported most frequently in the questionnaire study, two, i.e. fatigue and dissatisfaction with performance, were also reported in the focus groups. The symptoms reported most frequently in the questionnaire and the symptoms mentioned in the focus groups were consistent with those found in other studies. ${ }^{5,14-16}$

From the quantitative study no factors emerged that influenced the impact of role performance on SPs but the focus group discussions revealed several 
factors, such as the type of role, the number of consecutive performances and the time between performances. This difference in findings is probably attributable to the different research methods of the two studies. Apparently, focus groups were a more sensitive method than questionnaires for identifying correlations between factors that may contribute to the impact of role performance on SPs and the actual impact experienced by SPs. Although method actors are more likely to experience negative effects due to role playing ${ }^{5}$ we found no association between type of role training (consistent with method acting) and the impact of performance. A possible explanation for this is that the SPs in our study were only familiar with this type of training and therefore unaware of any adverse effects related specifically to this method.

We reported several measures to mitigate the negative impact of role playing on SPs (Figure 1, Chapter 7). The results also showed that SPs regarded negative effects as inherent in role performance and their work as SPs. Moreover, the impact of role playing did not diminish the SPs' enjoyment of their work. Consequently, one might wonder whether it is necessary to take measures to reduce the impact of role playing. However, just as it is an employer's responsibility to look after the health and wellbeing of his/her employees, we feel that SP programs should look after their SPs. We feel the measures to reduce the impact of role playing are easy to realize. These measures may be a small price to pay for remedying an important disadvantage of the use of SPs for teaching purposes.

Research question 2: What are the advantages and disadvantages of the use of SPs as opposed to real patients in undergraduate medical education?

The systematic literature review presented in Chapter 8 identified different roles of real patients and SPs in undergraduate medical education and the benefits and limitations of these roles. In the study described in Chapter 9, focus group interviews were conducted to explore students' views regarding the strengths and weaknesses of real patient contacts as opposed to SP contacts and to evaluate how the strengths of both types of patient contact can be optimally used and weaknesses remedied. In the experiment described in Chapter 10 we used quantitative and qualitative methods to evaluate whether real patient contacts or SP contacts were perceived as most instructive by students and which variables contributed to the perceived instructiveness. 
The literature review revealed several key advantages as well as disadvantages of the use of SPs as opposed to real patients, some of which were also reported by students in our study (Chapters 9 and 10). For example, students considered SPs very useful for learning "intimate" physical examination skills such as pelvic examination skills but less useful for other physical examination skills such as abdominal examination skills, because SPs lack actual abnormal physical findings. An advantage of SPs over real patients is their availability, since recruitment and selection of real patients appeared to be very difficult (Chapters 8 and 10).

Students in the clinical phase of a six-year undergraduate curriculum (years four and five) as well as first-year medical students considered SP encounters a good preparation for real patient encounters and preferred having several SP encounters before the introduction of real patient encounters. This is probably attributable to the SPs' advantage of offering a safe learning environment in which students do not need to worry about their skills being imperfect. Although the views of the fourth and fifth year students may have been biased because of their numerous SP encounters prior to experiences with real patients, this type of bias seems unlikely to have occurred among the first-year students. SP contacts prior to the introduction of real patient contacts thus seem a generally desirable strategy. Students considered SP encounters useful until the introduction of real patient contacts. However, it is not clear at which point in the curriculum real patient contacts should commence. They might be introduced at the end of the first year or at the start of the second year after students have had several SP encounters.

Students regarded the ability of SPs to provide feedback as an important advantage compared to real patients. However, from the systematic literature review it appeared that real patients can also give feedback, though this applies particularly to real patients in a teaching role (patient instructors). Although at Maastricht University SPs actively teach pelvic examination skills to medical students $^{17}$, real patients have no active teaching roles. Consequently, the only feedback students receive from real patients is from patients in passive teaching roles. This may explain the different findings for SPs and real patients with regard to feedback.

Students considered authenticity an important advantage of real patients compared to SPs. This is an interesting finding especially in light of research involving incognito SPs visiting practicing physicians (who knew about the visit but not about its timing) where SP detection rates of less than $15 \%$ of cases $^{18}$ and even less than $1 \%$ were reported. This suggests that SPs' authentic- 
ity can be high. Students in our studies may have been biased by their assumptions and expectations regarding real and simulated patient contacts and these expectations might have affected the students' perceptions of the authenticity of SP contacts. Authenticity is an important aspect in contextual learning: the closer the learning is to real life, the more quickly and effectively skills can be learned. ${ }^{19,20}$ Therefore, students' assumptions regarding the authenticity of patient encounters may affect their learning from these encounters (see section "Implications for further research").

The fact that SP encounters can be interrupted to discuss the case or give tips to students ("time-out") is generally considered an advantage of SP encounters as opposed to real patient encounters. ${ }^{21}$ However, the students in our study reported that it was easier for them to take a time-out in real patient contacts than in SP contacts. This is a remarkable finding. At Maastricht University, SP contacts are mostly limited to the early years of the curriculum while real patient contacts are the main format during the later years. The fact that students become more confident over the years might explain why they appear to be less hesitant to ask for a time-out in real patient contacts during the later years. Another explanation might be that the SP encounters were experienced as assessments by students, even though their primary purpose is to foster student learning. As we learned from conversations with students, some students experienced the SP encounters as a test because their performance is recorded on DVD and viewed and discussed by a teacher and a group of their peers. For these students, taking a time-out might feel like failing and consequently they may be reluctant to do so.

With the rapid development of realistic simulation techniques, one might question the additional value of contacts with patients (real and simulated patients) in medical education. However, in our opinion (simulated) patient contacts remain an essential component of medical education. SPs can add aspects of interpersonal and communication skills and medical professionalism to technical simulations. ${ }^{19}$ Integrating SPs and simulation techniques may offer a more authentic and richer educational experience than practicing with a simulator only. ${ }^{19,22}$ Also, the ability of SPs to provide feedback from a patient's perspective can help students obtain a fuller picture of their performance. ${ }^{19}$ 


\section{Limitations}

\section{Context}

A limitation of this thesis is that many of the studies were conducted within the setting of the undergraduate medical curriculum of Maastricht University. As we described in Chapter 1, SPs at Maastricht University are predominantly used for teaching purposes, in contrast to other settings notably in the USA and Canada where their role is largely confined to assessment. Although this may have affected the generalizability of our results to some extent, we think that most of our results can be generalized to the use of SPs in other teaching settings. Additionally, SPs at Maastricht University are mostly used in the teaching of communication skills during the early years of the medical curriculum. Later in the curriculum, especially during the clinical phase, students have encounters with real patients. The emphasis in real patient encounters is mainly on learning more complex clinical skills such as clinical reasoning and patient management and on integration of skills. This may have biased the views of students in our studies with regard to the strengths and weaknesses of SPs as opposed to real patients and may have reduced the transferability of the results to other settings.

\section{Continuum of real patients and SPS}

Another aspect that may complicate the transfer of results of this thesis to other settings is the continuum of real patients and SPs, as discussed in Chapter 1. The distinctions between real and simulated patients have become somewhat blurred because of the continuum of real patients in clinical practice who have received no training and SPs who have been extensively trained in portraying patient roles. Consequently, there is heterogeneity in reports on the use of real patients and SPs, with real patients simulating some aspects of their roles and SPs showing real abnormalities on physical examination. Furthermore, reports on research involving SPs often lack detailed information, for example regarding the SPs themselves and their training. ${ }^{23}$ Different interpretations of the concepts "real patient" and "SP" in different research settings may thus impair the transfer of research results to other settings. Recently, Howley et al. advocated increased rigour and uniformity in reporting research involving SPs. ${ }^{23} \mathrm{We}$ 
think this is essential to enhance the generalizability and (external) validity of research findings.

\section{Implications for further research}

An important area for further research that was identified in this thesis concerns the feedback provided by SPs. Feedback by SPs is characterized by heterogeneity and lack of evidence with regard to the methods and domains of feedback as well as SPs' training in providing feedback. More comparative research is needed to address these issues. Studies on the most effective methods for SP feedback could build on evidence from general studies on feedback. ${ }^{24-30} \mathrm{Al}-$ though feedback from the patient's perspective is generally recommended, there is no clear evidence to underpin this recommendation. Studies on preferred domains for SP feedback and effective feedback training for SPs are needed since these can lead to improvement in the quality of SPs' feedback and SPs' confidence in providing feedback. This is especially important considering the difficulty in providing feedback reported by SPs (Chapter 4).

Another area for future research may be the impact of role playing on adolescent SPs. Although we found no negative effects due to role performance in adolescent SPs (Chapter 3) we did find negative effects in adult SPs (Chapter 6 and 7). It would be valuable to address this issue in studies using more comprehensive questionnaires or qualitative methods, such as focus group interviews. We think it is important that efforts to develop feasible, longitudinal SP programs should be continued. Longitudinal SP encounters offer unique learning opportunities which have been evaluated positively by both students and teachers. Future studies might be directed at a more limited longitudinal SP program than the one explored in this thesis. Reducing its scope may increase the program's feasibility.

Yet another interesting area for further research would be the phase of the curriculum that is most suitable for the first introduction of real patient encounters. Studies in this thesis showed that students appreciated SP contacts in preparation for contacts with real patients and considered SP contacts useful until the introduction of real patient contacts. However, students' opinions differed as to the best phase of the curriculum for the introduction of real patients, ranging from the first year of medical school, after one or two SP encounters, to the third year. Further comparative research on this subject is needed. 
Finally, future research should explore the role of students' assumptions and expectations with regard to SP or real patient encounters. As discussed earlier, the students in our studies may have been biased by their assumptions and expectations regarding the authenticity of real and simulated patients, which in turn may influence the instructiveness of the encounters (see "Conclusions" in this chapter). Future studies might use incognito SPs to ensure that students are blinded as to whether the patient they encounter is real or simulated.

\section{Implications for practice}

Although we have already discussed many implications of this thesis for medical educational practice, we would like to elaborate on some additional implications.

At Maastricht University, students learn communication skills in encounters with SPs during the preclinical years of the undergraduate medical curriculum (see section "Setting", Chapter 1). As previously discussed in this thesis (Chapter 9), students considered SP encounters useful in learning communication skills and in preparing them for real patient encounters. However, students also indicated that in SP encounters they learned less about other clinical skills, such as clinical reasoning or physical examination skills. This affected the students' motivation for preparation and self-study. In a recent study conducted at Maastricht University by Diemers et al. students indicated that compared to real patients SPs have less educational potential to promote the development of clinical reasoning skills. ${ }^{31}$ SPs at Maastricht University are almost exclusively used for communication skill training, not for clinical reasoning skills training. Perhaps an important educational opportunity is being missed here. Effective learning of complex skills such as clinical reasoning can only be achieved if students are offered sufficient opportunity to integrate knowledge and skills. ${ }^{32}$ Separate teaching modules for knowledge and skills are therefore not desirable. Hence, the use of SPs might be extended to the teaching of complex clinical skills such as clinical reasoning. This may be particularly important in the second and third years when most students feel they have mastered the basic communication skills. Furthermore, the use of SPs might be extended to a more general educational format, for example tutorials in PBL curricula. In traditional PBL curricula, where paper patient problems are commonly used as triggers for learning, students experience difficulty in clinical problem solving and integra- 
tion of knowledge. ${ }^{33}$ The opportunities to study basic knowledge in the context of clinical cases are not fully exploited.$^{33}$ In 2001 , real patient encounters were introduced as triggers for learning in the last preclinical year (Year 3) of the PBL curriculum at Maastricht Medical School, replacing the paper patients used in years 1 and $2 .^{31,34}$ Students were enthusiastic, particularly about the link between theory and practice. ${ }^{34}$ Patient selection appeared to be a crucial factor in the success of real patient encounters in PBL. ${ }^{34}$ However, patient selection is often complicated by limited availability of suitable patients for teaching purposes (Chapters 8 and 10). This problem may be partly resolved by using SPs as triggers for learning, in addition to real patients. SP contacts can be introduced early in the curriculum without aggravating the problem of selecting suitable real patients, since SPs are available when needed and adaptable to students' needs. The latter would also open up the possibility of presenting cases of gradually increasing complexity to students. In this way, SP encounters and real patient encounters can fulfil complementary functions. For example, SP encounters in which SPs present "typical textbook cases" of diseases can be followed by encounters with real patients presenting different clinical manifestations of the same diseases. An alternative would be to present patients to tutorial groups in video format. Such video vignettes have been reported to work well. ${ }^{35}$

We found that students prepared themselves better for real patient encounters since they knew a doctor would be present and they were likely to be questioned about the case (Chapter 9). Since students do not automatically study the basic science underlying a patient problem or make links across patient problems, teachers are needed as a driving force of the development of students' clinical reasoning skills. ${ }^{31,33,36}$ The qualities of (clinical) teachers may well be more important in this respect than the type of encounter (real patient or SP). The teachers of the student groups in which SP encounters are discussed might address other skills besides communication skills, such as clinical reasoning skills. ${ }^{33}$ Teachers should receive appropriate training for this role.

As reported in Chapters 9 and 10, students think that physical examination skills are best learned in encounters with real patients because these patients present actual physical abnormalities. In the preclinical phase of the Maastricht undergraduate medical curriculum, students learn physical examination skills in small group sessions where they practice skills on their peers supervised by teachers. Since students are generally healthy subjects, students gain no experience in recording and interpreting abnormal physical findings until they see real patients during clinical training. However, at that stage of the curriculum 
students are hardly ever observed, supervised or given feedback on their performance. ${ }^{37}$ Students also feel insecure in recognizing pathology. ${ }^{37}$ Real patient contacts in addition to practicing on peers in the preclinical phase of the medical curriculum might help students to better master physical examination skills.

\section{References}

1. Stillman PL, Regan MD, Philbin M, Haley HL. Results of a survey on the use of standardized patients to teach and evaluate clinical skills. Academic Medicine. 1990;65(5):288-292.

2. Wallace P. Coaching standardized patients: for use in the assessment of clinical competence. New York: Springer Publishing Company; 2006.

3. van de Ridder JM, Stokking KM, McGaghie WC, ten Cate OT. What is feedback in clinical education? Med Educ. Feb 2008;42(2):189-197.

4. Wind LA, Van Dalen J, Muijtjens AM, Rethans JJ. Assessing simulated patients in an educational setting: the MaSP (Maastricht Assessment of Simulated Patients). Medical Education. Jan 2004;38(1):39-44.

5. Naftulin DH, Andrew BJ. The effects of patient simulations on actors. J Med Educ. 1975;50:87-89.

6. Blake K, Greaven S. Adolescent girls as simulators of medical illness. Medical Education. 1999;33(9):702-703.

7. Blake K, Gusella J, Greaven S, Wakefield S. The risks and benefits of being a young female adolescent standardized patient. Medical Education. Jan 2006;40(1):26-35.

8. Hanson M, Tiberius R, Hodges B, et al. Adolescent standardized patients: method of selection and assessment of benefits and risks. Teach Learn Med. Spring 2002;14(2):104-113.

9. Woodward CA, Gliva-McConvey G. Children as standardized patients: initial assessment of effects. Teach Learn Med. 1995;7(3):188-191.

10. Blake K, Vincent N, Wakefield S, Murphy J, Mann K, Kutcher M. A structured communication adolescent guide (SCAG): assessment of reliability and validity. Med Educ. May 2005;39(5):482-491.

11. Brown A, Anderson D, Szerlip HM. Using standardized patients to teach disease management skills to preclinical students: a pilot project. Teach Learn Med. Spring 2003;15(2):84-87.

12. Rull G, Rosher RB, McCann-Stone N, Robinson SB. A simulated couple aging across the four years of medical school. Teach Learn Med. Summer 2006;18(3):261-266.

13. Linssen T, van Dalen J, Rethans JJ. Simulating the longitudinal doctor-patient relationship: experiences of simulated patients in successive consultations. Med Educ. Sep 2007;41(9):873878.

14. McNaughton N, Tiberius R, Hodges B. Effects of portraying psychologically and emotionally complex standardized patient roles. Teach Learn Med. 1999;11(3):135-141.

15. Woodward CA. Standardized patients: a fixed role therapy experience in normal individuals. J Constructivist Psychol. 1998;11:33-48.

16. Woodward CA, Gliva-McConvey G. The effect of simulating on standardized patients. Academic Medicine. 1995;70(5):418-420. 
17. van Ravesteijn H, Hageraats E, Rethans JJ. Training of the gynaecological examination in the Netherlands. Med Teach. 2007;29(4):e93-99.

18. Rethans JJ, Gorter S, Bokken L, Morrison L. Unannounced standardized patients in real practice: a systematic literature review. Med Educ. Jun 2007;41(6):537-549.

19. Kneebone R, Nestel D, Wetzel C, et al. The human face of simulation: patient-focused simulation training. Acad Med. Oct 2006;81(10):919-924.

20. Lane C, Rollnick S. The use of simulated patients and role-play in communication skills training: a review of the literature to August 2005. Patient Educ Couns. Jul 2007;67(1-2):1320.

21. Barrows HS. An overview of the uses of standardized patients for teaching and evaluating clinical skills. Academic Medicine. 1993;68(6):443-451.

22. Cantrell MJ, Deloney LA. Integration of standardized patients into simulation. Anesthesiol Clin. Jun 2007;25(2):377-383.

23. Howley L, Szauter K, Perkowski L, Clifton M, McNaughton N. Quality of standardized patient research reports in the medical education literature: review and recommendations. Med Educ. 2008;42:350-58.

24. Ende J. Feedback in clinical medical education. Jama. Aug 12 1983;250(6):777-781.

25. Holmwood CB. The gentle art of feedback. Aust Fam Physician. Oct 1993;22(10):1811-1813.

26. Brinko KT. The practice of giving feedback to improve teaching. What is effective? J High Educ. 1993;64(5):574-593.

27. Kluger AN, DeNisi A. The effects of feedback interventions on performance: A historical review, a meta-analysis and a preliminary feedback intervention theory. Psychological Bulletin. 1996;119(2):254-284.

28. Hewson MG, Little ML. Giving feedback in medical education: verification of recommended techniques. J Gen Intern Med. Feb 1998;13(2):111-116.

29. Hattie J, Timperley H. The power of feedback. Review of Educational Research. 2007;77(1):81-112.

30. Shute V. Focus on formative feedback. Review of Education Research. Epub ahead of print.

31. Diemers AD, Dolmans DHJM, Verwijnen MGM, Heineman E, Scherpbier AJJA. Students'opinions about the effects of preclinical patient contacts on their learning. Adv Health Sci Educ Theory Pract. Jul 2007 (Epub ahead of print).

32. Janssen-Noordman AMB, Merriënboer JJG, van der Vleuten CPM, Scherpbier AJJA. Design of integrated practice for learning professional competencies. Med Teach 2006;28(5):447-52.

33. van de Wiel MWJ, Schaper NC, Scherpbier AJJA, van der Vleuten CPM, Boshuizen HPA. Students' experiences with real-patient tutorials in a problem-based curriculum. Teach Learn Med. 1999;11(1):12-20.

34. Diemers AD, Dolmans DHJM, van Santen M, van Luijk SJ, Janssen-Noordman AMB, Scherpbier AJJA. Students' perceptions of early patient encounters in a PBL curriculum: A first evaluation of the Maastricht experience. Med Teach 2007;29:135-42.

35. de Leng, B, Dolmans, D, van de Wiel M, Muijtjens A, van der Vleuten C. How video cases should be used as authentic stimuli in problem-based medical education. Med Educ 2007; 41(2):181-188.

36. Eva KW. What every teacher needs to know about clinical reasoning. Med Educ. 2005; 39:98-106.

37. Prince KJAH, van de Wiel MWJ, Scherpbier AJJA, van der Vleuten CPM, Boshuizen HPA. A qualitative analysis of the transition from theory to practice in undergraduate training in a PBL medical school. Adv Health Sci Educ Theory Pract 2000;5:105-116. 
Summary 


\section{Chapter 1}

Since their introduction in 1964 by Barrows, simulated patients and standardized patients have been used extensively in medical education. Simulated patients, defined as "normal persons who have been carefully coached to present the symptoms and signs of actual patients", are predominantly used for teaching purposes since the emphasis in their role performance is on realism and authenticity. Standardized patients are "people with or without actual disease who have been trained to portray a medical case in a consistent fashion". Since the emphasis is on consistency of role performance, standardized patients are predominantly used for evaluation purposes, particularly for high-stakes examinations. In this thesis we focused on the use of simulated patients for teaching purposes in undergraduate medical students.

Many advantages of simulated patients (SPs) as opposed to real patients have been described. For example, their ability to provide feedback to students or the possibility to adapt their role performance to specific educational purposes. Furthermore, people of different age groups, including adolescents, can be trained as SPs. A disadvantage of SPs is that they have been found to report negative effects such as exhaustion, irritability and physical complaints due to role playing. Furthermore, it has been suggested SPs can never replace real patient contacts.

Despite the extensive research on the use of SPs, there is paucity of research on the practical implications of assumed advantages and disadvantages in the use of SPs for teaching purposes. Furthermore, little is known about the added value of the use of SPs as opposed to real patients. Knowledge on the practical implications of SPs' advantages and disadvantages and on the added value of SPs as opposed to real patients is essential to optimize the use of SPs and real patients for teaching purposes.

The research questions in this thesis were: 1) What are the practical implications of the perceived advantages and disadvantages of the use of SPs in the undergraduate medical curriculum? How can the SPs' strengths be applied in medical education? What are the limitations of the use of SPs in medical education? How can the limitations be diminished? 2) What are the advantages and disadvantages of SPs as opposed to real patients? What do students regard more instructive: an encounter with a real patient or an SP encounter? What variables influence the perceived instructiveness? 


\section{Chapter 2}

In this chapter we discussed an essential advantage in the use of SPs: their ability to provide feedback on an encounter with a student. The importance of feedback by SPs is generally well recognized. Feedback is considered an integral part in the teaching with SPs and feedback provided by SPs is widely used in many medical schools. However, little is known about the most effective ways in which SPs can provide feedback to undergraduate medical students and about the training of SPs in providing feedback. We systematically reviewed the literature to identify the ways in which SPs provide feedback to undergraduate medical students (process of feedback), the domain on which SPs provide feedback and the ways in which SPs are trained to provide feedback.

In the majority of studies, feedback by SPs was used as a tool to teach skills to students. Surprisingly, we only found one comparative study in which two methods to provide feedback were evaluated. The ways in which SPs were trained to give feedback were found to be largely heterogeneous, similar to the process of feedback provided by SPs. Only few studies described feedback processes that are in accordance to the general recommendations for effective feedback, for example "start with the student's self-evaluation" and "clear standard with which the student's performance is compared". Although feedback from the patient's perspective is generally recommended, most SPs provided feedback on clinical skills and communication skills.

There appeared to be no clear standards with regard to effective feedback training for SPs. The process of feedback provided by SPs and the domain on which SPs give feedback often seemed to lack a solid scientific basis as well. Further (comparative) research is needed to fill these gaps.

\section{Chapter 3}

In this chapter we focused on adolescent SPs as they illustrate another advantage of SPs: people of various age groups can be trained as SPs. This is an important advantage since it enables students to practice specific communication skills required for interaction with various age groups in a safe learning environment. We evaluated the impact of role playing on adolescent simulated patients. Although no negative effects were reported in adolescents trained as standardized patients, the impact of role performance on adolescents trained as simulated patients has not been explored. Since simulated patients are trained to 
incorporate more of their own personal backgrounds in their roles to enhance authenticity, the impact of role performance on adolescent simulated patients might differ from that on adolescent standardized patients. We also evaluated the quality of adolescent SPs' role playing and feedback.

Nine young women, aged 16-18 years, were trained to portray roles of adolescents asking their general practitioner for an oral contraceptive. Three adolescent men were trained to portray roles of some of the girls' boyfriends. Each role was developed in consultation with the individual adolescent and was largely based on reality. Students rated the quality of the adolescent SP's role playing and feedback after each SP encounter on a validated questionnaire (the MaSP). The adolescent SPs and faculty teachers both completed questionnaires on their experiences. In general, students and teachers were satisfied with the quality of the role playing and feedback provided by the adolescent SPs. Students $(\mathrm{N}=341)$ gave the SPs' general performance a mean mark of 7.5 out of 10. There were some concerns about the quality of the feedback. For example, SPs could give more encouragement to students to ask questions and more examples from the encounter to illustrate their feedback. Adolescent SPs reported no negative effects due to their performance, which confirms earlier findings among adolescent standardized patients.

\section{Chapter 4}

We evaluated the views of teachers, students and adolescent SPs with regard to the adolescent SP program in our undergraduate curriculum and the changes that were made to the program in the past five years (from 2002-2003 until 2006-2007).

Adolescent girls were recruited to portray roles of adolescents asking their general practitioner for an oral contraceptive. Students rated the quality of the adolescent SPs' role performance and feedback on a validated questionnaire (the MaSP). Both adolescent SPs and faculty teachers completed questionnaires on their experiences. Over the past five years, students gave high marks for the overall performance of the adolescent SPs. Nevertheless, the mark for the overall performance of the adolescent SPs decreased by half a point from 8.0 (out of 10) in the first year of the program to 7.5 (out of 10) five years later. This might be attributable to the recruitment and selection of adolescent SPs becoming less rigid or to the increasing demands of the program for adolescent SPs. The evaluations by teachers and adolescent SPs about the adolescent SP 
program were very positive. The quality of the feedback by adolescent SPs has shown improvement over the past five years, although adolescents find it quite difficult to give feedback.

\section{Chapter 5}

An important advantage of SPs is that their roles can be adjusted to the learning needs of the student. SPs are mostly used in single-case encounters in which students have repeated unconnected encounters with SPs and receive feedback from SPs and/or teachers or peers afterwards. For training students in chronic care, however, longitudinal patient encounters are more suitable. We developed a longitudinal SP program and explored the evaluations of students and teachers regarding the new program. The evaluations of the longitudinal SP program were compared to the single-case SP program and the feasibility of the program was explored. We hypothesized that students preferred the longitudinal SP encounters to single-case encounters.

Year 3 students participating in the longitudinal SP program $(\mathrm{N}=272)$ had four encounters with the same SP portraying a chronic health problem in eight months. Student evaluations regarding the longitudinal SP program were assessed with a validated questionnaire (the MaSP) and both teachers and students completed another questionnaire on their views. In general, students and teachers were positive about the longitudinal SP program. We found no differences between student evaluations regarding the longitudinal SP program and those regarding the single-case SP program. So, in contrast to what we hypothesized, students considered the longitudinal SP program as good as the single-case SP program. Perhaps this was due to students not making full use of the opportunities of the program to practice continuity of care. It might also be due to the fact that the content of the longitudinal SP encounter was often not related to the cluster students were enrolled in. In the current form, the longitudinal SP program appeared not to be feasible because of uncooperative faculty staff and the workload. A smaller scale set-up might be more feasible.

\section{Chapter 6}

Student-SP encounters are generally instructive and enjoyable for both students and SPs. However, in conversations with SP trainers some SPs have mentioned 
experiencing adverse symptoms due to performing a patient role. Some published studies have reported similar findings in SPs. We explored the seriousness of this problem by surveying SPs on the occurrence and severity of stress symptoms related to performing patient roles. We also examined by which variables the symptoms were influenced.

An anonymous questionnaire was developed to investigate factors related to stress symptoms and the frequency and severity of stress symptoms. A burnout scale was also included in the questionnaire to determine whether high scores on our questionnaire were be related to burnout rather than to role performance. All SPs who had performed between March 2000 and March 2001 were asked to participate.

The response rate was $84 \%$. Of the SPs, $73 \%$ were found to have experienced stress symptoms, with a mean of 4 symptoms per SP. Fortunately, the symptoms were relatively mild (2.2 on a 5-point scale). No significant correlations were found between the occurrence of symptoms on the one hand and factors that might influence symptoms or the burnout scale on the other hand.

Measures should be taken to prevent and treat the stress symptoms. Debriefing sessions might play a role in this respect.

\section{Chapter 7}

We further explored the impact of simulation and the factors that might affect this impact. Our aim was to find ways of preventing negative effects of simulation impacting on our SPs.

Four focus groups interviews were conducted among 35 SPs at Skillslab, Maastricht University. The discussion was guided by 6 pre-established items. The majority of the SPs appeared to experience negative effects of performing a patient role. The effects were considered as inherent to acting as an SP or due to simulation being a strenuous activity. The impact was short-lived and did not affect SPs' enjoyment of their work. So, although the SPs were found to experience negative effects caused by playing patient roles, the frequency and intensity of the negative effects were minor. Factors that appeared to affect the impact of performing included: the type of role (whether it is emotionally complex or not); the number of consecutive performances; the length of time between performances; the giving of feedback; the amount of experience, and students. The focus group discussions led to various suggestions for measures to reduce the impact of simulation. 


\section{Chapter 8}

Patient contacts have always been an integral part of undergraduate medical education and may involve real patients or SP. Although the importance of patient contacts is generally recognized, we know little about the various roles of both real patients and SPs in undergraduate medical education and their value from the perspectives of students, teachers and patients. We reviewed the literature to identify the strengths and weaknesses of the roles of SPs and real patients in undergraduate medical education. Four types of patient roles are identified: real patients as an educational resource (passive role); real patients as teachers (active role); SPs as an educational resource; and SPs as teachers. Each of the four patient roles was found to have specific advantages and disadvantages from the perspectives of teachers, students and patients. For example, advantages of real patients as educational resource were patient-centered learning and high patient satisfaction. Disadvantages were their limited availability and the variability in learning experiences among students. Despite the considerable amount of literature we found, many gaps in knowledge about patient roles in medical education remain and should be addressed by future studies.

\section{Chapter 9}

Although it has been recognized as an important research area, there is paucity of literature on the value of real patient contacts as opposed to SP contacts from the perspectives of students. Students' views with regard to the strengths and weaknesses of real patient contacts as opposed to SP contacts in the undergraduate medical curriculum were explored. The aim was to evaluate how their strengths can be optimally used and weaknesses remedied.

Five focus group interviews were conducted among 38 fourth and fifth year medical students at Maastricht University in 2007, using a pre-established interview guide. The interviews were recorded, transcribed and analyzed using qualitative methods. In general, students considered real patient contacts more instructive and more authentic than SP contacts. However, students identified several strengths of SP contacts compared to real patient contacts. For example, SP contacts were helpful in preparing students for real patient contacts (particularly with regard to communication skills and self-confidence), in the teaching of "intimate" physical examination skills, such as gynecological examination 
skills, and in giving constructive feedback on communication skills. In contrast to what we had anticipated, taking a time-out was considered easier in real patient contacts. On the basis of strengths and weaknesses that were identified, suggestions were made for the use of real patients and SPs in undergraduate medical education.

\section{Chapter 10}

Few studies have compared the instructiveness of real patient contacts with SP contacts and most found no difference. Nevertheless, students often comment on the instructiveness of both encounters being dissimilar. The aims of this study were to evaluate which contact (real patient contact or SP contact) was perceived as most instructive by students and which variables contribute to this. We performed an experiment involving 163 first-year medical students, randomized to having a real patient contact $(\mathrm{N}=61)$ or SP contact $(\mathrm{N}=102)$. Both quantitative (questionnaires) and qualitative (focus groups) methods were used to evaluate the perceived instructiveness of the contact. The general instructiveness of both real patient contacts and SP contacts was marked high. Several differences between the evaluations of real patient contacts and SP contacts were found. For example, students considered real patient contacts less helpful in practicing communication skills and considered the real patients' feedback less relevant. The focus group interviews yielded explanations for many of the differences found. Students regarded real patients as more authentic. However, SPs were better informed about the routine of the consultation and provided the student with more specific feedback. The difficult recruitment is an important disadvantage of real patients. The choice of real patient contacts or SP contacts for medical education depends on factors like the phase of the curriculum and the aim of the encounter.

\section{Chapter 11}

We discussed the conclusions with regard to the practical implications of several important advantages in the use of SPs: their ability to provide feedback to medical students, the possibility to train adolescents as SP and the possibility to have longitudinal SP encounters. We also discussed the practical implications of an important disadvantage in the use of SPs, i.e. the impact of role perform- 
ance on SPs. In summary, the main implications of our research for medical educational practice are the following:

- Feedback by SPs should be in accordance with the evidence from studies on feedback in general (Box 2, Chapter 2) and should be from the patient's perspective.

- For teaching situations, adolescent simulated patients should be used rather than adolescent standardized patients.

- To maintain the quality of an adolescent SP program, continuous attention should be paid to recruitment and selection of adolescents and feedback provided by adolescent SPs.

- Measures such as maximum 7 performances per day or standby SPs, should be taken to reduce the impact of role playing on SPs.

- SPs should be used before the introduction of real patients in the medical curriculum.

- SPs should be used to teach "intimate" physical examination skills such as gynecological examination skills.

- SP encounters might be extended to the teaching of complex clinical skills such as clinical reasoning skills in addition to communication skills. Teachers should be trained accordingly.

- SPs might be used as triggers for learning in PBL curricula.

- Real patients might be used in the teaching of (non-intimate) physical examination skills to allow students to recognize abnormal physical findings.

Implications for further research were discussed, for example comparative research on the ways in which feedback is provided by SPs, the domain on which SPs provide feedback and the ways in which SPs are trained to provide feedback. Furthermore, the search for feasible, longitudinal SP program should be continued. With regard to real patient encounters and SP encounters, more research is needed on the phase of the undergraduate medical curriculum in which real patients should be introduced and on the role of assumptions and expectations of medical students about the type of encounter (real patient or SP). 

Samenvatting 


\section{Hoofdstuk 1}

Sinds Barrows hen in 1964 introduceerde, worden simulatiepatiënten en gestandaardiseerde patiënten op grote schaal ingezet in het medisch onderwijs. Simulatiepatiënten, gedefinieerd als "normale personen die zorgvuldig zijn opgeleid om de symptomen van echte patiënten te presenteren" worden voornamelijk gebruikt voor onderwijs doeleinden aangezien in hun optreden de nadruk ligt op realisme en authenticiteit. Gestandaardiseerde patiënten zijn "mensen met of zonder daadwerkelijke ziekte die zijn getraind een medische casus op een consistente manier uit te beelden". Aangezien de nadruk ligt op consistentie van het optreden worden gestandaardiseerde patiënten voornamelijk gebruikt voor toetsingsdoeleinden, in het bijzonder voor toetsen waar veel op het spel staat. In dit proefschrift hebben we ons gericht op het gebruik van simulatiepatiënten voor onderwijs doeleinden in het medisch onderwijs.

Er zijn vele voordelen van simulatiepatiënten (SP) ten opzichte van echte patiënten beschreven. Bijvoorbeeld de mogelijkheid feedback te geven aan studenten of de mogelijkheid de rol aan te passen aan specifieke onderwijs doelen. Bovendien kunnen mensen van verschillende leeftijden, inclusief adolescenten, getraind worden als SP. Een nadeel van SP is dat ze negatieve effecten kunnen ondervinden van het spelen van rollen, bijvoorbeeld vermoeidheid, geïriteerd zijn en lichamelijke klachten. Verder is gesuggereerd dat SP nooit de contacten met echte patiënten kunnen vervangen.

Ondanks het omvangrijke onderzoek naar het gebruik van SP, is er weinig onderzoek gedaan naar de praktische implicaties van de veronderstelde voor- en nadelen van het gebruik van SP voor onderwijs doeleinden. Ook is er weinig bekend over de additionele waarde van het gebruik van SP ten opzichte van echte patiënten. Kennis van de praktische implicaties en de additionele waarde van SP ten opzichte van echte patiënten is essentieel om het gebruik van SP en echte patiënten in het onderwijs te kunnen optimaliseren.

De onderzoeksvragen in dit proefschrift waren: 1) Wat zijn de praktische implicaties van de vermeende voor- en nadelen van het gebruik van SP in het medisch onderwijs? Hoe kunnen de sterktes van SP worden toegepast? Wat zijn de beperkingen van het gebruik van SP? Hoe kunnen de beperkingen worden verminderd? 2) Wat zijn de voor- en nadelen van SP ten opzichte van echte patiënten? Welk contact vinden studenten meer leerzaam: met een echte patiënt of met een SP? Welke variabelen beïnvloeden de ervaren leerzaamheid? 


\section{Hoofdstuk 2}

In dit hoofdstuk bestudeerden we een essentieel voordeel in het gebruik van SP: de mogelijkheid feedback te geven over een contact met een student. Het belang van feedback is algemeen erkend. Feedback wordt beschouwd als een integraal onderdeel in het onderwijs met SP en feedback door SP wordt gebruikt in een groot aantal medische opleidingen. We weten echter weinig over de meest effectieve manieren waarop SP feedback kunnen geven aan geneeskunde studenten en over de training van SP in het geven van feedback. We bestudeerden de literatuur systematisch om de manieren waarop SP feedback geven aan geneeskunde studenten (feedback proces), het domein waarop SP feedback geven en de manieren waarop SP worden getraind in het geven van feedback te identificeren. In de meerderheid van de studies werd feedback gebruikt als een middel om vaardigheden te onderwijzen aan studenten. Opmerkelijk genoeg vonden we slechts een vergelijkende studie waarin twee verschillende manieren om feedback te geven werden geëvalueerd. De manieren waarop SP getraind werden in het geven van feedback waren zeer heterogeen, net als het feedback proces. Slechts enkele studies beschreven een feedback proces dat overeenkwam met de algemene aanbevelingen voor effectieve feedback, zoals "begin met een zelf evaluatie door de student" en "een heldere standaard waarmee de prestatie van de student wordt vergeleken". Hoewel feedback vanuit het perspectief van de patiënt algemeen wordt aangeraden gaven de meeste SP feedback over klinische vaardigheden en communicatievaardigheden.

Er werden geen duidelijke standaarden gevonden met bestrekking tot effectieve feedback training voor SP. Met betrekking tot het feedback proces en het domein waarop SP feedback geven leek eveneens een solide wetenschappelijke basis te ontbreken. Verder (vergelijkend) onderzoek moet deze hiaten in onze kennis opvullen.

\section{Hoofdstuk 3}

In dit hoofdstuk richtten we ons op adolescente SP aangezien ze een ander belangrijk voordeel in het gebruik van SP illustreren: mensen van verschillende leeftijden kunnen worden getraind als SP. Dit is een belangrijk voordeel aangezien het studenten in staat stelt in een veilige omgeving, specifieke communicatievaardigheden te oefenen die nodig zijn voor interactie met mensen van verschillende leeftijdsgroepen. We evalueerden de invloed van het spelen van 
een patiëntenrol op adolescente SP. Hoewel er geen negatieve effecten zijn gerapporteerd in adolescenten die werden getraind als gestandaardiseerde patiënt, is de invloed van het spelen van een patiëntenrol op adolescenten die getraind zijn als simulatiepatiënt nog niet onderzocht. Aangezien simulatiepatienten zijn getraind om meer van hun persoonlijke achtergrond te verwerken in hun rol om de authenticiteit te vergroten, kan de invloed van een patiëntenrol op adolescente simulatiepatiënten verschillen van die op adolescente gestandaardiseerde patiënten. We onderzochten eveneens de kwaliteit van het rollenspel en de feedback van de adolescente SP.

Negen jonge vrouwen, in de leeftijd van 16-18 jaar, werden getraind rollen te spelen waarin adolescenten hun huisarts vragen om een oraal anticonceptivum (de pil). Drie jonge mannen werden getraind voor de rol van vriendje van drie van de meiden. Elke rol werd ontwikkeld samen met de adolescent en werd grotendeels gebaseerd op de werkelijkheid. Studenten scoorden de kwaliteit van het rollenspel en de feedback van de adolescente SP na elk SP contact op een gevalideerde vragenlijst (de MaSP). De adolescente SP en docenten vulden vragenlijsten in over hun ervaringen. In het algemeen waren studenten en docenten tevreden met de kwaliteit van het rollenspel en de feedback van de adolescente SP. Studenten ( $=341)$ gaven het algemene optreden van de SP een gemiddeld cijfer van 7.5 (op schaal 0-10). Er waren enkele zorgen om de kwaliteit van de feedback. Bijvoorbeeld, SP zouden de studenten meer kunnen aanmoedigen tot het stellen van vragen en zouden meer voorbeelden uit het contact kunnen geven om hun feedback te illustreren. Adolescente SP rapporteerden geen negatieve effecten door het spelen van rollen, hetgeen de eerdere bevindingen bij adolescente gestandaardiseerde patiënten ondersteunt.

\section{Hoofdstuk 4}

We evalueerden de meningen van docenten, studenten en adolescente SP met betrekking tot het adolescente SP programma in ons curriculum en de veranderingen die het programma onderging in de afgelopen vijf jaar (van 2002-2003 tot 2006-2007).

Jonge vrouwen werden geworven om de rol te spelen van adolescenten die hun huisarts vragen om een oraal anticonceptivum (de pil). Studenten scoorden de kwaliteit van het rollenspel en de feedback van de adolescente SP op een gevalideerde vragenlijst (de MaSP). Zowel adolescente SP als docenten vulden vragenlijsten in over hun ervaringen. De afgelopen vijf jaar gaven studenten 
hoge cijfers voor het algemene optreden van de adolescente SP. Desondanks verminderde het cijfer voor het algemene optreden van de adolescente SP met een half punt, van 8.0 in het eerste jaar van het programma tot 7.5 (op schaal 010) vijf jaar later. Mogelijk wordt dit verklaard door het minder streng worden van de werving en selectie van adolescente SP of door de hogere eisen die het programma stelt aan de adolescente SP. De evaluaties van docenten en adolescente SP waren zeer positief. De kwaliteit van de feedback van adolescente SP is verbeterd in de loop van de afgelopen vijf jaar, hoewel adolescenten het moeilijk vinden om feedback te geven.

\section{Hoofdstuk 5}

Een belangrijk voordeel van SP is dat de rollen kunnen worden aangepast aan de leerbehoeften van de student. SP worden voornamelijk ingezet in losse casus contacten waarbij studenten meerdere, niet onderling verbonden contacten hebben met de SP en feedback krijgen van de SP en/of docenten na afloop van het contact. Om studenten te trainen in chronische zorg, zijn longitudinale patiëntcontacten echter meer geschikt. We ontwikkelden een longitudinaal SP programma en onderzochten de beoordelingen van studenten en docenten met betrekking tot het nieuwe programma. De beoordelingen van het longitudinale SP programma werden vergeleken met het losse casussen SP programma en de haalbaarheid van het programma werd onderzocht. Onze hypothese was dat studenten het longitudinale SP programma beter vonden dan het losse casussen SP programma.

Jaar 3 studenten die deelnamen aan het longitudinale SP programma $(\mathrm{N}=272)$ hadden vier contacten in acht maanden met dezelfde SP die een patiënt met een chronische ziekte speelde. Student beoordelingen met betrekking tot het longitudinale SP programma werden onderzocht met een gevalideerde vragenlijst (de MaSP) en zowel docenten als studenten vulden een andere vragenlijst in over hun ervaringen. In het algemeen waren studenten en docenten positief over het longitudinale SP programma. We vonden geen verschillen tussen student beoordelingen met betrekking tot het longitudinale SP programma en die met betrekking tot het losse casussen SP programma. Dus, in tegenstelling tot onze hypothese, vonden studenten het longitudinale SP programma even goed als het losse casussen SP programma. Misschien werd dit veroorzaakt door het feit dat sommige studenten niet volledig gebruik maakten van de mogelijkheden van het longitudinale SP programma om continuïteit van zorg te bieden. Het werd 
mogelijk ook veroorzaakt door het feit dat de inhoud van het longitudinale SP contact vaak niet overeenkwam met de inhoud van het cluster waar de student op dat moment mee bezig was. In de huidige vorm bleek het longitudinale SP programma niet haalbaar vanwege de hoge werklast en het niet meewerken van faculteitspersoneel. Een opzet op kleinere schaal is mogelijk meer haalbaar.

\section{Hoofdstuk 6}

Student-SP contacten zijn in het algemeen leerzaam en leuk voor zowel studenten als SP. In gesprekken met SP trainers hebben sommige SP echter aangegeven negatieve effecten te ervaren door het spelen van patiëntenrollen. Enkele studies hebben vergelijkbare bevindingen bij SP gerapporteerd. We onderzochten de ernst van dit probleem door SP te ondervragen over het optreden en de ernst van stress symptomen gerelateerd aan het spelen van patiëntenrollen. We onderzochten ook door welke variabelen de symptomen beïnvloed werden.

Een anonieme vragenlijst werd ontwikkeld om de factoren gerelateerd aan stress symptomen en de frequentie en ernst van stress symptomen na te gaan. Een burnout lijst werd ook toegevoegd aan de vragenlijst om uit te sluiten dat hoge scores op onze lijst gerelateerd waren aan burnout in plaats van aan het spelen van patiëntenrollen. Alle SP die een rol speelden tussen maart 2000 en maart 2001 werden uitgenodigd om deel te nemen.

De respons bedroeg $84 \%$. Van de SP had $73 \%$ last van stress symptomen, met een gemiddelde van 4 symptomen per SP. Gelukkig waren de symptomen relatief mild ( 2.2 op een 5 puntschaal). Er werden geen significante correlaties gevonden tussen het optreden van symptomen en factoren die de symptomen beïnvloeden of de burnout lijst. Maatregelen zouden moeten worden genomen om stress symptomen te voorkomen en behandelen. Debriefing sessies zouden een rol hierin kunnen spelen.

\section{Hoofdstuk 7}

We onderzochten de effecten van simulatie en de factoren die deze effecten beïnvloeden uitvoeriger. Ons doel was het vinden van manieren om de negatieve effecten van simulatie op onze SP te voorkomen.

Vier focusgroep interviews werden gehouden onder 35 SP van het Skillslab, Universiteit Maastricht. De discussie werd geleid aan de hand van 6 vooraf 
opgestelde items. De meerderheid van de SP bleek negatieve effecten te ervaren door het spelen van patiëntenrollen. Deze effecten werden beschouwd als inherent aan het optreden als SP of als gevolg van het feit dat simulatie een inspannende bezigheid is. De invloed was kortdurend en had geen invloed op het plezier dat SP beleven aan hun werk. Dus, hoewel SP negatieve effecten ervaren van het spelen van patiëntenrollen, zijn de frequentie van het optreden van negatieve effecten en de intensiteit van de negatieve effecten minimaal. Factoren die de negatieve effecten beïnvloeden zijn: de aard van de rol (emotioneel complex of niet); het aantal achtereenvolgende optredens; de tijd tussen de optredens; het geven van feedback; de ervaring als SP en de studenten. De focusgroepen leverden diverse suggesties op voor maatregelen om de negatieve effecten van simulatie te verminderen.

\section{Hoofdstuk 8}

Patiëntcontacten vormen een integraal onderdeel van de opleiding tot arts en hebben betrekking op zowel echte patiënten als SP. Hoewel het belang van patiëntcontacten algemeen erkend is, weten we slechts weinig over de verschillende rollen van echte patiënten en SP in het medisch onderwijs en de waarde ervan vanuit het perspectief van studenten, docenten en patiënten. We bestudeerden de literatuur om de voor- en nadelen van de rollen van SP en echte patiënten in het medisch onderwijs te identificeren. We onderscheidden vier verschillende rollen van patiënten: echte patiënten als onderwijsmiddel (passieve rol); echte patiënten als docenten (actieve rol); SP als onderwijsmiddel en SP als docenten. We vonden dat elk van de vier rollen specifieke voor- en nadelen heeft vanuit het perspectief van docenten, studenten en patiënten. Bijvoorbeeld, voordelen van echte patiënten als onderwijsmiddel zijn het patiënt gericht leren en de hoge patiënt tevredenheid. Nadelen zijn hun beperkte beschikbaarheid en de variabiliteit in leerervaringen tussen studenten. Ondanks de behoorlijke hoeveelheid literatuur die we vonden, bleven er vele hiaten bestaan in de kennis over rollen van patiënten in het medisch onderwijs. Vervolgonderzoek zou zich moeten richten op deze hiaten. 


\section{Hoofdstuk 9}

Hoewel het erkend is als een belangrijk onderzoeksterrein, is er slechts weinig literatuur over de waarde van echte patiënt contacten ten opzichte van SP contacten vanuit het perspectief van studenten. Meningen van studenten met betrekking tot de voor- en nadelen van echte patiënt contacten en SP contacten in het medisch onderzoek werden onderzocht. Het doel was na te gaat hoe voordelen optimaal benut kunnen worden en nadelen kunnen worden verminderd.

Vijf focusgroep interviews werden gehouden onder 38 vierde- en vijfdejaars geneeskunde studenten van de Universiteit Maastricht in 2007. Hierbij werd gebruik gemaakt van een vooraf opgestelde interview leidraad. De interviews werden opgenomen, letterlijk uitgeschreven en geanalyseerd met behulp van kwalitatieve methoden. In het algemeen vonden studenten echte patiënt contacten leerzamer en authentieker dan SP contacten. Studenten stelden echter verschillende voordelen van SP ten opzichte van echte patiënten vast. Bijvoorbeeld, SP waren nuttig om de student voor te bereiden op echte patiënt contacten (voornamelijk met betrekking tot communicatievaardigheden en zelfvertrouwen), in het onderwijs van "intieme" lichamelijk onderzoeksvaardigheden zoals gynaecologisch onderzoeksvaardigheden en in het geven van opbouwende feedback over communicatievaardigheden. In tegenstelling tot wat we hadden verwacht werd het nemen van een time-out makkelijker gevonden in echte patiënt contacten. Op basis van de vastgestelde voor- en nadelen, werden suggesties gedaan voor het gebruik van echte patiënten en SP in het medisch onderwijs.

\section{Hoofdstuk 10}

Enkele studies hebben de leerzaamheid van echte patiënt contacten en SP contacten vergeleken. De meeste studies vonden geen verschil. Desondanks geven studenten vaak aan dat de leerzaamheid van beide contacten verschillend is. De doelen van deze studie waren na te gaan welk contact (echte patiënt contact of SP contact) door studenten werd ervaren als meest leerzaam en welke variabelen hieraan bijdragen. We voerden een experiment uit waarbij 163 eerstejaars geneeskunde studenten werden gerandomiseerd naar het hebben van een echte patiënt contact $(\mathrm{N}=61)$ of een SP contact $(\mathrm{N}=102)$. Zowel kwantitatieve (vragenlijsten) als kwalitatieve (focusgroepen) methoden werden gebruikt 
om de ervaren leerzaamheid van het contact te bepalen. Er werd een hoog cijfer gegeven voor de algemene leerzaamheid van zowel de echte patiënt contacten als de SP contacten. Er werden enkele verschillen gevonden tussen de beoordelingen van echte patiënt contacten en SP contacten. Bijvoorbeeld, studenten vonden de echte patiënt contacten minder nuttig voor het oefenen van communicatievaardigheden en beschouwden de feedback van de echte patiënten als minder relevant. De focusgroepen leverden verklaringen op voor veel van de gevonden verschillen. Studenten vonden echte patiënten authentieker. Echter, SP waren beter geïnformeerd over de gang van zaken tijdens het consult en gaven specifiekere feedback aan de student. De moeilijke werving van echte patiënten is een belangrijk nadeel van echte patiënten. De keuze voor echte patiënt contacten of SP contacten in het medisch onderwijs hangt af van factoren zoals de fase van het curriculum en het doel van het contact.

\section{Hoofdstuk 11}

We bespraken de conclusies met betrekking tot de praktische implicaties van verscheidene belangrijke voordelen in het gebruik van SP: de mogelijkheid feedback te geven aan geneeskunde studenten, de mogelijkheid adolescenten te trainen als SP en de mogelijkheid longitudinale SP contacten te hebben. We bespraken ook de praktische implicaties van een belangrijk nadeel in het gebruik van SP, namelijk de negatieve effecten die SP ervaren door het spelen van rollen. Samenvattend, zijn de belangrijkste implicaties van ons onderzoek voor de medische onderwijspraktijk:

- Feedback door SP zou in overeenstemming moeten zijn met de bevindingen van studies over feedback in het algemeen (Box 2, Hoofdstuk 2) en zou vanuit het perspectief van de patiënt gegeven moeten worden

- Voor onderwijs doeleinden zouden adolescente simulatiepatiënten moeten worden gebruikt in plaats van adolescente gestandaardiseerde patiënten.

- Om de kwaliteit van een adolescente SP programma te behouden zou continu aandacht moeten worden besteed aan werving en selectie van adolescenten en de feedback door adolescente SP.

- Maatregelen zoals maximaal 7 optredens per dag en reserve SP zouden moeten worden genomen om de negatieve effecten door het spelen van patiëntenrollen op SP te verminderen.

- SP zouden moeten worden ingezet voor de introductie van echte patiënten in de medische opleiding. 
- SP zouden moeten worden gebruikt voor het aanleren van "intieme" lichamelijk onderzoeksvaardigheden zoals gynaecologische onderzoeksvaardigheden.

- SP contacten zouden kunnen worden uitgebreid naar het aanleren van complexe klinische vaardigheden zoals klinisch redeneren in aanvulling op communicatievaardigheden. Docenten zouden hiervoor moeten worden getraind.

- SP zouden gebruikt kunnen worden als aanleiding tot verdere studie in PGO curricula

- Echte patiënten zouden kunnen worden ingezet in het onderwijs van (nietintieme) lichamelijk onderzoeksvaardigheden om studenten in staat te stellen abnormale bevindingen bij lichamelijk onderzoek te herkennen.

Implicaties voor verder onderzoek werden besproken, bijvoorbeeld vergelijkend onderzoek naar de manieren waarop SP feedback geven, het domein waarop SP feedback geven en de manieren waarop SP worden getraind in het geven van feedback. Verder zou de zoektocht naar een haalbaar longitudinaal SP programma moeten worden voortgezet. Met betrekking tot echte patiënt contacten en SP contacten is meer onderzoek nodig naar de fase waarin echte patiënten het best kunnen worden geïntroduceerd in de medische opleiding en naar de rol van verwachtingen van geneeskunde studenten ten aanzien van het soort contact (echte patiënt of SP). 


\section{Dankwoord}

Tenslotte wil ik graag een aantal mensen bedanken zonder wiens hulp dit proefschrift niet tot stand had kunnen komen.

Allereerst de (simulatie)patiënten en medisch studenten die hebben deelgenomen aan de onderzoeken in dit proefschrift. Zonder jullie medewerking was het onderzoek onmogelijk geweest.

Mijn promotores Prof. dr. C.P.M. van der Vleuten en Prof. dr. A.J.J.A. Scherpbier: Beste Cees en Albert, ik heb veel van jullie geleerd. Jullie inzet en enthousiasme werkten zeer motiverend en samen met jullie snelle reacties via de mail (zelfs 's nachts!) hield dit goed de vaart erin. In tijden dat het met het onderzoek wat minder vlotte naast het werk als AIOS kindergeneeskunde was het heerlijk te merken dat er aandacht was voor wat wel al gedaan was en wat kon, in plaats van voor alles wat nog moest.

Mijn copromotor Dr. J.J.E. Rethans: Beste Jan-Joost, dankzij jou is het onderzoek dat ik begon als student-assistent op het skillslab uitgegroeid tot een echt promotieonderzoek. Je betrokkenheid bij het onderzoek was groot en je deur stond altijd open voor vragen, in figuurlijke zin zelfs vanuit Japan.

Cees, Albert en Jan-Joost, tijdens de bijeenkomsten over de voortgang van mijn onderzoek was het een voorrecht gebruik te mogen maken van jullie uitgebreide kennis en ervaring. Terugblikkend was goed merkbaar hoe jullie elkaar aanvullen en hoe krachtig jullie zijn als team. Een leerling kan geen meester worden zonder de wijze lessen van de ware meesters.

Jan van Dalen, het was een genoegen deelgenoot te zijn van jouw expertise tijdens diverse onderzoeken in dit proefschrift. Jouw kritische blik en rode pen waren zeer waardevol bij het verbeteren van de manuscripten. Ik vind het een eer dat je deel wilde nemen aan de beoordelingscommissie.

Robbert Duvivier, jouw hulp bij het analyseren van de focusgroep interviews kwam als geroepen na het plotselinge vertrek van de student-assistent. De analyses gingen door zelfs naast je eigen promotieonderzoek en tijdens ons bezoek aan het Ottawa congres in Melbourne, Australië.

Lonneke van Heurn, dankzij jouw hulp als moderator tijdens de focusgroep interviews kwam er veel leuke, nuttige en soms zelfs opmerkelijke informatie boven tafel. 
Secretariaat van het Skillslab, in het bijzonder Willeke Destreel en Joyce Angenent, bedankt voor jullie praktische ondersteuning, variërend van het reserveren van kamers tot het opzoeken van informatie over simulatiepatiëntcontacten en rollen.

Studentassistenten SPC, jullie hulp tijdens het experiment was erg waardevol.

Dan de collega's van O\&O, een jaartje weg uit de kliniek was aanvankelijk erg wennen voor mij maar dankzij jullie belangstelling, de gezellige lunches en uitjes voelde ik me al snel thuis in de wereld van het medisch onderwijs. Een aantal van jullie wil ik in het bijzonder bedanken.

Mereke, bedankt voor het zorgen voor "fluency en efficiency" in mijn manuscripten.

Guus, bedankt voor je hulp bij het tevoorschijn toveren van de MaSP gegevens en je ondersteuning bij de bewerking ervan in SPSS.

Kamergenootjes Jonne en Tanja, bedankt voor het sparren en spuien en de gezelligheid.

En tenslotte Lilian, bedankt voor al het regelwerk. Afspraken inplannen, iris cheques en broodjes verzorgen voor de focusgroepen, brieven versturen naar het Collega van Decanen; je bent onmisbaar voor een promovendus bij O\&O.

Karin van der Zanden, bedankt voor jouw hulp bij het maken van de omslag van het proefschrift. Het is erg mooi geworden.

Lieve vrienden, jullie wil ik graag bedanken voor de broodnodige afleiding en de gezelligheid naast het werk en onderzoek. Fijn dat we ondanks onze drukke levens en banen toch regelmatig de tijd vinden voor elkaar. Hopelijk blijft dat zo in de verdere toekomst. Lieve Jos en Juud, ik kan me geen betere paranimfen wensen. Jullie weten me als geen ander mezelf te laten zijn.

Lieve schoonfamilie, Frans, Elly, Dignar, Emiel en Linda, jullie steun en belangstelling is hartverwarmend.

Lieve pap en mam, ook al moet het voor jullie soms lastig zijn geweest te volgen waar ik precies mee bezig was, ik besef dat ik dit nooit had kunnen bereiken zonder jullie. Niet in de laatste plaats omdat jullie me voor een belangrijk deel gevormd hebben tot wie ik nu ben. 
Jasper, geweldig hoe jij van alle markten thuis kan zijn: van verstandige grote broer tot lief, klein broertje met wie ik ontzettend kan lachen. Pap, mam en Jap, geweldig hoe jullie me met beide benen op de grond houden.

En tenslotte mijn allerliefste Hein, mijn maatje en onvoorwaardelijke steun en toeverlaat. Bedankt voor het bewaken van onze vrije tijd, je hulp bij statistiek, je eindeloze geduld met mij (en mijn zwangerschapstranen), bedankt voor alles. We gaan er lekker van genieten met z'n tweetjes en straks met z'n drietjes. Ik hou van je. 



\section{Curriculum Vitae}

Lonneke Bokken was born on the $12^{\text {th }}$ of July 1979 in Weert, the Netherlands. She obtained her secondary school diploma at the Philips van Horne Scholengemeenschap in Weert in 1997. She started studying Medicine at the University of Maastricht in 1998 after completing a foundation course in Health Sciences at the University of Maastricht. During her undergraduate years, she started her research into the impact of simulation on simulated patients at the Skillslab. In 2003 she obtained her Master's degree and in 2004 she graduated as a medical doctor, both cum laude. Subsequently, she started working at the pediatric department of the Máxima Medical Centre in Veldhoven, where she also began her residency in pediatrics in 2005. Concurrently, she started her $\mathrm{PhD}$ thesis at the Department of Educational Development and Research, University of Maastricht. In June 2007 she interrupted her residency to finish her PhD thesis. Since June 2008 she continued her residency at the pediatric department of the University Medical Centre St. Radboud, Nijmegen. Lonneke is married to Hein van Onzenoort. 